\title{
THE WORLD DISTRIBUTION OF INCOME (ESTIMATED FROM INDIVIDUAL COUNTRY DISTRIBUTIONS)
}

\author{
Xavier Sala-i-Martin \\ Working Paper 8933 \\ http://www.nber.org/papers/w8933 \\ NATIONAL BUREAU OF ECONOMIC RESEARCH \\ 1050 Massachusetts Avenue \\ Cambridge, MA 02138 \\ May 2002
}

This paper was partly written when I was visiting Universitat Pompeu Fabra in Barcelona. I thank Sanket Mohapatra for extraordinary research assistance and for comments, suggestions and short speeches related to this paper. I also benefitted from the comments of Elsa V. Artadi, Robert Barro, François Bourguignon, Laila Haider and Casey B. Mulligan. The views expressed herein are those of the author and not necessarily those of the National Bureau of Economic Research.

(C) 2002 by Xavier Sala-i-Martin. All rights reserved. Short sections of text, not to exceed two paragraphs, may be quoted without explicit permission provided that full credit, including (C) notice, is given to the source. 
The World Distribution of Income (estimated from Individual Country Distributions)

Xavier Sala-i-Martin

NBER Working Paper No. 8933

May 2002

JEL No. D31, F0, I30, I32, O00

\begin{abstract}
We estimate the world distribution of income by integrating individual income distributions for 125 countries between 1970 and 1998 . We estimate poverty rates and headcounts by integrating the density function below the $\$ 1 /$ day and $\$ 2 /$ day poverty lines. We find that poverty rates decline substantially over the last twenty years. We compute poverty headcounts and find that the number of onedollar poor declined by 235 million between 1976 and 1998 . The number of $\$ 2 /$ day poor declined by 450 million over the same period. We analyze poverty across different regions and countries. Asia is a great success, especially after 1980. Latin America reduced poverty substantially in the 1970s but progress stopped in the 1980s and 1990s. The worst performer was Africa, where poverty rates increased substantially over the last thirty years: the number of $\$ 1 /$ day poor in Africa increased by 175 million between 1970 and 1998, and the number of $\$ 2 /$ day poor increased by 227 . Africa hosted $11 \%$ of the world's poor in 1960. It hosted $66 \%$ of them in 1998 . We estimate nine indexes of income inequality implied by our world distribution of income. All of them show substantial reductions in global income inequality during the 1980s and 1990s.
\end{abstract}

\footnotetext{
Xavier Sala-i-Martin

Department of Economics

Columbia University

420 West 118th Street, 1005

New York, NY 10027

and NBER and UPF

xs23@columbia.edu
} 


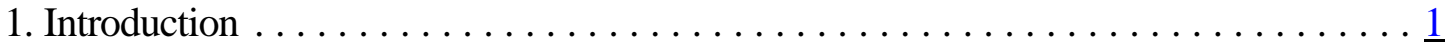

2. Estimating the World Distribution of Income $\ldots \ldots \ldots \ldots \ldots \ldots \ldots \ldots \ldots \ldots \ldots \ldots \ldots \ldots$

A.- Step 1: Estimating Yearly Income Shares between 1970 and $1998 \ldots \ldots \ldots \underline{3}$

B.- Step 2: Estimating Country Histograms $\ldots \ldots \ldots \ldots \ldots \ldots \ldots \ldots \ldots \ldots$

C.- Step 3. Estimating Each Country's Income Distribution. . . . . . . . . . 7

Comparing Country Poverty Estimates with Quah (2002) $\ldots \ldots \ldots \underline{12}$

D.- Step 4: Estimating the World Income Distribution Function .......... 12

"Vanishing Twin-Peaks" and "Emergence of a World Middle-Class". . . 14

The Cumulative Distribution Function . . . . . . . . . . . . . . 15

Kernel of Kernels vs. Kernel of Quintiles $\ldots \ldots \ldots \ldots \ldots \ldots \ldots, \underline{16}$

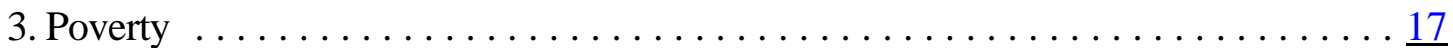

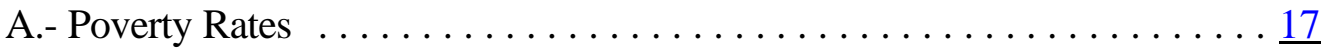

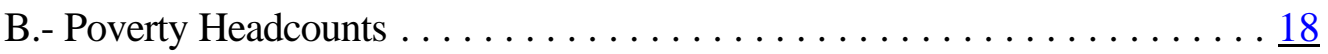

C.- Comparing Poverty Rates and Headcounts with Sala-i-Martin (2002) . . . 19

D.- Consumption vs. Income Poverty: Comparing with Chen and Ravallion (2002)

................................... 20

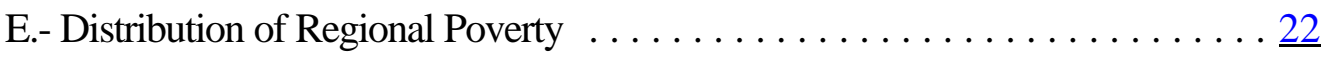

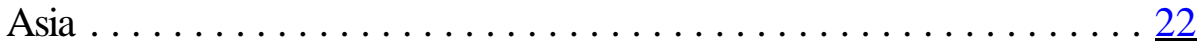

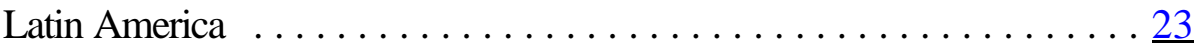

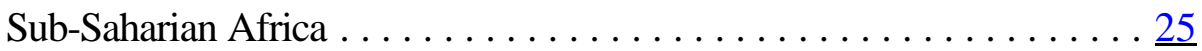

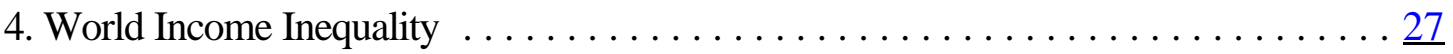

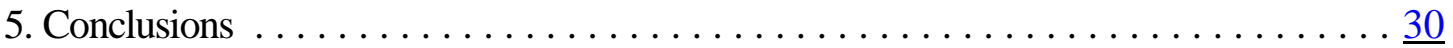

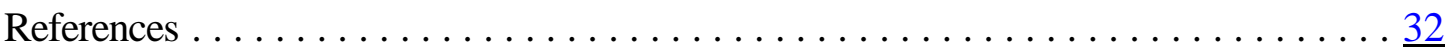

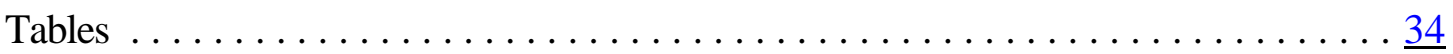

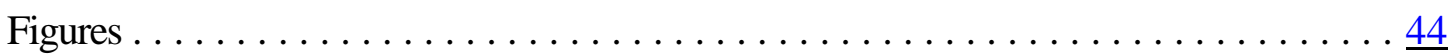

Appendix Figures: Income Shares for Selected Large Countries . . . . . . . . . . . $\underline{59}$ 


\section{Introduction}

Economists, journalists, politicians and critics of all varieties have recently paid a lot of attention to the world distribution of income. Different observers care about different aspects of this distribution: some worry about individual income disparities (or income inequality) and their evolution over time, some worry about the fraction of the worldwide population that live with less than one or two dollars a day (the so called, poverty lines), some worry about the total number of poor and some worry about the polarization between the haves and the havenots.

Estimating the world distribution of individual income is not easy because the level of income of each person on the planet is not known. As a result, previous researchers have been forced to make a number of approximations. For example, economists like Quah (1996, 1997), Jones (1997), and Kremer, Onatski and Stock (2001) estimate a distribution of world per capita GDPs in which each country is one data point. This approach is sensible if one wants to analyse the success of individual country policies or institutions and if we think of each country as performing an independent "policy experiment". However, it is not a good assumption if one wants to discuss global welfare: treating countries like China and Grenada as two data points with equal weight does not seem reasonable because there are about 12,000 Chinese citizens for each person living in Grenada. In other words, if income per capita in Grenada grows by $300 \%$ over a period of 20 years, the world distribution of individual income does not change by much because there aren't many Grenadians in the world. However, if income per capita in China grows at the same rate, then the incomes of one fifth of the world's citizens increase substantially and this has a great impact on global human welfare.

Some researchers like Theil (1979, 1996), Berry, Bourguignon and Morrisson (1983), Grosh, M. and E.W. Nafziger (1986), Theil and Seale (1994), Schultz (1998), Firebaugh (1999) and Melchior, Telle and Wiig (2000) solve this problem by using population-weighted GDP per capita. Although this is a step in the right direction, these papers still ignore intra-country income disparities. For example, when China's GDP per capita grows, the income of all its citizens does not increase in the same proportion. Dowrick and Akmal (2001), Bourguignon and Morrisson (2002) and Sala-i-Martin (2002) allow for within-country income disparities. For example, Sala-iMartin (2002) uses the Deininger and Squire (1996) estimates of five income shares for selected 
years to construct five income categories per country and year. The population of each country is divided into five different types and each type is assigned an income level. He then estimates a world income distribution with these five categories per country. ${ }^{1}$ The drawback of this approach is that it assumes that all individuals within each of the five categories for each country are assumed to have the same level of income. This assumption, for example, leads to a systematic underestimation of the level inequality within the distribution, although it is not clear the direction in which it biases its evolution over time. When we estimate the fraction of the distribution below a certain threshold (as we do, for example, when we estimate poverty rates), we assign the whole quintile to be either below or above the threshold. In reality, only a fraction of the population of that particular quintile may be below the threshold. Although this clearly introduces a bias in our estimates, it is not clear the direction in which this bias goes.

This paper goes one step further and uses the same income shares to estimate a yearly income distribution for 97 countries between 1970 and 1998. We then integrate all these individual density functions to construct a worldwide income distribution. We complement our original 97 economies data set with 28 additional countries for which there are no income shares so we have a total of 125 countries. Overall, we cover about $90 \%$ of the world's population. To our knowledge, this is the first attempt to construct a world income distribution by aggregating individual-country distributions.

The rest of the paper is organized as follows. Section 2 discusses the data and the estimation of the individual country distributions for each year between 1970 and 1998. We display graphically the evolution of these distributions for the nine most populous countries in the world. We discuss the construction of the world income distribution and analyze how it evolves over time. Section 3 estimates worldwide poverty rates and headcounts. It also analyzes the regional distribution of world poverty and its evolution over time. We report estimates for individual countries within Asia, Latin America and Africa. Section 4 estimates global income inequalities using seven popular indexes. Section 5 concludes.

${ }^{1}$ Bourguignon and Morrisson (2002) use a similar methodology for selected years going back to 1820 using the Maddison data set. 


\section{Estimating the World Distribution of Income}

Our goal is to estimate the worldwide distribution of individual incomes. In principle, we need to know the income level of each person in the world. Since we obviously do not, we have to approximate individual incomes using available aggregate data. We use the following four-step procedure.

\section{A.- Step 1: Estimating Yearly Income Shares between 1970 and 1998}

We start with the PPP-adjusted GDP data from Heston, Summers, and Aten (2001). One of our goals is to generate a time series of worldwide income distribution density functions. Hence, we need to have the same sample of countries every year. The Summers-Heston data set goes back to 1950 for just a few countries. Therefore, if we try to take our estimates back to 1950, we lose many of them. If we restrict our analysis to 1970-1998, however, we can extend our analysis to 125 countries with close to $90 \%$ of the world's population.

We also use the income shares estimated by Deininger and Squire (DS) which have been extended with the World Development Indicators (WDI) of the World Bank. These studies report income shares for five quintiles for a number of countries for selected years based on national-level income and expenditure surveys. ${ }^{2}$ Let $\boldsymbol{s}_{\boldsymbol{i k t} \boldsymbol{t}}$ be the income share for quintile $\mathrm{k}$, for country i during year $\mathrm{t}$.

Using these data we have three broad groups of countries (listed in Appendix Table 1):

Group A.- Those for which the income shares are reported for more than one year.

Group B.- Those for which we have only one observation between 1970 and 1998.

Group C.- Those for which we have NO observations of income shares.

There are 68 countries in group A. Together, in 1998 they had 4.7 billion inhabitants, which account for $88 \%$ of our sample population. For these countries, we plot the income shares over time and we observe that they tend to follow very smooth trends (see the Appendix Figures). In

\footnotetext{
${ }^{2}$ These survey data have been criticized by Atkinson and Brandolini (2001).
} 
other words, although the income shares estimated by Deininger and Squire and the World Bank are not constant, they do not seem to experience large movements in short periods of time. Instead, they seem to have smooth time trends. ${ }^{3}$ Using this information, we regress income shares on time to get a linear trend for each country. This was done using two methods. First, the regressions were estimated independently for each of the five quintiles without worrying about adding-up constraints. A second method estimated the regressions for the top two and the bottom two quintiles, leaving the income share of the middle quintile as the residual. Both methods gave identical results. ${ }^{4} \mathrm{We}$ use the projected income shares, $\hat{\boldsymbol{s}}_{\boldsymbol{i k t}}$ from these regressions.

There are 29 countries in group B, with 316 million people (or $6 \%$ of the total 1998 population). The income shares for this group were assumed to be constant for the period 1970-98. Hence, for group B, we allow for within-country income disparities, but we do not let them change over time. That is, we assume $\hat{\boldsymbol{s}}_{\boldsymbol{i k \boldsymbol { k }}}=\boldsymbol{s}_{\boldsymbol{i k}}$ for all $\mathrm{t}^{5}$ To the extent that income inequality within these countries changes, our assumption introduces a measurement error in the estimation of the world's income distribution. However, given that we do not know the direction in which disparities have changed within these countries, the direction of the error is unknown. An alternative would have been to restrict our analysis to the states that have time-series data (that is, Group A), as is done by other researchers (see for example Dowrick and Akmal (2001)). The problem is that this may introduce substantial bias which might change some of the results. The reason is that the countries that are excluded tend to be poor and tend to have "diverged". Their exclusion from our analysis, therefore, tends to bias the results towards finding an excessive compactness of the distribution. Since, as it turns out, we will find that the distribution becomes more compact over time

\footnotetext{
${ }^{3}$ Obviously, these trends can only be temporary since income shares are bounded between 0 and 1.

${ }^{4}$ It can be persuasively argued that India experienced a large increase in inequality after the liberalization policies enacted after 1991. Sala-i-Martin (2002) allows for two "slopes" for India (one for before and one for after liberalization) and argues that his measures of global income inequality are not very different from those estimated with the same trend for both periods.

${ }^{5}$ This assumption was made by Berry et al. (1983) for ALL countries.
} 
(that is, income inequalities go down over time), we do not wish to introduce a bias that favors one of the main conclusions of the paper by stacking the cards in our favor. Thus, we include these countries in our analysis.

If we add up groups A and B we see that, out of the 125 countries in the Summers-Heston data set, income inequality based on quintile income shares could be calculated for 97 countries, which cover $95 \%$ of the sample population.

The 28 countries of group $\mathrm{C}$ have no data on income shares. We therefore treat all individuals within these states as if they all had the same level of income. In other words, we assume $s_{\boldsymbol{i k} \boldsymbol{t}}=1 / 5$. Again, we could exclude this group from the analysis, but we prefer not to do so

because, as we already stated, their exclusion may lead to important biases in the results. ${ }^{6}$ An alternative would be to assign to each of the countries in Group $\mathrm{C}$ the income shares estimated for other countries that the researcher believes to have similar characteristics. ${ }^{7}$ The problem with this approach is that there is an undesirable amount of arbitrariness on the part of the researcher who has to decide which countries are "similar". We prefer to avoid this arbitrariness and neglect

${ }^{6}$ The largest countries excluded from our sample are those from the former Soviet Union. There is little we can do to incorporate them because they did not exist until the early 1990s. It is unclear how the exclusion affects our global inequality measures. On the one hand, it seems clear that disparities within these countries have increased. On the other hand, they were relatively "rich" and have experienced negative aggregate growth rates. Thus, the individual incomes for these countries has "converged" towards those of the 1.2 billion Chinese, 1 billion Indians and 700 million Africans. The first effect leads to an increase in global inequality whereas the second effect tends to lower it. The overall effect of excluding the former Soviet Union on worldwide inequality, therefore, is unclear.

The effects on poverty, on the other hand, are a lot clearer since the collapse of incomes in the former soviet republics have brought about substantial increases in poverty rates and headcounts. Chen and Ravallion (2002) estimate that the overall poverty rate for "Eastern Europe and Central Asia" increased from $0.24 \%$ in 1987 to 5.14\% in 1998. In Section 3D we compare the Chen and Ravallion results for the world with ours and we show that their estimates of poverty are larger than ours. But if we use their estimates of the evolution of poverty in Eastern Europe and Central Asia we see that the total number of poor increased from 1 to 24 million people between 1987 and 1998, not nearly enough to offset the overall decline in poverty headcounts.

${ }^{7}$ This approach was followed by Bourguignon and Morrisson (2002). Alternatively, we could assign the income shares of a typical country to the economies in Group C. We preferred not 'create' any data and use only the data that are available. 
inequalities within the countries in Group C. ${ }^{8}$ In any event, quantitatively, the evolution of the worldwide distribution of income will not depend on this assumption because, overall, Group C comprises a very small fraction of the world's population.

In sum, we have a data set of 125 countries with a combined 1998 population of 5.23 billion (or $88 \%$ of the world's 5.9 billion inhabitants in 1998).

\section{B.- Step 2: Estimating Country Histograms}

Once we have estimated the income shares, $\hat{\boldsymbol{s}}_{\boldsymbol{i k \boldsymbol { t }}}$, we assign a preliminary level of income to each fifth of the population. We divide each country's population in five groups and assign to them a different level of income. Let $\boldsymbol{N}_{\boldsymbol{i} \boldsymbol{t}}$ be the population in country i at time t, and let $\boldsymbol{y}_{\boldsymbol{i} \boldsymbol{t}}$ be

the income per capita for country $i$ at time t. We assign to each fifth of the population, $\frac{\mathbf{N}_{\mathbf{j t}}}{\mathbf{S}}$, the

income level $5 \boldsymbol{s}_{\boldsymbol{i k \boldsymbol { t }}} \boldsymbol{y}_{\boldsymbol{i t}}$. In this intermediate step, each individual is assumed to have the same level of income within each quintile. Figures $1 \mathrm{a}$ and $1 \mathrm{~b}$ put together the individual histograms for all countries for 1970 and 1998. Naturally, China has the tallest bars because it has the largest population, followed by India and the United States. It is interesting to note that, if we compare the histograms for 1970 and 1998, China's columns seem to have shifted to the right (China's growth rate has been positive and large) and the Chinese columns seem to have spread (inequality within China has increased). ${ }^{9}$ Notice that the rest of the picture is a bit confusing due to the large number of little columns that obscure the overall pattern. This is one reason for constructing individualcountry distributions. And this is what we do next.

${ }^{8}$ Sala-i-Martin (2002c) assigns to each of the countries in group $C$ the average income shares of the continent in which this country is located.

${ }^{9}$ Despite the increase in inequalities across the five quintiles in China, it is apparent that the level of income of the lowest quintile increases significantly. In other words, even the poorest Chinese citizens enjoy a higher level of income. 


\section{C.- Step 3. Estimating Each Country's Income Distribution.}

Sala-i-Martin (2002) utilized the data used to create the histograms reported in Figure 1 to directly estimate a kernel density function that captures the world distribution of income for each year between 1970 and 1998. This procedure assumes that all individuals within a quintile of each country have the same level of income and, therefore, ignores differences in income levels within quintiles. There are two ways to get around this. One is to assume that the density function within each country has a particular functional form and use the quintile data to estimate the income distribution. For example, if we assume that the density function is lognormal, we can estimate the whole distribution from knowledge of mean log-income and the variance (which can be computed from our income shares). ${ }^{10}$ Quah (2002) shows that one can estimate the income distribution of a country if one assumes that its functional form is Pareto and one knows the Gini coefficient and the mean or per capita income. He applies this finding to China and India for 1980 and 1992.

Alternatively, we can estimate a kernel density function for each country and each year. A kernel density function is an approximation to the true density function $f\left(\boldsymbol{y}_{\boldsymbol{i j} \boldsymbol{t}}\right)$ from observations on $\boldsymbol{y}_{\boldsymbol{i j \boldsymbol { t }}}$. Although some assumptions have to be made on how to estimate this function, this procedure does not restrict the country distribution to have a specific functional form. ${ }^{11}$ One key

${ }^{10}$ Most of the literature on income distribution agrees that country income distributions are close to lognormal (See Mulligan (2002) and Cowell (1995)). It has been argued that, for the United States, the upper tail of the distribution is not well captured by a lognormal since this distribution tends to underestimate the number of obscenely rich people. Thus, some analysts proxy the overall distribution with a lognormal function for most of the levels of income and a Pareto function (which has a thicker upper tail) for the larger levels of income. See Mulligan (2002) for a discussion and for some estimates of the bias of assuming a lognormal function for all levels of income.

${ }^{11}$ We use the gaussian kernel density function but we experimented with other kernels. For example, using the Epanechnikov kernel function delivers exactly the same results, as long as the bandwidth is held constant across estimation methods. 
parameter that needs to specified or assumed is the bandwidth of the kernel. ${ }^{12}$ The convention in the literature suggests a bandwidth of $w=0.9 * s d^{*}\left(n^{-1 / 5}\right)$, where $s d$ is the standard deviation of (log) income and $n$ is the number of observations. Obviously, each country has a different standard deviation so, if we use this formula for $w$, we would have to assume a different $w$ for each country and year. Instead, we prefer to assume the same bandwidth $w$ for all countries and periods. One reason is that, with a constant bandwidth it is very easy to visualize whether the variance of the distribution has increased or decreased over time. Given a bandwidth, the density function will have the regular hump (normal) shape when the variance of the distribution is small. As the variance increases, the kernel density function starts displaying peaks and valleys. Hence, a country with a distribution that looks 'normal' is a country with small inequalities, and a country with a weird distribution (with many peaks and valleys) is a country with large income inequalities.

In choosing the bandwidth, we note that the average $s d$ for the United States between 1970 and 1998 is close to 0.9 , the average Chinese $s d$ is 0.6 (although it has increased substantially over time) and the average Indian $s d$ is 0.5 . For many European countries the average sd is close to 0.6. We settle on $s d=0.6$, which means that the bandwidth we use to estimate the gaussian kernel density function is 0.35 . We evaluate the density function at 100 different points so that each country's distribution is decomposed into 100 centiles.

Once the kernel density function is estimated, we normalize it (so the total area under it equals to one) and we multiply by the population $\boldsymbol{N}_{\boldsymbol{i t}}$ to get the number of people associated with each of the 100 income "categories" for each year. In a way, what we do is to estimate the incomes of a 100 centiles for each country and each year between 1970 and 1998 .

Figure 2 displays the results for the nine largest countries for 1970, 1980, 1990 and 1998. Panel $2 \mathrm{a}$ shows the evolution of the Chinese distribution of income. ${ }^{13}$ The figure also plots two

${ }^{12}$ One particular kernel density function is the histogram, a function that counts the number of observations in a particular income interval or bin. As is well known, the shape of the interval depends crucially on the number of bins. The bandwidth of a kernel is similar to the inverse of the number of bins in a histogram in that smaller widths provide more detail.

${ }^{13}$ Economists have recently pointed out that Chinese statistical reporting during the last few years has been less than accurate (see for example, Ren (1997), Maddison (1998), Meng and 
vertical lines which correspond to the World Bank's official poverty lines: the one-dollar-a-day (\$1/day) line and the two-dollar-a-day (\$2/day) line. ${ }^{14}$ Since the World Bank defines "absolute poverty" in 1985 values and the Summers and Heston data that we are using are reported in 1996 dollars, the annual incomes that define the $\$ 1 /$ day and $\$ 2 /$ day poverty in our data set are $\$ 532$ and $\$ 1064$ respectively. The unit of the horizontal axis is the logarithm of income so that the two poverty lines are at 6.28 and 6.97 respectively.

We notice that the Chinese distribution for 1970 is hump-shaped with a mode at 6.8 (\$898). About one-third of the function lies to the left of the $\$ 1 /$ day poverty line (which means that about one-third of the Chinese citizens in 1970 lived in absolute poverty) and close to threequarters of the distribution lies to the left of the $\$ 2 /$ day line. We see that the whole density function"shifts" to the right over time, which reflects the fact that Chinese incomes are growing. The incomes of the richest Chinese increases substantially (the upper tail of the distribution shifts rightwards significantly). The incomes of the poor also experience positive improvements. By 1998, the distribution has a mode at $7.6(\$ 2,000)$ and it appears that a local maximum starts to arise at $8.5(\$ 4,900)$. The fraction of the distribution below the one-dollar line is now less than $3 \%$ and the fraction below the two-dollar line is less than one-fifth. An interesting feature to notice is that the distribution seems to be more "dispersed" in 1998 than it was in 1970 or 1980. This reflects the well known increase in income inequality within China. In sum, over the last twenty years, the incomes of the Chinese have grown, poverty rates have been reduced dramatically and income inequalities within the most populous nation in the world have increased.

Wang (2000), and Rawski (2001).) The complaints pertain mainly to the period starting in 1996 and especially after 1998 (see Rawski (2001)). This coincides with the very end of and after our sample period, so it does not affect our estimates. However, we should remember that we do not use the official statistics of Net Material Product supplied by Chinese officials. We use the numbers estimated by Heston, Summers and Aten (2001), who attempt to deal with some of the anomalies following Maddison (1998). For example, the growth rate of Chinese GDP per capita in our data set is $4.8 \%$ per year, more than two percentage points less than the official estimates (the growth rate for the period $1978-1998$ is $6.1 \%$ in our data set as opposed to the $8.0 \%$ reported by the Chinese Statistical Office).

${ }^{14}$ Ravallion et al. (1991) define poverty in terms of consumption rather than income. We discuss the differences between their estimates and ours in Section 3D. 
Figure $2 \mathrm{~b}$ reproduces the income distributions for India, the second most populated country in the world. The positive growth rates of India over this period have shifted the distribution to the right, especially during the eighties and nineties. This has reduced dramatically the fraction of poor: while two-thirds of the distribution lay to the left of the two-dollar line in 1970, the fraction of twodollar poor in 1998 was less than one-fifth. If we use the one-dollar definition, we note that the fraction of poor declined from $33 \%$ in 1970 to less than 1.5\% in 1998. Inequalities in India do not appear to have increased or decreased substantially over the sample period.

Figure $2 \mathrm{c}$ shows the incomes for the United States, the third largest country in the world in terms of population. Again, we see that the positive aggregate growth rate has shifted the whole distribution to the right, lifting the incomes of virtually all Americans. We notice that the fraction of the distribution below the poverty lines is zero for all years. Three interesting points about the U.S. must be noted. Firstly, there seems to be a local maximum at the bottom end, which reflects that fact that the lowest quintile of the American incomes are and remain substantially behind the rest of the distribution. Secondly, even the lower tail of the distribution shifts to the right (so income of the poorest Americans increases over time). Thirdly, the upper tail of the distribution seems to shift further, which suggests that inequalities within the United States have increased over the last three decades. This is not because the poor have been hurt, but because the rich have gained relatively more.

Figure 2d displays a very interesting case: Indonesia. In 1970, the mode of the distribution coincided with the $\$ 1 /$ day poverty line, close to one half of the distribution lay to the left of the onedollar line and three-quarters lay below the two-dollar definition. Indonesian citizens were extremely poor. Over time, the distribution shifted to the right substantially, and the fraction lying to the left of the poverty lines declined dramatically. In fact, the fraction below the one-dollar and two-dollar lines in 1998 were less than $0.1 \%$ and less than $6 \%$ respectively. ${ }^{15}$ Indeed, Indonesia displays a remarkable success in eliminating poverty. An interesting aspect is that, as Indonesia grew and eliminated poverty at extraordinary rates, its distribution became more compact. Thus, income inequality in Indonesia declined as the economy grew. This is important because some analysts

${ }^{15}$ This is true, despite the $15.6 \%$ decline in GDP that, according to our data, Indonesia suffered in 1998 as a direct consequence of the East Asian financial crises. Poverty rates in 1997 were even smaller: $0.007 \%$ and $1.4 \%$ respectively. 
suggest that growth and increasing income inequality usually go together. The case of Indonesia does not support this view.

The distribution for Brazil, displayed in Figure 2e, does not appear to be "normal" in the sense of being "hump-shaped". The reason is that the variance of the Brazilian distribution is much larger than the variance we used to compute the bandwidth. Hence, the appearance of nonnormality of this density function simply reflects that Brazil has a very unequal income distribution. In terms of poverty, we see that the fraction of the distribution below the one-dollar line declined substantially between 1970 and 1980, but then it remained fairly constant (at around 3\%) over the following two decades. The same is true for the $\$ 2 /$ day rate: it declined from $35 \%$ to $18 \%$ between 1970 and 1980, and it remained stable after that.

Figure $2 \mathrm{f}$ shows the distribution of Pakistan. It seems to have shifted a little bit to the right over time, but the changes are less dramatic than those experienced by China, India or Indonesia. The \$1/day poverty rate did not change much between 1970 and 1980 (and it remained close to 15-20\%), it then fell to about 5\% in 1990 and it remained there during the last eight years. Inequality in Pakistan does not appear to have changed dramatically.

The evolution of Japan's income distribution (Figure 2g) is similar to that of Indonesia in the sense that it has shifted to the right (Japanese citizens have become richer) and it has become more compact (inequality has declined) which again shows that positive growth rates do not always come with more unequal distributions. The fraction of the density function to the left of the poverty lines was practically zero for all years.

The income distribution in Bangladesh (Figure 2h) was very flat in 1970, and well over 50\% of the people lived under two dollars per day. The distribution worsened during the 1970s: by 1980, almost $65 \%$ of the people lived with less than two dollars and $29 \%$ with less than one dollar. Things improved dramatically during the 1980s and 1990s, as the income distribution shifted to the right. \$1/day rates fell to 5\% and \$2/day rates fell to 34 in 1998. Among the largest Asian countries, Bangladesh is still the one with largest poverty rates and should still be a cause for concern. But things seem to have improved over the last twenty years.

Finally, Figure 2i displays what is perhaps the most interesting case: Nigeria. As it is the case for a lot of African nations, Nigerian GDP per capita has grown at negative rates over the last thirty years, which is reflected in Figure $2 \mathrm{i}$ by a shift of the distribution to the left. The dramatic 
implication of these negative growth rates is that the fraction of people living with less than $\$ 1 /$ day increased from $9 \%$ in 1970 , to $17 \%$ in 1980 , to $31 \%$ in 1990 , to $46 \%$ in 1998 . The explosion of \$2/day poverty was also dramatic: from $45 \%$ in 1970 to $70 \%$ in 1998 . The interesting part is that, although the average GDP declined, inequalities in Nigeria increased so dramatically that the upper tail of the distribution has actually shifted to the right! In other words, although the average citizen was worse off in 1998 than in 1970, the richest Nigerian was much better off. This is an example where the increases in inequality within a country more than offset the aggregate growth trends so that different parts of the distribution move in different directions. Unfortunately, although this phenomenon is unique among the nine largest countries reported in Figure 2, it is not uncommon in Africa.

\section{Comparing Country Poverty Estimates with Quah (2002)}

Quah (2002) uses the Gini coefficient and the average per capita income to estimate a Pareto distribution function for India and China in 1980 and 1992. He then estimates \$2/day poverty rates and headcounts for these two countries by integrating the density function below the poverty lines. Quah finds that the poverty rate for China in 1980 was somewhere between 0.37 and 0.54 (see Table 3 of Quah (2002).) Our poverty rate for China in 1980 is 0.56 , slightly above but very close to Quah's. Quah estimates that the number of poor in China ranges from 360 million and 530 million. We estimate that there are 554 million poor in China in 1980.

For India, Quah finds that the poverty rate was between 0.48 and 0.62 . Our estimate is 0.54 , right in the middle of his range. His headcount ranges from 326 and 426 million. Ours is 373 , again right in the middle of his range. We conclude that Quah's (2002) methodology for estimating poverty rates delivers similar results to ours, at least for China and India.

\section{D.- Step 4: Estimating the World Income Distribution Function}

We have now assigned a level of income to each individual in a country for every year between 1970 and 1998. We can use these individual income numbers to estimate a gaussian kernel density function that proxies for the world distribution of individual income.

Previous researchers have used kernel densities to estimate world income distributions. For example, Quah (1996, 1997), Jones (1997), and Kremer, Onatski and Stock (2001) estimate it by 
assuming that each country is one data point (and the concept of income is per capita GDP). Instead, we use the individual incomes estimated in the previous section. Thus, our unit of analysis is not a country but a person.

Figure 3 reports the estimates of the density functions for 1970, 1980, 1990 and $1998 .{ }^{16}$ To see how the world distribution is constructed from the individual country functions, we also plot the distributions for the 9 largest countries in the same graph. We start our analysis with Figure 3a, which displays our 1970 estimates. Since we have computed it so that the area under the distribution is proportional to the country's population, the "tallest" distribution corresponds to China, followed by India and the United States. These individual distributions correspond exactly to the ones reported in Figure 2. In the earlier figure, each panel reported a single country for various years whereas now we report all the countries together for a single year.

The world distribution of income is the aggregate of all the individual country density functions. We notice that the mode in 1970 occurs at 6.8 (\$897), below the two-dollar poverty line. More than one-third (and close to 40\%) of the area under the distribution lies to the left of the two-dollar line and almost one fifth-lays below the one-dollar line. The fraction of the world population living in poverty in 1970 was, therefore, staggering! The distribution seems to have a local maximum at $9.07(\$ 8,690)$, which mainly captures the larger levels of income of the United States, Japan, and Europe.

The picture for 1980 (Figure 3b) is very similar to that of 1970. The maximum is slightly higher at 6.93 (\$1022), still very close to the two-dollar line, and the local maximum of the rich is now at $9.22(\$ 10,097)$ which suggest that the world was slightly richer in 1980 than in 1970 , but the picture looks basically identical.

Things change dramatically in the 1990s (Figure 3c and 3d correspond to 1990 and 1998 respectively). We notice that as China, India, Indonesia start growing (their individual distributions shift to the right), the lower part of the world distribution (which contains most of the people in the 1970s and 1980s) also shifts rightward. Within countries, we see that, while the Indian distribution retains the same shape, the Chinese density function becomes flatter and more dispersed. This reflects the fact that, while inequality within India has not increased dramatically over this period,

16 The bandwidth used is 0.35 . 
inequality within China has. The fraction of the worldwide distribution of income to the left of the poverty lines declines dramatically. By 1998, less than one-fifth lies below the two-dollar line (down from over $40 \%$ in 1970) and less than 7\% lies below the one-dollar line (down from 17\% in 1970). The world, therefore, has had an unambiguous success in the war against poverty rates during the last three decades. The bad news is that, if we look closely at the lower left corner of Figure $2 \mathrm{~d}$ for 1998, we see that Nigeria seems to show up from nowhere. Actually, Nigeria has been in our analysis all along, but it was "buried" below India, China and Indonesia in the previous pictures. While the three Asian nations grew (and their distributions shifted to the right), the African country became poorer over time (and its distribution shifted to the left). Thus, in 1998, it stands as the only large country with a substantial portion of its population living to the left of the poverty lines. Moreover, Nigeria is only one example of what happened in Africa over the last thirty years (although it is the most important example since it is the most populated nation in the continent).

\section{"Vanishing Twin-Peaks" and "Emergence of a World Middle-Class"}

To make the comparison over time easier, Figure 4a reports the four worldwide income distributions for 1970, 1980, 1990 and 1998 in the same figure. It is now transparent that the distribution shifts rightward so that the incomes of the majority of the world's citizens increase over time. It is also clear that the fraction of the world population living to the left of the poverty lines declines dramatically. An interesting point worth emphasizing is that the "bimodality" of the 1970 distribution seems to have disappeared by 1998. Quah (1996) suggests that the world distribution of income is characterized by "emerging twin peaks" which means that the world distribution of income is the 1960s and 1970s was unimodal and, over time, became bimodal or "twin-peaked". Our results differ sharply from those of Quah. In fact, we reach the exact opposite conclusion: any trace of bimodality which may have existed in the 1970s, is gone by 1998. Rather than the “emerging twin-peaks" found by Quah (1996) in the cross-country data, our individual data suggests “vanishing twin-peaks". The key difference stems from the fact that Quah's unit of analysis are countries, whereas ours are individuals. The distinction turns out to be important because countries like China, India and Indonesia are just three data points in Quah's sample whereas they represent more than one-third of our sample of citizens (since they comprise more than one third of the world's population). Thus, when these three very poor countries grow, they have a negligible 
effect on Quah's world distribution of income but they change ours in two important ways. Firstly, the growth of the incomes of the poorest people in these countries has led to a reduction in "height" of the lowest maximum (there are less people in the world with very low levels of income) and shift of this maximum to the right. And secondly, the levels of income of the richest quintiles in these three countries have "caught up" to the levels of income to some of the citizens of the OECD. This has led to the disappearance of the second maximum (or the "twin peak", as Quah would put it) and the emergence of a "world middle class".

Later in the paper we measure income inequality more precisely, but a simple look at Figure 4 suggests that dispersion has declined over time. This can be seen by observing that the lower tail of the distribution has shifted rightwards more dramatically than the upper tail. The implication is that worldwide income inequality has decreased.

\section{The Cumulative Distribution Function}

Figure $4 \mathrm{~b}$ shows the world's cumulative income distribution functions (CDFs) for the same four years reported in Figure 4a. We see that the CDF constantly shifts to the south-east which suggests that most levels of incomes improved over time. We also see that the $1998 \mathrm{CDF}$ lies completely to the right of the $1970 \mathrm{CDF}$. This suggests that 1998 displays first order stochastic dominance over 1970. We also see that this is not true for the lower end of the 1990 distribution. In other words, the 1998 CDF does not dominate the 1990 distribution. As we will see later, the explanation is given by the dismal performance of Africa and, in particular, of two of its largest countries: Congo-Zaire and Nigeria.

The CDFs offer a simpler way to see poverty rates visually: the $\$ 1 /$ day rate is simply the image of the CDF corresponding to $\log (532)$ (that is, the image of 6.2766 ). Similarly, the $\$ 2 /$ day rate is the image of the CDF corresponding to 6.9698. Figure $4 \mathrm{~b}$ shows clearly that the images of these two numbers decline substantially between 1970 and 1980, between 1980 and 1990 and between 1990 and 1998 . Thus, it is clear that $\$ 1$ and $\$ 2$ poverty rates have fallen continuously over the last thirty years. 


\section{Kernel of Kernels vs. Kernel of Quintiles}

The methodology used in this paper to compute the worldwide distribution of individual income across individuals is a bit different from the one used in Sala-i-Martin (2002). Both papers exploit the stability of income shares over time to estimate the income shares for the years between 1970 and 1998 where these are not directly available. Both papers use these fitted income shares and the country-wide GDP per capita to estimate the level of income of the five population quintiles for each year and assign that particular level of income to each person within each quintile for each country for each year. And here is where they depart: while Sala-i-Martin (2002) estimates the worldwide kernel density function by fitting it through the quintile data, in this paper we estimate an individual kernel density function for each country and then use these estimates to construct the worldwide kernel density function. In other words, whereas Sala-i-Martin (2002) estimates the worldwide "kernel of quintiles", in this paper we estimate a "kernel of kernels". The basic difference is that Sala-i-Martin (2002) implicitly assumes that all individuals within a quintile for each country are assumed to have the same level of income whereas we allow for differences within quintiles.

The interesting question is whether the two methods deliver radically different worldwide distributions of income. The answer is no. Figure 5 displays the two density functions for 1998 . We see that, by and large, the two functions are very similar. As expected, the kernel of kernels used in this paper is a little smoother than the kernel of quintiles estimated by Sala-i-Martin (2002). One difference is that the kernel of kernels lies a bit above the kernel of quintiles at very low levels of income, which means that our estimated poverty rates will be larger than those of Sala-i-Martin (2002). Another difference is that the kernel of quintiles seems to have one absolute mode (which is the same in both distributions and it is located at 7.6 or $\$ 2,000$ ) and two local modes: one at 8.5 $(\$ 4,915)$ and one at $9.7(\$ 16,318)$. The kernel of kernels tends to smooth these two local modes into a big world middle class at around $\$ 5,000$. The reason for the disappearance of the middle modes is that the richest quintiles of China and India tend to stand up above the rest of the quintiles so that, when we estimate the kernel directly out of this quintile data, we get a slight bump. On the other hand, when we estimate the kernel density function for China and India before integrating them into the worldwide distribution function, the top quintile numbers get smoothed away. Despite 
these small differences, however, we see that the two distributions are remarkably similar, as seen in Figure 5 .

\section{Poverty}

\section{A.- Poverty Rates}

We can now use the individual and worldwide income distributions estimated in the previous section to compute poverty rates and headcounts. Absolute poverty rates can be inferred from our estimated density functions. Poverty rates are defined as the fraction of the world's population that live below the absolute poverty line. As we have been doing throughout the paper, we use two of the conventional definitions of absolute poverty: less than $\$ 1 /$ day and less than \$2/day in 1985 prices which, again, correspond to annual incomes of \$532 and \$1064 in our data set. As suggested in Section 2, we already offered two visual representations of the poverty rates: one was the area under the distribution (reported in Figure 4a) that lies to the left of the poverty lines. Another was the image of the CDF function (reported in Figure $4 b$ ) for the values corresponding to the log of $\$ 532$ and $\$ 1064$.

To compute poverty rates more precisely, we need to divide the integral of the density function between 0 and $\$ 532$ ( $\$ 1064$ for the two-dollar definition) by the integral between 0 and infinity. That is, the poverty rate for period $t$ is given by

$$
R_{t}=\frac{\int_{-\infty}^{P} f\left(\ln y_{j t}\right) d j}{\int_{-\infty} f\left(\ln y_{j t}\right) d j} .
$$

where $P$ takes the value $\ln (532)$ and $\ln (1064)$ for the $\$ 1 /$ day and $\$ 2 /$ day definitions respectively, and $f($.$) is the estimated density function.$

The calculations for the world poverty rates are reported in Table 1 and displayed graphically in Figure 6a. For the $\$ 1 /$ day definition, we observe that the poverty rate remained fairly 
constant over the 1970s (the poverty rate was $17 \%$ in 1970 and $16.3 \%$ in 1976), and then declined dramatically over the following two decades. Indeed, the lowest poverty rate corresponds to the last year of the sample, 1998, with $6.7 \%$. The poverty rate, therefore, was cut by a factor of almost three over the last thirty years. The poverty rate fell by 0.04 during the $1970 \mathrm{~s}$, by 0.045 during the 1980 s and by 0.019 during the 1990 s.

The reduction of the poverty rate when we use the $\$ 2 /$ day definition was even more dramatic. The rate fell monotonically throughout the period. It declined from $41 \%$ in 1970 to $18.6 \%$ in 1998, a reduction of close to $60 \%$. The rate fell by 0.064 during the 1970 s, by 0.088 during the 1980 s and by 0.072 during the 1990s. Thus, although there was an unambiguous success throughout, the largest declines occurred during the 1980s, followed by the 1990s.

The reader who is interested in computing the evolution of other poverty rates can do so by simply using Figure $4 \mathrm{~b}$. The reader can pick his own poverty line and check the evolution of the corresponding poverty rate over time by looking at the image of that line for the four CDFs. A simple look at Figure $4 \mathrm{~b}$ suggests that it does not matter what definition one wants to use: poverty rates fell between 1970 and $1998^{17}$.

\section{B.- Poverty Headcounts}

Some have argued that the poverty rates are irrelevant and that the really important information is the number of people in the world that live in poverty (some times this is called "poverty headcount"). The distinction is important because, although poverty rates have declined, the increase in world population could very well have brought with it, an increase in the total number of poor citizens. A veil of ignorance argument, however, suggests that the world improves if poverty rates decline. To see why, we could ask ourselves whether, with the veil of ignorance, we would prefer our children to be born in a country of a million people with half a million poor (poverty rate of $50 \%$ ) or in a country of two million people and 600,000 poor (a poverty rate of $33 \%$ ). Our chance of being poor is much smaller in the country with a smaller poverty rate so we prefer our

${ }^{17}$ The poverty rate did not fall between 1990 and 1998 if one uses a rate of less than $\$ 0.55 /$ day. We will later argue that this might be a statistical artifact due to the fact that Congo is a type C country. See footnote 20. 
offsprings to live in the country with smaller poverty rates...although they have a larger headcount. ${ }^{18}$ Thus, we should say that the world is improving if the poverty rates, not the headcounts, decrease.

Of course the best of the worlds would be one in which both the poverty rates and poverty headcounts decline over time. Although this wonderful world might appear to be too much to ask for, we next show that it is exactly the world in which we live! To see this, we estimate poverty headcounts by multiplying our poverty rates by the overall population each year. The results are displayed in Figure 6b. Using the $\$ 1 /$ day definition, the overall number of poor increased during the first half of the 1970s from 554 in 1970 to close to 600 million in 1976. After that, it declined to 352 million in 1998, an overall reduction in the number of poor by more than 235 million people. If we breakup the numbers by decades, the number of poor went down by 40 million, 134 million and 47 million in the 1970s, 1980s and 1990s respectively.

Using the two-dollar definition, the number of poor also increased in the first half of the 1970s from 1.32 billion to 1,43 billion in 1976. After that, the number declined to 973 million in 1998. The number of poor, therefore, declined by more than 450 million people between 1976 and 1998. The breakup by decades shows that the total number of $\$ 2 /$ day poor increased during the 70s and decreased dramatically after that: 153 million during the 1980s and 226 million during the 1990s.

In sum, world poverty has declined substantially over the last twenty five years. This is true if we use the $\$ 1 /$ day or the $\$ 2 /$ day definition and whether we use poverty ratios or poverty counts.

\section{C.- Comparing Poverty Rates and Headcounts with Sala-i-Martin (2002)}

An interesting question is how our estimates of poverty rates and headcounts compare with those of Sala-i-Martin (2002) who computes the world distribution of income under the assumption that all individuals within a quintile for each country and year have the same level of income. Table 2 reports the comparisons and Figure 6 also displays the numbers estimated by Sala-i-Martin (2002). The main conclusion is that the two methods deliver a remarkably similar picture and yield a remarkably similar lesson. They both show a substantial decline in poverty rates (using the $\$ 1 /$ day

${ }^{18}$ Those people who might still prefer the country with the smaller headcount should ask themselves if they would also prefer a country of half a million people with 499,999 poor. 
and the \$2/day definitions) during the last thirty years. The two-dollar poverty rates from quintile data are a little bit larger than our kernel estimates in 1970, but the rates converge to virtually the same number by 1998. This means, of course, that Sala-i-Martin (2002) tends to slightly overestimate the decline in the two-dollar poverty rates (his rate declines by 25.8 percentage points whereas ours falls by 22.4 points). The $\$ 1 /$ day rates, on the other hand, are virtually identical in 1970 and slightly different in 1998. Our 1998 rate is slightly above Sala-i-Martin (2002) which again suggests that he tends to slightly overestimate the decline. According to our estimates, the $\$ 1 /$ day falls by 10.4 percentage points (from $17.2 \%$ to 6.7\%) whereas Sala-i-Martin (2002)'s declines by $11.1 \%$ (from $16.5 \%$ to $5.5 \%$ ).

In terms of poverty headcounts, our estimates are that the number of $\$ 1 /$ day poor decline by 201.4 million between 1970 and 1998 whereas Sala-i-Martin (2002) estimates a reduction of 247.9 million people. The declines in the \$2/day headcounts are 350.1 million and 457.7 million citizens respectively. The estimated reductions since the peak year (1976) are 452.2 and 499.3 respectively.

\section{D.- Consumption vs. Income Poverty: Comparing with Chen and Ravallion (2002)}

It is interesting to compare our estimates of poverty rates and headcounts with those computed by the World Bank. Ravallion and Chen (1997) and Chen and Ravallion (2002) compute poverty rates based on survey data which is similar to ours. Their estimates of poverty rates are reported in Column 2 of Table 3. For example, their $\$ 1 /$ day poverty rate for 1987 is 0.83 and their $\$ 2 /$ day rate is 0.61 . Our two rates for the same year are substantially lower: 0.088 and 0.270 respectively. Why are our estimates so different?

There are three main reasons. Firstly, the sample of countries is different. While we have 125 countries in our sample, they only have 88 . One central difference is that we do not include the former soviet republics in our sample and they do include some of them. Given that, according to Chen and Ravallion (2002), poverty rates appear to have increased substantially in these countries, between 1987 and 1998, this could account for some of the differences in poverty rates, but given that the population in the countries of the Soviet Union is not very large, this clearly cannot be the only difference. 
The second difference between our estimates and those of Chen and Ravallion (2002) is that we use income data whereas they use consumption data. The original poverty line (adopted by the World Bank) was defined by Ravallion et al. (1991). A person is said to be poor if he or she consumes less than one (or two) dollars a day. Thus, they measured poverty in terms of consumption expenditure using survey data. When one uses aggregate data (as we and Chen and Ravallion (2002) do), we need to decide whether to use aggregate consumption or aggregate income data to adjust the survey data to construct poverty rates. The reason is that if we use national accounts consumption data, we implicitly assume that everyone in the economy consumes (and saves) the same fraction of their income. In particular, if we adjust our income data by the national savings rate to estimate individual consumption, we implicitly assume that the people whose income is less than one dollar a day save the same fraction of their income as the average person in the economy. This is probably not a good approximation since people with less than one dollar a day probably do not save anything. Hence, we believe that income poverty is probably a better measure of consumption poverty than consumption poverty itself.

Having said this, we can calculate consumption distributions for each and every country for each and every year between 1970 and 1998 by simply repeating the procedure described in Section 2 but using per capita consumption rather than using per capita income. The details are reported in Sala-i-Martin (2002b) and a summary of the results are reported in the last two columns of Table 3. We observe that the one and two-dollar poverty rates for 1987 are 0.215 and 0.436 respectively, much closer to those reported by Chen and Ravallion. Thus, a substantial fraction of the difference between our results and theirs can be explained by the fact that they use consumption rather than income.

The third difference is that their definition of poverty rates refers to the fraction of the THIRD WORLD POPULATION that lives with less than one or two dollars a day. Our definition of worldwide poverty rates refers to the fraction of the WORLD'S POPULATION that lives with less than one or two dollars a day. In other words, our denominator includes the population of the whole world whereas their denominator includes the population of poor countries only. Thus, if the numerators were the same, then our rates would automatically be larger because the number of poor people living with less than one dollar a day in rich countries is virtually zero. To assess the importance of this effect, we divide our aggregate consumption-poverty in 1987 (reported in Table 
3) by third world population rather than worldwide population, and we find that the two poverty rates are 0.27 and 0.54 , almost the same as the 0.28 and 0.61 reported by Chen and Ravallion.

Since we have computed the poverty rates using consumption rather than income data, we can see the evolution of the consumption-poverty rates over time, which we depict in Figure 7. Panel A shows the one-dollar poverty rates. We see that, although the income poverty rate line lies below the consumption poverty line, the two decline significantly between 1978 and 1998. Figure 7a also displays the estimates from Chen and Ravallion (2002) for the years 1987, 1990, 1993, 1996 and 1998. We see that the overall pattern is about the same to ours for the corresponding years: the rate goes up between 1987 and 1990, but it declines over the nineties. The main lessons are broadly the same for the $\$ 2 /$ day rates, reported in Figure $7 \mathrm{~b}$.

The conclusion is that the different sample of countries, the fact that we deal with income rather than consumption and the fact that we define worldwide poverty rates as the fraction of world population (rather than the fraction of the THIRD WORLD population) can account for the poverty rates estimated by Chen and Ravallion (2002) and those estimated in this paper.

\section{E.- Distribution of Regional Poverty}

The substantial reduction in worldwide poverty rates and headcounts documented in the previous section delivered an unambiguously optimistic picture of the world: global poverty is declining. The question is whether this reduction is homogeneously distributed across the land. To get an answer, we analyze poverty across various regions around the world. The summary results for Asia, Latin America and Africa are reported in Table 4 and in Figures 8 and 9. The results for individual countries within each of the three regions are reported in Tables 5, 6 and 7 respectively.

\section{Asia}

Table 4 shows that the biggest success occurs, without a doubt, in Asia. The \$1/day poverty rate declined from 0.22 in 1970 to 0.02 in 1998 . The $\$ 2 /$ day rate declined from 0.60 to 0.16. The reduction in headcounts was also dramatic: 369 million people abandoned the $\$ 1 /$ day poverty status and 650 the $\$ 2 /$ day one. Obviously, some of this success is due to the positive growth rates experienced by the largest country in the world: China. 
Table 4 shows that this is partially true, but that it is not the whole story. The number of $\$ 1 /$ day poor Chinese went down by about 186 million during the last thirty years and the number of \$2/day by 377 million. The corresponding numbers for non-Chinese Asians are 183 and 274. Thus, about one-half of the reduction in the number of poor in Asia can be accounted for by China, and one-half by the rest of the continent.

If we break up the reductions by decades, we see that the largest decline in $\$ 1 /$ day Asian poor occurred in the 1980s (192 million), followed by the 1990s (121 million) and the 1970s (56 million), whereas the largest decline in the \$2/day occurred in the 1990s (335 million), followed by the 1980s (298 million) and the 1970s (18 million).

Table 5 decomposes the Asian rates across countries. We see that, although China is an extraordinary success, it is by no means an exception. $\$ 1 /$ day poverty rates were almost eliminated everywhere (Nepal was the only Asian country with more than $10 \%$ of the population living below the $\$ 1 /$ day poverty line in 1998 , and the only one that witnessed an increase in its poverty headcount). The most remarkable example, in fact, is not China but Indonesia: a poverty rate of $37 \%$ in 1970 and virtually zero in 1998 . The overall number of $\$ 1 /$ day poor in Indonesia was cut by 43 million. India's poverty rates and headcounts declined during the 80s and 90s (although not during the 70s, when its aggregate growth performance was dismal) and the same is true for Bangladesh. All countries in Asia reduced both poverty rates between 1970 and 1998. The only ones that did not (Japan, Taiwan, Hong Kong and Singapore), already had zero poverty rates.

In terms of $\$ 2 /$ day poverty, the rates declined or stayed the same in all countries. However, because of the large population growth, poverty headcounts increased in Pakistan (by 0.7 million), Bangladesh (by 3.5 million), Philippines (by 0.1 million), and Nepal (by 3.1 million).

The overall success of Asia meant that, while it hosted $76 \%$ of the world's one-dollar poor in 1970, it had only $15 \%$ of them by 1998 (see Table 4c).

\section{Latin America}

The picture for Latin America is a little different and a little bit less optimistic. Table 4a shows that the $\$ 1 /$ day poverty rate was a lot smaller than that in Asia in 1970 (5\% compared to 22.4\%). However, by 1998, the rate was larger in Latin America (2.2\%) than in Asia (1.7\%). The total number of Latin American poor went down by 8.6 million during the last thirty years. The 
problem is that all of the progress occurred in the 1970s, when poverty rates fell from $5 \%$ to $1.2 \%$. The rates increased to $1.9 \%$ during the 1980 s and to $2.2 \%$ during the $90 \mathrm{~s}$. After decreasing by 15.2 million in the 1970s, the number of Latin American poor went up by 4 million during the 1980s (the "lost decade" of the international debt crisis) and by 2.7 million during the 1990s.

Table 6 decomposes the evolution of Latin American poverty by countries. We see that those that had the largest $\$ 1 /$ day poverty rates where those that experienced the largest declines ${ }^{19}$ : Brazil, Dominican Republic, Panama, Jamaica and Trinidad and Tobago. The number of poor in Brazil alone declined by 11 million during the whole period (although the headcount increased by about one million during the 1980s). Mexico's poor decreased by about 3 million. At the other end of the spectrum, the total number of poor increased in Colombia, Peru, Venezuela, Guatemala, Bolivia. Honduras, El Salvador, Paraguay and Costa Rica. It decreased in Brazil, Mexico, Chile, Ecuador, Panama, Jamaica, Trinidad and Tobago, and Guyana.

The \$2/day poverty rate in Latin America was about a third of that in Asia in 1970 (22\% versus $60 \%$ ). After declining to $10.5 \%$ by 1998 , the rate was still below the Asian at the end of the sample period. Notice that the rate in Latin America in 1998 was about the same as in 1980. The losses of the $1980 \mathrm{~s}$ (when $\$ 2 /$ day poverty rates grew by 0.036 ) were partially offset during the 1990s (when poverty fell by 0.035). The total amount of $\$ 2 /$ day poor in Latin America declined by about 9.3 million. The reduction was very large during the 1970s (24.1 million), but the 'terrible' 1980s brought 23.1 million back. Luckily, poverty declined again during the 1990s by about 8.3 million people. Brazil and Mexico contributed by about 8 million each. The largest increases occurred in Colombia, Peru, Venezuela, Bolivia, Honduras, and Nicaragua. In general, most of the increases happened during the 1980s.

Table $4 \mathrm{c}$ shows that Latin America has hosted between 1\% and 3\% of the world's poorest and between $3 \%$ and $5 \%$ of the two-dollar poor. The fraction has remained quite stable over time.

${ }^{19}$ Believers in mean-reversion should not find this surprising, although this is not necessarily a general phenomenon, as we will see in the next section when we discuss Africa. 


\section{Sub-Saharian Africa}

The biggest disaster of the last three decades occurred in Sub Saharian Africa. Table 4 shows that, in 1970 , the $\$ 1 /$ day poverty rate $(22.2 \%)$ was very similar to that of Asia (22.4\%). By 1998, however, the African rate almost doubled to $40.5 \%$ whereas the Asian almost disappeared (1.7\%). The increase was very small during the 1970s but substantial during the 1980s and 1990s. The number of poor increased by 175.5 million over the entire period: 22.8 million in the 1970s, 51.7 in the 1980s and 101 million in the 1990s. ${ }^{20}$

Table 7 shows that the largest increases in poverty rates occurred in Madagascar, Nigeria, Zambia, Central African Republic, Mozambique, Sierra Leone, Burundi, Ghana and Tanzania. In 1998, nine countries had poverty rates of more than 50\%: Tanzania (which had the world's record with $70 \%$ of the population living below the $\$ 1 /$ day line), Ethiopia, Guinea Bissau, Sierra Leone, Central African Republic, Zambia, Mali, Burundi and Madagascar.

Because of its large population, Nigeria is the country with the largest number of poor: 56 million. This was not true in 1970, when Ethiopia had this dubious honor and Tanzania, Uganda and Ghana had more poor than Nigeria. But its horrible growth performance together with the increase in inequality documented in Section 2 have made of Nigeria one of the world's disasters. This is especially true in the 1990s, a period in which the number of Nigerian poor increased by about 26 million.

Although the African picture looks very bleak, not all the news coming from the continent is bad. We observe, for example, that $\$ 1 /$ day poverty rates were reduced between 1970 and 1998 in

${ }^{20}$ The increase in the 1990s might be a little bit of a statistical artifact. The reason is that one large country, the Republic of Congo (Zaire for most of the sample period) witnessed a substantial reduction of per capita GDP. In fact, it went from above the \$1/day poverty line in 1990 to below the line in 1998. Since Congo is in our Group C, that is, it is a country for which we do not have income shares, we assign the same level of income to all its citizens. Thus, poverty increased by about 50 million people during this period. In reality, however, a fraction of the Congolese population was already poor in 1990 and a fraction remained above the line by 1998 so the overall reduction in our numbers is somewhat artificial.

Although Congo is an important part of the story, it is not the whole story: the number of $\$ 1 /$ day poor outside Congo increased by about 50 million citizens during the 90 s. 
13 countries: South Africa, Kenya, ${ }^{21}$ Uganda, Cote d'Ivoire, Zimbabwe, Burkina Faso, Mali, Rwanda, Guinea, Lesotho, Gabon, Mauritius and Botswana. In fact, Botswana cut poverty rates spectacularly from $35 \%$ to less than $1 \%$ in less than thirty years. The performance of Asia's poorest countries (which looked very similar to Africa in terms of poverty rates in 1970) and that of these African success stories suggests that there is hope for reducing poverty in the Sub Saharan continent, provided that the right policies are implemented and the right institutions are developed.

The \$2/day rates in Africa in 1970 were about 10\% smaller than in Asia (53\% in Africa versus $60.3 \%$ in Asia). By 1998, Asia's rates were $15.6 \%$ whereas Africa's had shot up to $64 \%$. The total number of poor increased by 227 million Africans: an increase in 52 million in the 1970s, 78 million in the 80s and 98 million in the 1990s. The worst performers were, again, Nigeria, Mozambique, Madagascar, Niger, Zambia and the Central African Republic.

The largest cuts in \$2/day poverty rates occurred in Botswana (from 60\% in 1970 to $9 \%$ in 1998), Lesotho (from $68 \%$ to $43 \%$ ), and Uganda (from $88 \%$ to $69 \%$ ).

The combination of spectacular reductions in Asian poverty with the disastrous increases in Africa led to a dramatic shift in the fraction of the world's poor hosted by each continent (reported in Table 4C). In 1970, only 11\% of the world's one-dollar poor lived in Africa and 76\% in Asia. By 1998, the numbers had almost reversed: $66 \%$ lived in Africa and $15 \%$ in Asia.

The main reason for decline in poverty in Asia is almost all the countries in that continent experienced rapid aggregate growth. The main reason for the increase in poverty in Africa is that almost all countries in that continent experienced negative growth. The lesson is very clear: if we want to reduce poverty rates in Africa, we must find a way for that continent to grow. The welfare implications of finding how to turn around the growth performance of Africa are so staggering, that this has probably become the most important question in economics.

${ }^{21}$ Kenya's rate declined substantially in the 1970s, but then it rose back up in the following two decades. The behavior of Uganda's rate is exactly the opposite: up in the 1970s, and down in the 80 s and 90 s. 


\section{World Income Inequality}

We can now analyze other aspects of the world distribution of income estimated in the previous sections. In particular, we can estimate its dispersion, which reflects the extent to which individual incomes across the planet are unequal. Many indexes of income inequality have been proposed in the literature. Some have desirable properties and some do not. Some can be derived from social welfare functions, and some cannot. Since the scope of this paper is not to settle the question of what index best represents worldwide income inequalities, we will simply report the nine most popular indexes used in the literature ${ }^{22}$ : The Gini coefficient, the Theil Index (which corresponds to the Generalized Entropy Index with coefficient 1), the Mean Logarithmic Deviation (MLD, which corresponds to the Generalized Entropy Index with coefficient 0), the Atkinson indexes with coefficient 0.5 and $1,{ }^{23}$ the squared of the coefficient of variation (which is the standard deviation divided by the mean), the variance of the logarithm of income, the ratio of the average income of top $20 \%$ of the distribution to the bottom $20 \%$ and the ratio of income of the person located at the bottom of the top quintile divided by the income of the person located at the top of the bottom quintile .

The results of estimating each of the first seven indexes for each year between 1970 and 1998 are reported in Table 7 and Figures 10a through 10g (the relevant lines in Figure 10 are those labeled "from Kernels"24). The main lessons from these estimations are the following. Firstly, they all show a remarkably similar pattern of worldwide inequality over time. Secondly, inequality remained more or less constant (or maybe increased) during the 1970s. Thirdly, inequality declined substantially during the 1980s and 1990s. The size of the decline depends a bit on the exact measure: the largest reduction corresponds to the MLD index, which declined by almost $13 \%$ since its peak in 1978 . The Theil index went down by more than $10 \%$, the two Theil indexes decreased

${ }^{22}$ See Cowell (1995) for a description and properties of each of them.

${ }^{23}$ See Atkinson (1970).

${ }^{24}$ The label is supposed to reflect the fact that these indexes have been computed from the individual incomes estimated using a kernel for each country. We use this label because, later in this section we compare our estimates to those of Sala-i-Martin (2002), who estimates a worldwide kernel density function using quintile data (and we call that approach "kernel of quintiles" rather than "kernel of kernels"). 
by $11 \%$ and $8 \%$, the coefficient of variation declined by $9.6 \%$, the variance of the logarithm by $6.7 \%$ and the Gini coefficient by $5 \%$. Despite these small differences across measures, the overall picture is clear: inequality has reduced substantially during the last twenty years.

This conclusion was also reached by Sala-i-Martin (2002), who computed the exact same indexes for a world income distribution estimated directly out of quintile data for each country (as described in Section 2 of this paper). It is interesting to see how our estimates compare with his. To make this comparison, Figures 10a-c also display a line labeled "From Quintiles". Some interesting lessons arise from this comparison. Firstly, our estimates of global inequality are higher than those of Sala-i-Martin (2002). This was expected because Sala-i-Martin (2002) estimates the world distribution of income by assuming that all individuals within a quintile (for each country and year) have the same level of income. In the present paper, we estimate the differences of incomes within quintiles by fitting a country density function. Naturally, our method allows for greater disparities across individual incomes and this shows up in terms of a larger estimated aggregate inequality. The fact that our level of inequality is higher than the one estimated by researchers who assume equal income within quintiles implies that our estimate of the fraction of global inequality accounted for by within-country disparities is larger. The reason is that the across-country inequalities (that is, the disparities that arise from estimating worldwide income inequality under the assumption that all individuals in a country have the same level of income) are, by construction, independent of how we allocate income across individuals within a country. Since our estimate of global inequality is larger and the across-country index is the same, the ratio of across to global must be smaller. It follows that the fraction of inequality accounted for by across-country disparities is smaller and, correspondingly, the fraction accounted for by within-country inequality must be larger.The difference is not quantitatively large, but it is noticeable. For example, for the MLD, we estimate that $65 \%$ of world inequality can be accounted for by across-country disparities whereas Sala-iMartin's (2002) estimate is $69 \%$. For the Theil index, we estimate that $66 \%$ of world inequality comes from across-country dispersion whereas Sala-i-Martin (2002) estimates that the fraction is 
$72 \%$. Finally, for the squared of the coefficient of variation, we get that $51 \%$ of the overall inequality is accounted for by across-country dispersion whereas Sala-i-Martin (2002) gets $59 \%{ }^{25}$

The second lesson from Figures 10a-g is that the two lines are virtually parallel. This suggests that, although the assumption of same income within quintile made by Sala-i-Martin (2002) tends to underestimate overall inequality, it allows for a correct estimation of the evolution of inequality over time. Thus, both this paper and Sala-i-Martin (2002) reach the same conclusion about the evolution of global income inequality: it declined substantially between 1980 and 1998 .

Finally, Figure 10h displays two additional popular measures of income inequality. The first is the ratio of the average income of the to $20 \%$ of the population to the bottom $20 \%$. We see that this ratio increased from 40 in 1970 to 45 in 1980. During the last 20 years, however, the ratio declined to 41 in 1990 and to 39 in 1998. The second measure is the ratio of the income of the person located at the bottom of the top quintile (the person located in the $80 \%$ of the distribution) to the income located at the top of the bottom quintile (the person located in the $20 \%$ of the distribution). This ratio remained virtually constant at 10 between 1970 and 1980, and it declined to 9.2 in 1990 and to 8.6 in 1998.

${ }^{25}$ Bourguignon (1979), Shorrocks (1980), and Cowell (1995) show that the only measures that can be decomposed into within and across country indexes are the ones of the Generalized Entropy Index class. Of our measures, only MLD, the Theil index and the Squared of the Coefficient of Variation correspond to that class so the decompositions cannot be made for the other measures. 


\section{Conclusions}

Using the Deininger and Squire (1996) and World Bank estimates of income shares for selected years and selected countries, we estimated five income shares for 97 countries from 1970 to 1998 . Based on these shares, we estimated the distribution of income for each country and each year. We then integrated these individual distributions to construct the world distribution of income. The analysis of various aspects of this global income distribution led us to a number of interesting conclusions:

Firstly, the distribution "shifted to the right" remarkably over the last thirty years. This reflects the fact that, by and large, individual incomes increased substantially over this period.

Secondly, the world distribution of income seemed to show certain bimodality in 1970: the peak for the poor lay between the one-dollar and two-dollar poverty lines whereas the peak for the rich lay around \$9,000. By 1998, these "twin peaks" had vanished giving rise to a large "world middle class". The "emerging twin peaks" found by Quah (1996) using aggregate country data become"vanishing twin peaks" when one uses individual income data.

Thirdly, global poverty rates declined significantly between 1970 and 1998. This is true for the $\$ 1 /$ day definition as well as for the $\$ 2 /$ day definition.

Fourthly, global poverty headcounts also declined substantially over this period, but especially after 1976. The total number of one-dollar poor declined by 234 million between 1976 and 1998. The number of two-dollar poor decreased by more than 450 million people. The success in reducing poverty is, therefore, clear.

Fifthly, success does not mean victory. The number of poor is still embarrassingly large: in 1998, more than 350 million people still had an income of less than a dollar a day and close to a billion citizens had to live with less than two dollars a day.

Sixthly, the decomposition of poverty rates across regions, suggests that the reductions in poverty were not uniform across continents. The bulk of the decline took place in Asia. Latin America reduced poverty overall, but most of the gains occurred during the 1970s with little or no gains after that. Africa was the worst performer since poverty headcounts in that continent increased by 175 million people according to the one-dollar definition and by 227 million according to the 
two-dollar line. One-dollar poverty rates in Africa doubled from $22 \%$ to $44 \%$ and two-dollar rates increased from $53 \%$ to $64 \%$.

Seventhly, we estimated nine measures of global income inequality. All of them deliver the same picture: inequality declined substantially during the last two decades.

Eighthly, we compared our level estimates of income inequality with those estimated by Sala-i-Martin (2002) (under the assumption that all individuals within a quintile for each country and year have the same level of income). We find that Sala-i-Martin (2002) underestimates the global level of income inequality but gets the correct pattern over time. Hence, studies that aim to estimate the evolution of income inequality can get the correct answer if they treat all citizens within a quintile identically.

The final conclusion is that the last three decades saw a reversal of roles between Africa and Asia: in 1970, 11\% of the world's poor were in Africa and 76\% in Asia. By 1998, Africa hosted $66 \%$ of the poor and Asia's share had declined to $15 \%$. Clearly, this reversal was caused by the very different aggregate growth performances. Poverty reduced remarkably in Asia because Asian countries grew. Poverty increased dramatically in Africa because African countries did not grow. As a result, perhaps the most important lesson to be learned from this paper is that a central question economists interested in human welfare should ask, therefore, is how to make Africa grow. 


\section{References}

Atkinson A. B. (1970), "On the Measurement of Inequality”, Journal of Economic Theory, 2, 244-263.

Atkinson A. B. Ad A. Brandolini, (2001), "Promise and Pitfalls in the use of 'Secondary' DataSets: Income Inequality in OECD Countries as a Case Study", Journal of Economic Literature, vol XXXIX, number 3, pp.771-800, September.

Barro R. J. and X. Sala-i-Martin, (1998) "Economic Growth", MIT Press.

Berry, A., F. Bourguignon and C. Morrisson, (1983), "Changes in the World Distribution of Income Between 1950 and 1977", The Economic Journal, June, pp. 331-350.

Bourguignon, F., (1979) “Decomposable Income Inequality Measures”, Econometrica 47, pp. 901-920.

Bourguignon, F. and C. Morrisson, C., (2002) , "Inequality Among World Citizens: 1820-1992", forthcoming American Economic Review.

Chen, S. and M. Ravallion, (2002), "How did the World's Poorest Fare in the 1990s?", World Bank Working Paper..

Cowell, F.A., (1995), "Measuring Income Inequality", $2^{\text {nd }}$ Edition, Harvester Wheatsheaf, Hemel Hempstead.

Deininger, K. and L. Squire, (1996), "A New Data Set Measuring Income Inequality," World Bank Economic Review, Vol. 10, pp. 565-91.

Dowrick, S. and M. Akmal, (2001), "Contradictory Trends in Global Income Inequality: A Tale of Two Biases", mimeo Australian National University, March.

Firebaugh, G., (1999), "Empirics of World Income Inequality", American Journal of Sociology, 104: $1597-1630$.

Grosh, M. and E.W. Nafziger, (1986), "The Computation of World Income Distribution”, Economic Development and Cultural Change, pp 347-359.

Heston, A. R. Summers, and B. Aten, (2001), Penn World Table Version 6.0, Center for International Comparisons at the University of Pennsylvania (CICUP), December.

Jones, C. I., (1997) "On the Evolution of the World Income Distribution", Journal of Economic Perspectives, Summer.

Kremer, M., A. Onaski, and J. Stock, (2001), "Searching for Prosperity", Carnegie-Rochester Conference Series on Public Policy, vol 55, December.

Maddison, A. (1998), "Chinese Economic Performance in the Long Run", Edited by OECD.

Melchior, A, K. Telle and H. Wiig, (2000), Globalisation and Inequality - World Income Distribution and Living Standards, 1960-1998. Oslo: Royal Norwegian Ministry of Foreign Affairs, Report 6b/2000.

Meng, L. and X. Wang, (2000), “An Estimate of the Reliability of Statistical Data on China's Economic Growth", Jingji yanji (economic Research), 10: 3-13.

Milanovic, B., "True World Inequality 1988 and 1993: First Calculations Based on Household Surveys Alone", World Bank Working Paper, 2000 
Mulligan, C. B. (2002), 'Economic Limits on 'Rational’ Democratic Redistribution', mimeo University of Chicago.

Quah, D., (1997), "Empirics for Growth and Distribution: Polarization, Stratification, and Convergence Clubs", Journal of Economic Growth, 2.

Quah, D., (1996), "Twin Peaks: Growth and Convergence in Models of Distribution Dynamics", Economic Journal, July.

Quah, D. (2002), "One-Third of the World's Growth and Inequality”, mimeo LSE.

Ravallion, M. and S. Chen, (1997), "What Can New Survey Data Tell Us About Recent Changes in Distribution and Poverty?" World Bank Economic Review. 11: 357-82.

Ravallion, M., Datt, G., and van de Walle, D. (1991) "Qualifying Absolute Poverty in the Developing World", Review of Income and Wealth, 37, 345-361.

Rawski, T. G., "What's Happening to Chinese Statistics?", China Economic Review, December. Ren, R., (1997), "China's Economic Performance in International Perspective”, OECD, Paris. Sala-i-Martin, X. (2002), “The Disturbing 'Rise' of Global Income Inequality”, NBER Working Paper 8904, April.

Sala-i-Martin, X. (2002b), "Consumption vs. Income Poverty: Estimation from a World Distribution of Individual Consumption", mimeo Columbia University.

Sala-i-Martin, X. (2002c), "New Estimates of the World Distribution of Income", mimeo Columbia University.

Schultz, T.P., (1998), "Inequality and the Distribution of Personal Income in the World: How it is Changing and Why", Journal of Population Economics, pp. 307-344.

Shorrocks, A. F., (1980), "The Class of Additively Decomposable Inequality Measures”, Econometrica 48, pp 613-625.

Summers, R. and A. Heston, (1988), "A new set of international comparisons of real product and price levels estimates for 130 countries, 1950-1985", Review of Income and Wealth, 34(1), March, 1-25.

Summers, Robert and Heston, Alan., (1991), The Penn World Table (Mark 5): an expanded set of international comparisons, 1950-1988, Quarterly Journal of Economics, 106(2), May, 327-68.

Theil, H., (1967), “Economics and Information Theory”, North-Holland, Amsterdam,

Theil, H., (1979), "World Income Inequality”, Economics Letters, 2: 99-102.

Theil, H., (1996), "Studies in Global Econometrics”, Kluwert Academic Publishers, Amsterdam.

Theil, H. And J. L. Seale, (1994), “The Geographic Distribution of World Income, 1950-1990", The Economist, 4. 


\section{Tables}

TABLE 1. WORLD POVERTY RATES

\begin{tabular}{|c|c|c|c|c|}
\hline \multirow[b]{2}{*}{ Year } & \multicolumn{2}{|c|}{ Poverty Rates } & \multicolumn{2}{|c|}{$\begin{array}{l}\text { Poverty Headcounts } \\
\text { (millions) }\end{array}$} \\
\hline & \$1/Day & \$2/Day & \$1/Day & \$2/Day \\
\hline 1970 & 0.172 & 0.410 & 554.2 & $1,323.8$ \\
\hline 1971 & 0.168 & 0.405 & 554.9 & $1,337.0$ \\
\hline 1972 & 0.170 & 0.406 & 573.7 & $1,369.9$ \\
\hline 1973 & 0.166 & 0.399 & 569.7 & $1,373.2$ \\
\hline 1974 & 0.164 & 0.396 & 576.9 & $1,389.8$ \\
\hline 1975 & 0.157 & 0.389 & 563.4 & $1,390.7$ \\
\hline 1976 & 0.161 & 0.391 & 587.3 & $1,425.9$ \\
\hline 1977 & 0.151 & 0.377 & 558.3 & $1,397.6$ \\
\hline 1978 & 0.148 & 0.372 & 559.6 & $1,404.2$ \\
\hline 1979 & 0.139 & 0.358 & 533.4 & 1.374 .3 \\
\hline 1980 & 0.131 & 0.346 & 514.0 & $1,352.4$ \\
\hline 1981 & 0.126 & 0.337 & 501.6 & $1,339.7$ \\
\hline 1982 & 0.120 & 0.328 & 485.4 & $1,326.4$ \\
\hline 1983 & 0.113 & 0.316 & 463.7 & $1,300.7$ \\
\hline 1984 & 0.103 & 0.299 & 431.1 & $1,251.5$ \\
\hline 1985 & 0.096 & 0.285 & 410.7 & $1,216.6$ \\
\hline 1986 & 0.092 & 0.276 & 396.9 & $1,198.8$ \\
\hline 1987 & 0.088 & 0.270 & 389.6 & $1,193.9$ \\
\hline 1988 & 0.084 & 0.261 & 378.6 & $1,172.8$ \\
\hline 1989 & 0.087 & 0.264 & 399.9 & $1,207.0$ \\
\hline 1990 & 0.086 & 0.258 & 400.2 & $1,199.5$ \\
\hline 1991 & 0.085 & 0.252 & 400.9 & $1,189.1$ \\
\hline 1992 & 0.080 & 0.239 & 385.1 & $1,148.1$ \\
\hline 1993 & 0.076 & 0.225 & 370.5 & $1,096.4$ \\
\hline 1994 & 0.076 & 0.217 & 374.3 & $1,072.3$ \\
\hline 1995 & 0.072 & 0.206 & 360.5 & $1,032.5$ \\
\hline 1996 & 0.069 & 0.195 & 351.0 & 993.1 \\
\hline 1997 & 0.067 & 0.189 & 348.4 & 975.6 \\
\hline \multirow[t]{11}{*}{1998} & 0.067 & 0.186 & 352.9 & 973.7 \\
\hline & \multicolumn{2}{|c|}{ Change Since 1970} & \multicolumn{2}{|c|}{ Change Since 1970} \\
\hline & \multicolumn{2}{|l|}{-0.104} & -201.4 & -350.1 \\
\hline & & & \multicolumn{2}{|c|}{ Change Since 1976} \\
\hline & & & -234.4 & -452.2 \\
\hline & \multicolumn{2}{|c|}{ Change During 70s } & \multicolumn{2}{|c|}{ Change During 70s } \\
\hline & -0.040 & -0.064 & -40.2 & 28.7 \\
\hline & \multicolumn{2}{|c|}{ Change During 80s } & \multicolumn{2}{|c|}{ Change During 80s } \\
\hline & -0.045 & -0.088 & -113.8 & -152.9 \\
\hline & \multicolumn{2}{|c|}{ Change During 90s } & \multicolumn{2}{|c|}{ Change During 90s } \\
\hline & -0.019 & -0.072 & -47.4 & -225.8 \\
\hline
\end{tabular}


TABLE 2. COMPARING POVERTY RATES FROM KERNELS AND QUINTILES

Poverty Rates

\begin{tabular}{|c|cc|cc|}
\cline { 2 - 5 } \multicolumn{1}{c|}{} & $\begin{array}{c}\text { \$1/Day } \\
\text { KerneL }\end{array}$ & $\begin{array}{c}\text { \$1/Day } \\
\text { Quintile }\end{array}$ & $\begin{array}{c}\text { \$2/Day } \\
\text { Kernel }\end{array}$ & $\begin{array}{c}\text { \$2/Day } \\
\text { Quintile }\end{array}$ \\
\hline 1970 & 0.172 & 0.165 & 0.410 & 0.445 \\
1972 & 0.170 & 0.186 & 0.406 & 0.437 \\
1974 & 0.164 & 0.197 & 0.396 & 0.409 \\
1976 & 0.161 & 0.163 & 0.391 & 0.406 \\
1978 & 0.148 & 0.150 & 0.372 & 0.391 \\
1980 & 0.131 & 0.109 & 0.346 & 0.370 \\
1982 & 0.120 & 0.104 & 0.328 & 0.350 \\
1984 & 0.103 & 0.098 & 0.299 & 0.312 \\
1986 & 0.092 & 0.101 & 0.276 & 0.295 \\
1988 & 0.084 & 0.091 & 0.261 & 0.277 \\
1990 & 0.086 & 0.069 & 0.258 & 0.275 \\
1992 & 0.080 & 0.065 & 0.239 & 0.230 \\
1994 & 0.076 & 0.064 & 0.217 & 0.223 \\
1996 & 0.069 & 0.056 & 0.195 & 0.198 \\
1998 & 0.067 & 0.055 & 0.186 & 0.187 \\
\hline
\end{tabular}

Poverty Headcounts

\begin{tabular}{|c|cc|cc|}
\multicolumn{4}{c}{} & \multicolumn{4}{c|}{ Poverty Headcounts } \\
\cline { 2 - 5 } \multicolumn{1}{c|}{} & $\begin{array}{c}\text { \$1/Day } \\
\text { Kernel }\end{array}$ & $\begin{array}{c}\text { \$1/Day } \\
\text { Quintile }\end{array}$ & $\begin{array}{c}\text { \$2/Day } \\
\text { Kernel }\end{array}$ & $\begin{array}{c}\text { \$2/Day } \\
\text { Quintile }\end{array}$ \\
\hline 1970 & 554.2 & 534.0 & $1,323.8$ & $1,437.5$ \\
1972 & 573.7 & 626.4 & $1,369.9$ & $1,473.4$ \\
1974 & 576.9 & 692.4 & $1,389.8$ & $1,435.6$ \\
1976 & 587.3 & 595.6 & $1,425.9$ & $1,479.1$ \\
1978 & 559.6 & 567.1 & $1,404.2$ & $1,475.8$ \\
1980 & 514.0 & 427.6 & $1,352.4$ & $1,446.6$ \\
1982 & 485.4 & 419.1 & $1,326.4$ & $1,417.1$ \\
1984 & 431.1 & 410.6 & $1,251.5$ & $1,307.3$ \\
1986 & 396.9 & 440.1 & $1,198.8$ & $1,279.5$ \\
1988 & 378.6 & 410.6 & $1,172.8$ & $1,244.2$ \\
1990 & 400.2 & 319.3 & $1,199.5$ & $1,278.4$ \\
1992 & 385.1 & 311.0 & $1,148.1$ & $1,104.4$ \\
1994 & 374.3 & 315.2 & $1,072.3$ & $1,102.5$ \\
1996 & 351.0 & 286.3 & 993.1 & $1,008.0$ \\
1998 & 352.9 & 286.1 & 973.7 & 979.8 \\
\hline
\end{tabular}

\begin{tabular}{|lrrr|}
\hline \multicolumn{2}{|c|}{ Change } & $1970-1998$ \\
-0.104 & -0.111 & -0.224 & -0.258 \\
\hline
\end{tabular}

Change 1970-1998

\begin{tabular}{llll}
-201.4 & -247.9 & -350.1 & -457.7 \\
\hline
\end{tabular}

\begin{tabular}{|lrrr|}
\hline \multicolumn{2}{|c|}{ Change } & $1976-1998$ \\
-234.4 & -309.5 & -452.2 & -499.3 \\
\hline
\end{tabular}

Source: Poverty rates and headcounts from Quintiles are taken from Sala-i-Martin (2002). 
TABLE 3A. CONSUMPTION vs. INCOME POVERTY RATES

\begin{tabular}{|c|c|c|c|c|c|c|}
\hline \multirow[b]{2}{*}{ Year } & \multicolumn{2}{|c|}{ Income Poverty Rates } & \multicolumn{2}{|c|}{ Ravallion et. al Rates } & \multicolumn{2}{|c|}{ Consumption Poverty } \\
\hline & \$1/Day & \$2/Day & \$1/Day & \$2/Day & \$1/Day & \$2/Day \\
\hline 1970 & 0.172 & 0.410 & & & 0.314 & 0.541 \\
\hline 1971 & 0.168 & 0.405 & & & 0.317 & 0.542 \\
\hline 1972 & 0.170 & 0.406 & & & 0.317 & 0.542 \\
\hline 1973 & 0.166 & 0.399 & & & 0.313 & 0.539 \\
\hline 1974 & 0.164 & 0.396 & & & 0.309 & 0.532 \\
\hline 1975 & 0.157 & 0.389 & & & 0.305 & 0.530 \\
\hline 1976 & 0.161 & 0.391 & & & 0.310 & 0.531 \\
\hline 1977 & 0.151 & 0.377 & & & 0.296 & 0.518 \\
\hline 1978 & 0.148 & 0.372 & & & 0.303 & 0.518 \\
\hline 1979 & 0.139 & 0.358 & & & 0.293 & 0.511 \\
\hline 1980 & 0.131 & 0.346 & & & 0.279 & 0.498 \\
\hline 1981 & 0.126 & 0.337 & & & 0.262 & 0.485 \\
\hline 1982 & 0.120 & 0.328 & & & 0.255 & 0.479 \\
\hline 1983 & 0.113 & 0.316 & & & 0.240 & 0.467 \\
\hline 1984 & 0.103 & 0.299 & & & 0.227 & 0.453 \\
\hline 1985 & 0.096 & 0.285 & & & 0.221 & 0.444 \\
\hline 1986 & 0.092 & 0.276 & & & 0.217 & 0.440 \\
\hline 1987 & 0.088 & 0.270 & 0.283 & 0.610 & 0.215 & 0.436 \\
\hline 1988 & 0.084 & 0.261 & & & 0.204 & 0.425 \\
\hline 1989 & 0.087 & 0.264 & & & 0.209 & 0.429 \\
\hline 1990 & 0.086 & 0.258 & 0.290 & 0.617 & 0.207 & 0.423 \\
\hline 1991 & 0.085 & 0.252 & & & 0.202 & 0.416 \\
\hline 1992 & 0.080 & 0.239 & & & 0.195 & 0.403 \\
\hline 1993 & 0.076 & 0.225 & 0.282 & 0.601 & 0.188 & 0.391 \\
\hline 1994 & 0.076 & 0.217 & & & 0.184 & 0.381 \\
\hline 1995 & 0.072 & 0.206 & & & 0.173 & 0.369 \\
\hline 1996 & 0.069 & 0.195 & 0.245 & 0.561 & 0.163 & 0.352 \\
\hline 1997 & 0.067 & 0.189 & & & 0.163 & 0.351 \\
\hline \multirow[t]{9}{*}{1998} & 0.067 & 0.186 & 0.240 & 0.560 & 0.160 & 0.347 \\
\hline & Change Si & 1987-98 & Change Si & 1987-98 & Change Si & $1987-98$ \\
\hline & -0.021 & -0.085 & -0.044 & -0.050 & -0.054 & -0.090 \\
\hline & Change D & g 70s & Change D & g 70s & Change D & $70 s$ \\
\hline & -0.040 & -0.064 & NA & NA & -0.036 & -0.043 \\
\hline & Change D & g $80 s$ & Change D & g $80 s$ & Change D & $80 s$ \\
\hline & -0.045 & -0.088 & NA & NA & -0.072 & -0.075 \\
\hline & Change D & g 90s & Change D & g $90 s$ & Change D & $90 \mathrm{~s}$ \\
\hline & -0.019 & -0.072 & -0.050 & -0.057 & -0.046 & -0.077 \\
\hline
\end{tabular}

Sources: Sala-i-Martin (2002b), Chen and Ravallion (2002) and author's own calculations as described in the text. 
TABLE 4A. POVERTY BY REGION: \$1/DAY

\begin{tabular}{|c|c|c|c|c|c|c|c|c|c|c|c|c|c|c|c|c|c|}
\hline & \multirow{2}{*}{\begin{tabular}{|c} 
Population 98 \\
(millions)
\end{tabular}} & \multicolumn{4}{|c|}{ Poverty Rates $\$ 1 /$ day } & \multicolumn{4}{|c|}{ Changes Over Time } & \multicolumn{4}{|c|}{ Number of $1 \$$ Poor (millions) } & \multicolumn{4}{|c|}{ Changes Over Time (millions) } \\
\hline & & 1970 & 1980 & 1990 & 1998 & $1970-98$ & $70 \mathrm{~s}$ & $80 \mathrm{~s}$ & $90 \mathrm{~s}$ & 1970 & 1980 & 1990 & 1998 & $1970-98$ & $70 \mathrm{~s}$ & $80 \mathrm{~s}$ & $90 \mathrm{~s}$ \\
\hline World & 5.240 & 0.172 & 0.131 & 0.086 & 0.067 & -0.10 & -0.04 & -0.05 & -0.02 & 554.2 & 514.0 & 4002 & 352.9 & -2013 & -40.2 & -113.8 & -47.3 \\
\hline Asia & 3,084 & 0.224 & 0.158 & 0.063 & 0.017 & -0.21 & -0.07 & -0.10 & -0.05 & 420.9 & 364.9 & 173.0 & 52.1 & -368.8 & -56.0 & -191.9 & -120.9 \\
\hline China & 1,239 & 0.267 & 0.198 & 0.097 & 0.026 & -0.24 & -0.07 & -0.10 & -0.07 & 218.3 & 194.8 & 109.5 & 32.4 & -185.9 & -23.5 & -85.2 & -77.2 \\
\hline Asia Minus China & 1845 & 0.192 & 0.129 & 0.039 & 0.011 & -0.18 & -0.06 & -0.05 & -0.03 & 2027 & 170.1 & 63.5 & 197 & -182.9 & -32.5 & -106.7 & -43.8 \\
\hline Latin America & 486 & 0.050 & 0.012 & 0.019 & 0.022 & -0.03 & -0.04 & 0.01 & 0.00 & 19.3 & 4.0 & 8.0 & 107 & -8.6 & -152 & 4.0 & 27 \\
\hline írica & 579 & 0.222 & 0.234 & 0.286 & 0.405 & 0.18 & 0.01 & 0.05 & 0.12 & 592 & 81.9 & 133.7 & 234.7 & 175.5 & 22.8 & 517 & 101 \\
\hline
\end{tabular}

TABLE 4B. POVERTY BY REGION: \$2/DAY

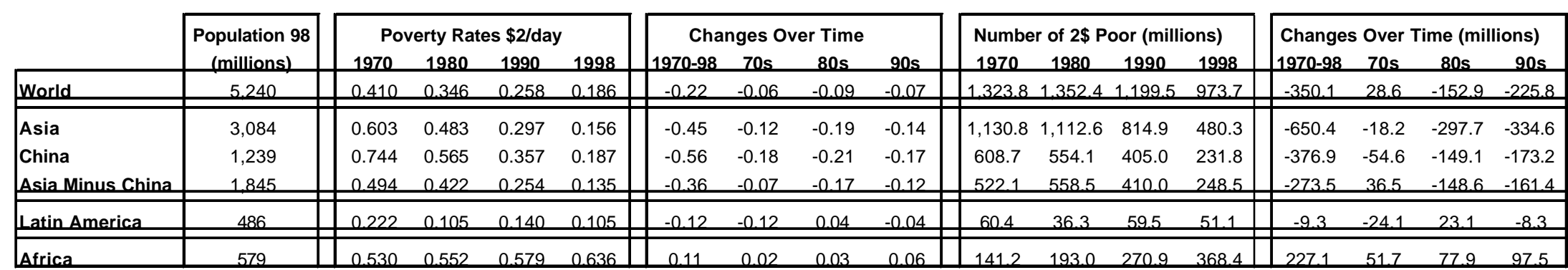

TABLE 4C. FRACTION OF WORLD'S POOR ACCOUNTED FOR BY REGION

\begin{tabular}{|c|c|c|c|c|c|c|c|c|}
\hline \multirow[b]{2}{*}{ World } & \multicolumn{4}{|c|}{\begin{tabular}{|cccc}
\multicolumn{4}{|c}{ Fraction of World's $\$ 1 /$ day Poor } \\
$1970 \quad 1980$ & 1990 & 1998 \\
\end{tabular}} & \multicolumn{4}{|c|}{$\begin{array}{l}\text { Fraction of World's } \$ 2 / \text { day Poor } \\
1970 \quad 1980 \quad 1990 \quad 1998 \\
\end{array}$} \\
\hline & 1 & 1 & 1 & 1 & 1 & 1 & 1 & 1 \\
\hline Asia & 0.76 & 0.71 & 0.43 & 0.15 & 0.85 & 0.82 & 0.68 & 0.49 \\
\hline China & 0.39 & 0.38 & 0.27 & 0.09 & 0.46 & 0.41 & 0.34 & 0.24 \\
\hline Asia Minus China & 0.37 & 0.33 & 0.16 & 0.06 & 0.39 & 0.41 & 0.34 & 0.26 \\
\hline Latin America & 0.03 & 0.01 & 0.02 & 0.03 & 0.05 & 0.03 & 0.05 & 0.05 \\
\hline Africa & 0.11 & 0.16 & 0.33 & 0.66 & 0.11 & 0.14 & 0.23 & 0.38 \\
\hline
\end{tabular}


TABLE 5A. POVERTY IN ASIA: \$1/DAY

\begin{tabular}{|c|c|c|c|c|c|c|c|c|c|c|c|c|c|c|c|c|c|}
\hline & \multirow{2}{*}{\begin{tabular}{|c} 
Population 98 \\
(millions)
\end{tabular}} & \multicolumn{4}{|c|}{ Poverty Rates $\$ 1 /$ day } & \multicolumn{4}{|c|}{ Changes Over Time } & \multicolumn{4}{|c|}{ Number of $1 \$$ Poor (millions) } & \multicolumn{4}{|c|}{\begin{tabular}{|l|} 
Changes Over Time (millions) \\
\end{tabular}} \\
\hline & & 1970 & 1980 & 1990 & 1998 & $1970-98$ & $70 \mathrm{~s}$ & 805 & ans & 1970 & 1980 & 1990 & 1998 & $1970-98$ & $70 s$ & $80 s$ & ans \\
\hline China & 1,239 & 0.27 & 0.20 & 0.10 & 0.03 & -0.24 & -0.07 & -0.10 & -0.07 & 218.3 & 194.8 & 109.5 & 32.4 & $\mid-185.9$ & -23.5 & -85.2 & -77.2 \\
\hline India & 980 & 0.21 & 0.17 & 0.05 & 0.01 & -0.20 & -0.04 & -0.12 & -0.04 & 113.3 & 114.4 & 38.4 & 6.4 & -107.0 & 1.1 & -76.1 & -32.0 \\
\hline Indonesia & 204 & 0.37 & 0.07 & 0.00 & 0.00 & -0.37 & -0.30 & -0.07 & 0.00 & 43.1 & 10.2 & 0.6 & 0.1 & -43.1 & -33.0 & -9.6 & -0.5 \\
\hline Pakistan & 132 & 0.13 & 0.11 & 0.03 & 0.02 & -0.11 & -0.03 & -0.07 & -0.01 & 8.0 & 8.7 & 3.7 & 2.9 & -5.1 & 0.7 & -5.0 & -0.8 \\
\hline Japan & 126 & 0.00 & 0.00 & 0.00 & 0.00 & 0.00 & 0.00 & 0.00 & 0.00 & 0.0 & 0.0 & 0.0 & 0.0 & 0.0 & 0.0 & 0.0 & 0.0 \\
\hline Bangladesh & 126 & 0.28 & 0.29 & 0.13 & 0.05 & -0.23 & 0.02 & -0.16 & -0.09 & 18.5 & 25.5 & 14.7 & 5.7 & -12.8 & 7.1 & -10.9 & -9.0 \\
\hline Philip & 75 & 0.16 & 0.04 & 0.03 & 0.01 & -0.14 & -0.11 & -0.01 & -0.02 & 5.8 & 2.1 & 2.0 & 1.1 & -4.8 & -3.8 & -0.1 & -0.9 \\
\hline Thailand & 61 & 0.19 & 0.09 & 0.00 & 0.00 & -0.19 & -0.10 & -0.08 & 0.00 & 6.7 & 4.0 & 0.2 & 0.0 & -6.7 & -2.7 & -3.8 & -0.2 \\
\hline Korea, Rep. & 46 & 0.02 & 0.00 & 0.00 & 0.00 & -0.02 & -0.02 & 0.00 & 0.00 & 0.8 & 0.0 & 0.0 & 0.0 & -0.8 & -0.8 & 0.0 & 0.0 \\
\hline Nep & 23 & 0.27 & 0.28 & 0.20 & 0.15 & -0.12 & 0.01 & -0.09 & -0.04 & 3.1 & 4.1 & 3.7 & 3.5 & 0.4 & 1.0 & -0.4 & -0.2 \\
\hline Malaysia & 22 & 0.14 & 0.01 & 0.00 & 0.00 & -0.14 & -0.12 & -0.01 & 0.00 & 1.5 & 0.2 & 0.0 & 0.0 & -1.5 & -1.3 & -0.1 & 0.0 \\
\hline Taiwan & 22 & 0.00 & 0.00 & 0.00 & 0.00 & 0.00 & 0.00 & 0.00 & 0.00 & 0.0 & 0.0 & 0.0 & 0.0 & 0.0 & 0.0 & 0.0 & 0.0 \\
\hline Sri Lanka & 19 & 0.14 & 0.06 & 0.01 & 0.00 & -0.14 & -0.08 & -0.04 & -0.01 & 1.7 & 0.8 & 0.2 & 0.0 & -1.7 & -0.9 & -0.6 & -0.2 \\
\hline Hong Kong & 7 & 0.00 & 0.00 & 0.00 & 0.00 & 0.00 & 0.00 & 0.00 & 0.00 & 0.0 & 0.0 & 0.0 & 0.0 & 0.0 & 0.0 & 0.0 & 0.0 \\
\hline Singapore & 3 & 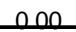 & ممـمـ & مممــ & مممــ & م0م0 & مممــ & ـممـــ & مـمـــ مــ & مـمـ & معم & ممـ & مـ & ممـ & مـ & مـم & معم \\
\hline
\end{tabular}

\begin{tabular}{|llllll|llllll|l|l|llllll}
\hline Total & 3,084 & -0.21 & -0.07 & -0.10 & -0.05 & 0.224 & 0.158 & 0.063 & 0.017 & 364.9 & 173.0 & 52.1 & -368.8 & -56.0 & -191.9 & -120.9 \\
\hline
\end{tabular}

TABLE 5B. POVERTY IN ASIA: \$2/DAY

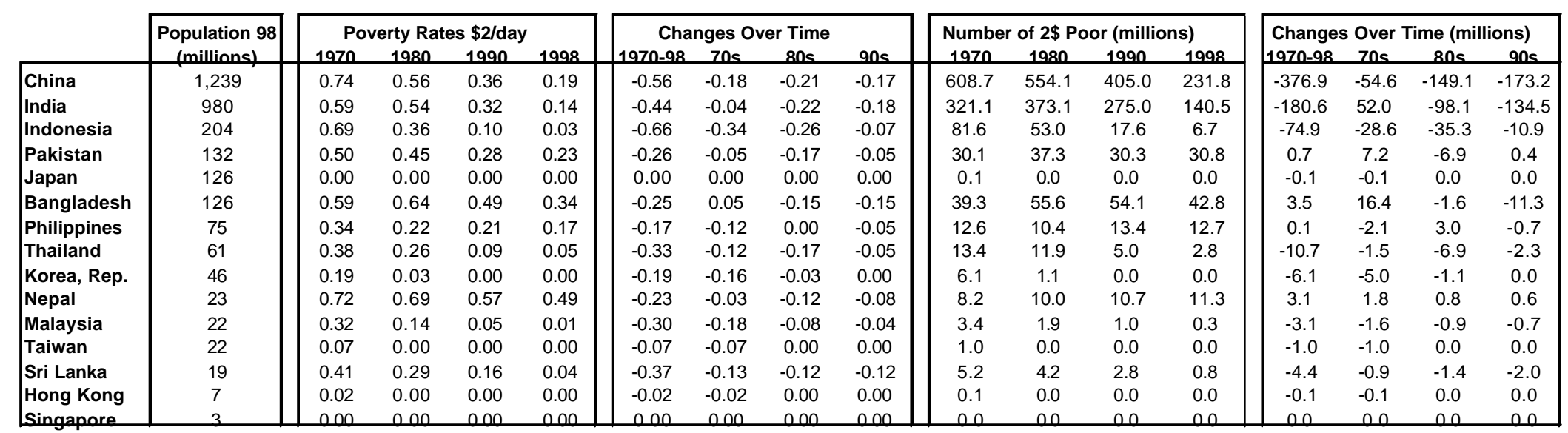

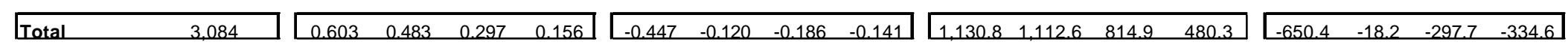


TABLE 6A. POVERTY IN LATIN AMERICA: \$1/DAY

\begin{tabular}{|c|c|c|c|c|c|c|c|c|c|c|c|c|c|c|c|c|c|}
\hline & \multirow{2}{*}{$\begin{array}{c}\text { Population } 98 \\
\text { (millions) }\end{array}$} & \multicolumn{4}{|c|}{ Poverty Rates $\$ 1 /$ day } & \multicolumn{4}{|c|}{ Changes Over Time } & \multicolumn{4}{|c|}{ Number of $1 \$$ Poor (millions) } & \multicolumn{4}{|c|}{ Changes Over Time (millions) } \\
\hline & & 1970 & 1980 & 1990 & 1998 & $1970-98$ & $70 \mathrm{~s}$ & $80 \mathrm{~s}$ & $90 \mathrm{~s}$ & 1970 & 1980 & 1990 & 1998 & $1970-98$ & $70 \mathrm{~s}$ & $80 \mathrm{~s}$ & $90 \mathrm{~s}$ \\
\hline Brazil & 166 & 0.137 & 0.019 & 0.022 & 0.010 & -0.13 & -0.12 & 0.00 & -0.01 & 13.14 & 2.27 & 3.24 & 1.73 & -11.42 & -10.87 & 0.97 & -1.51 \\
\hline Mexico & 96 & 0.058 & 0.002 & 0.001 & 0.000 & -0.06 & -0.06 & 0.00 & 0.00 & 2.96 & 0.15 & 0.07 & 0.01 & -2.95 & -2.81 & -0.09 & -0.05 \\
\hline Colombia & 41 & 0.038 & 0.018 & 0.030 & 0.035 & 0.00 & -0.02 & 0.01 & 0.01 & 0.85 & 0.51 & 1.03 & 1.43 & 0.59 & -0.33 & 0.52 & 0.40 \\
\hline Peru & 25 & 0.001 & 0.000 & 0.013 & 0.010 & 0.01 & 0.00 & 0.01 & 0.00 & 0.01 & 0.00 & 0.28 & 0.26 & 0.24 & -0.01 & 0.27 & -0.02 \\
\hline Venezuela & 23 & 0.000 & 0.000 & 0.001 & 0.001 & 0.00 & 0.00 & 0.00 & 0.00 & 0.00 & 0.00 & 0.01 & 0.02 & 0.02 & 0.00 & 0.01 & 0.01 \\
\hline Chile & 15 & 0.006 & 0.005 & 0.005 & 0.000 & -0.01 & 0.00 & 0.00 & -0.01 & 0.06 & 0.06 & 0.07 & 0.00 & -0.05 & 0.00 & 0.01 & -0.07 \\
\hline Ecuador & 12 & 0.065 & 0.002 & 0.010 & 0.010 & -0.06 & -0.06 & 0.01 & 0.00 & 0.39 & 0.02 & 0.10 & 0.12 & -0.27 & -0.37 & 0.08 & 0.01 \\
\hline Guatemala & 11 & 0.055 & 0.021 & 0.086 & 0.113 & 0.06 & -0.03 & 0.07 & 0.03 & 0.29 & 0.14 & 0.75 & 1.22 & 0.93 & -0.15 & 0.61 & 0.46 \\
\hline Dominican Republic & 8 & 0.104 & 0.023 & 0.039 & 0.003 & -0.10 & -0.08 & 0.02 & -0.04 & 0.46 & 0.13 & 0.28 & 0.03 & -0.43 & -0.33 & 0.15 & -0.25 \\
\hline Bolivia & 8 & 0.002 & 0.000 & 0.055 & 0.238 & 0.24 & 0.00 & 0.05 & 0.18 & 0.01 & 0.00 & 0.36 & 1.89 & 1.88 & -0.01 & 0.36 & 1.53 \\
\hline Honduras & 6 & 0.002 & 0.005 & 0.133 & 0.301 & 0.30 & 0.00 & 0.13 & 0.17 & 0.00 & 0.02 & 0.65 & 1.85 & 1.85 & 0.01 & 0.63 & 1.20 \\
\hline El Salvador & 6 & 0.005 & 0.011 & 0.040 & 0.025 & 0.02 & 0.01 & 0.03 & -0.01 & 0.02 & 0.05 & 0.20 & 0.15 & 0.14 & 0.03 & 0.15 & -0.05 \\
\hline Paraguay & 5 & 0.228 & 0.154 & 0.136 & 0.128 & -0.10 & -0.07 & -0.02 & -0.01 & 0.54 & 0.48 & 0.58 & 0.67 & 0.13 & -0.06 & 0.10 & 0.09 \\
\hline Nicaragua & 5 & 0.000 & 0.000 & 0.069 & 0.266 & 0.27 & 0.00 & 0.07 & 0.20 & 0.00 & 0.00 & 0.26 & 1.28 & 1.28 & 0.00 & 0.26 & 1.01 \\
\hline Costa Rica & 4 & 0.018 & 0.004 & 0.008 & 0.005 & -0.01 & -0.01 & 0.00 & 0.00 & 0.03 & 0.01 & 0.02 & 0.02 & -0.01 & -0.02 & 0.02 & -0.01 \\
\hline Uruguay & 3 & 0.000 & 0.000 & 0.000 & 0.000 & 0.00 & 0.00 & 0.00 & 0.00 & 0.00 & 0.00 & 0.00 & 0.00 & 0.00 & 0.00 & 0.00 & 0.00 \\
\hline Panama & 3 & 0.115 & 0.038 & 0.035 & 0.006 & -0.11 & -0.08 & 0.00 & -0.03 & 0.17 & 0.07 & 0.09 & 0.02 & -0.16 & -0.10 & 0.01 & -0.07 \\
\hline Jamaica & 3 & 0.099 & 0.047 & 0.003 & 0.002 & -0.10 & -0.05 & -0.04 & 0.00 & 0.18 & 0.10 & 0.01 & 0.00 & -0.18 & -0.08 & -0.09 & 0.00 \\
\hline Trinidad and Tobago & 1 & 0.132 & 0.001 & 0.001 & 0.001 & -0.13 & -0.13 & 0.00 & 0.00 & 0.13 & 0.00 & 0.00 & 0.00 & -0.13 & -0.13 & 0.00 & 0.00 \\
\hline Guyana & 1 & 0.018 & 0.009 & 0.055 & 0.009 & -0.01 & -0.01 & 0.05 & -0.05 & 0.01 & 0.01 & 0.04 & 0.01 & -0.01 & -0.01 & 0.04 & -0.04 \\
\hline Barbados & 0 & 0.013 & 0.004 & 0.004 & 0.003 & -0.01 & -0.01 & 0.00 & 0.00 & 0.00 & 0.00 & 0.00 & 0.00 & 0.00 & 0.00 & 0.00 & 0.00 \\
\hline
\end{tabular}

Countries in Group C

\begin{tabular}{|l|c|}
\hline Countries in Group C & \\
\hline Argentina & 36 \\
Haiti & 8 \\
Belize & 0 \\
Grenada & 0 \\
\hline
\end{tabular}

\begin{tabular}{|llll|}
\hline 0 & 0 & 0 & 0 \\
0 & 0 & 0 & 0 \\
0 & 0 & 0 & 0 \\
0 & 0 & 0 & 0 \\
\hline
\end{tabular}

\begin{tabular}{|llll|}
\hline 0.00 & 0.00 & 0.00 & 0.00 \\
0.00 & 0.00 & 0.00 & 0.00 \\
0.00 & 0.00 & 0.00 & 0.00 \\
0.00 & 0.00 & 0.00 & 0.00 \\
\hline
\end{tabular}

Total 485 
TABLE 6B. POVERTY IN LATIN AMERICA: \$2/DAY

\begin{tabular}{|c|c|c|c|c|c|c|c|c|c|c|c|c|c|c|c|c|c|}
\hline & \multirow{2}{*}{\begin{tabular}{|c|}
$\begin{array}{c}\text { Population } 98 \\
\text { (millions) }\end{array}$ \\
\end{tabular}} & \multicolumn{4}{|c|}{ Poverty Rates \$2/day } & \multicolumn{4}{|c|}{ Changes Over Time } & \multicolumn{4}{|c|}{ Number of $2 \$$ Poor (millions) } & \multicolumn{4}{|c|}{ Changes Over Time (millions) } \\
\hline & & 1970 & 1980 & 1990 & 1998 & 1970-98 & $70 \mathrm{~s}$ & $80 \mathrm{~s}$ & $90 \mathrm{~s}$ & 1970 & 1980 & 1990 & 1998 & 1970-98 & $70 \mathrm{~s}$ & $80 \mathrm{~s}$ & $90 \mathrm{~s}$ \\
\hline Brazil & 166 & 0.310 & 0.154 & 0.165 & 0.129 & -0.18 & -0.16 & 0.01 & -0.04 & 29.77 & 18.74 & 24.34 & 21.41 & -8.36 & -11.04 & 5.61 & -2.93 \\
\hline Mexico & 96 & 0.202 & 0.071 & 0.045 & 0.018 & -0.18 & -0.13 & -0.03 & -0.03 & 10.24 & 4.77 & 3.73 & 1.76 & -8.48 & -5.47 & -1.04 & -1.97 \\
\hline Colombia & 41 & 0.251 & 0.163 & 0.172 & 0.170 & -0.08 & -0.09 & 0.01 & 0.00 & 5.65 & 4.64 & 6.01 & 6.95 & 1.30 & -1.01 & 1.37 & 0.94 \\
\hline Peru & 25 & 0.066 & 0.029 & 0.153 & 0.125 & 0.06 & -0.04 & 0.12 & -0.03 & 0.88 & 0.50 & 3.31 & 3.10 & 2.22 & -0.38 & 2.81 & -0.21 \\
\hline Venezuela & 23 & 0.014 & 0.013 & 0.042 & 0.048 & 0.03 & 0.00 & 0.03 & 0.01 & 0.15 & 0.20 & 0.83 & 1.11 & 0.96 & 0.06 & 0.63 & 0.28 \\
\hline Chile & 15 & 0.104 & 0.099 & 0.101 & 0.022 & -0.08 & 0.00 & 0.00 & -0.08 & 0.99 & 1.10 & 1.33 & 0.33 & -0.66 & 0.12 & 0.23 & -1.00 \\
\hline Ecuador & 12 & 0.286 & 0.076 & 0.139 & 0.136 & -0.15 & -0.21 & 0.06 & 0.00 & 1.71 & 0.61 & 1.43 & 1.65 & -0.06 & -1.10 & 0.82 & 0.23 \\
\hline Guatemala & 11 & 0.316 & 0.221 & 0.285 & 0.251 & -0.06 & -0.09 & 0.06 & -0.03 & 1.66 & 1.51 & 2.49 & 2.72 & 1.06 & -0.15 & 0.99 & 0.22 \\
\hline Dominican Republic & 8 & 0.316 & 0.181 & 0.226 & 0.084 & -0.23 & -0.14 & 0.04 & -0.14 & 1.40 & 1.03 & 1.61 & 0.69 & -0.71 & -0.37 & 0.57 & -0.92 \\
\hline Bolivia & 8 & 0.072 & 0.022 & 0.265 & 0.401 & 0.33 & -0.05 & 0.24 & 0.14 & 0.30 & 0.12 & 1.74 & 3.19 & 2.88 & -0.18 & 1.62 & 1.44 \\
\hline Honduras & 6 & 0.103 & 0.131 & 0.367 & 0.472 & 0.37 & 0.03 & 0.24 & 0.10 & 0.27 & 0.47 & 1.79 & 2.90 & 2.64 & 0.20 & 1.32 & 1.11 \\
\hline El Salvador & 6 & 0.125 & 0.152 & 0.216 & 0.168 & 0.04 & 0.03 & 0.06 & -0.05 & 0.45 & 0.70 & 1.10 & 1.02 & 0.57 & 0.25 & 0.40 & -0.08 \\
\hline Paraguay & 5 & 0.390 & 0.244 & 0.228 & 0.223 & -0.17 & -0.15 & -0.02 & -0.01 & 0.92 & 0.76 & 0.96 & 1.16 & 0.25 & -0.16 & 0.21 & 0.20 \\
\hline Nicaragua & 5 & 0.001 & 0.016 & 0.288 & 0.473 & 0.47 & 0.01 & 0.27 & 0.19 & 0.00 & 0.05 & 1.10 & 2.27 & 2.26 & 0.04 & 1.05 & 1.17 \\
\hline Costa Rica & 4 & 0.149 & 0.083 & 0.112 & 0.092 & -0.06 & -0.07 & 0.03 & -0.02 & 0.26 & 0.19 & 0.34 & 0.32 & 0.07 & -0.07 & 0.15 & -0.01 \\
\hline Uruguay & 3 & 0.020 & 0.004 & 0.009 & 0.001 & -0.02 & -0.02 & 0.01 & -0.01 & 0.06 & 0.01 & 0.03 & 0.00 & -0.05 & -0.04 & 0.02 & -0.03 \\
\hline Panama & 3 & 0.265 & 0.182 & 0.179 & 0.100 & -0.17 & -0.08 & 0.00 & -0.08 & 0.40 & 0.36 & 0.43 & 0.28 & -0.12 & -0.04 & 0.07 & -0.15 \\
\hline Jamaica & 3 & 0.230 & 0.214 & 0.081 & 0.061 & -0.17 & -0.02 & -0.13 & -0.02 & 0.43 & 0.46 & 0.19 & 0.16 & -0.27 & 0.02 & -0.26 & -0.04 \\
\hline Trinidad and Tobago & 1 & 0.216 & 0.017 & 0.004 & 0.001 & -0.21 & -0.20 & -0.01 & 0.00 & 0.21 & 0.02 & 0.00 & 0.00 & -0.21 & -0.19 & -0.01 & 0.00 \\
\hline Guyana & 1 & 0.172 & 0.125 & 0.272 & 0.128 & -0.04 & -0.05 & 0.15 & -0.14 & 0.12 & 0.09 & 0.22 & 0.11 & -0.01 & -0.03 & 0.12 & -0.11 \\
\hline Barbados & 0 & 0.121 & 0.043 & 0.026 & 0.017 & -0.10 & -0.08 & -0.02 & -0.01 & 0.03 & 0.01 & 0.01 & 0.00 & -0.02 & -0.02 & 0.00 & 0.00 \\
\hline Argentina & 36 & 0 & 0 & 0 & 0 & & & & & 0.00 & 0.00 & 0.00 & 0.00 & & & & \\
\hline Haiti & 8 & 1 & 0 & 1 & 0 & & & & & 4.52 & 0.00 & 6.47 & 0.00 & & & & \\
\hline Belize & 0 & 0 & 0 & 0 & 0 & & & & & 0.00 & 0.00 & 0.00 & 0.00 & & & & \\
\hline Grenada & 0 & 0 & 0 & 0 & 0 & & & & & مممـ & مممــ & مممــ & 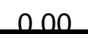 & & & & \\
\hline Total & 485 & 0.222 & 0.105 & 0.140 & 0.105 & -0.117 & -0.117 & 0.036 & -0.035 & 60.40 & 36.32 & 59.46 & 51.13 & -9.27 & -24.0 & 23.1 & -8.3 \\
\hline
\end{tabular}


TABLE 7A. POVERTY IN AFRICA: \$1/DAY

\begin{tabular}{|c|c|c|c|c|c|c|c|c|c|c|c|c|c|c|c|c|c|}
\hline & \multirow{2}{*}{\begin{tabular}{|c|}
$\begin{array}{c}\text { Population } 98 \\
(\text { millions })\end{array}$ \\
\end{tabular}} & \multicolumn{4}{|c|}{ Poverty Rates $\$ 1 /$ day } & \multicolumn{4}{|c|}{ Changes Over Time } & \multicolumn{4}{|c|}{ Number of 1\$ Poor (millions) } & \multicolumn{4}{|c|}{\begin{tabular}{|l} 
Changes Over Time (millions) \\
\end{tabular}} \\
\hline & & 1970 & 1980 & 1990 & 1998 & 1970-98 & $70 \mathrm{~s}$ & $80 \mathrm{~s}$ & $90 \mathrm{~s}$ & 1970 & 1980 & 1990 & 1998 & $1970-98$ & $70 \mathrm{~s}$ & $80 \mathrm{~s}$ & $90 \mathrm{~s}$ \\
\hline Nigeria & \begin{tabular}{|l|}
120.8 \\
\end{tabular} & 0.085 & 0.166 & 0.309 & 0.459 & 0.375 & 0.081 & 0.143 & 0.150 & 4.50 & 11.80 & 29.75 & 55.50 & 51.00 & 7.29 & 17.96 & 25.75 \\
\hline Ethiopia & 61.3 & 0.605 & 0.565 & 0.629 & 0.611 & 0.006 & -0.039 & 0.064 & -0.018 & 17.50 & 21.32 & 32.20 & 37.43 & 19.94 & 3.83 & 10.87 & 5.24 \\
\hline South Africa & 41.4 & 0.059 & 0.032 & 0.038 & 0.043 & -0.016 & -0.027 & 0.006 & 0.005 & 1.30 & 0.87 & 1.33 & 1.78 & 0.48 & -0.42 & 0.46 & 0.44 \\
\hline anzania & 32.1 & 0.571 & 0.528 & 0.639 & 0.702 & 0.131 & -0.042 & 0.111 & 0.063 & 7.82 & 9.82 & 16.28 & 22.56 & 14.74 & 2.00 & 6.46 & 6.28 \\
\hline Kenya & 29.3 & 0.500 & 0.338 & 0.352 & 0.350 & -0.150 & -0.161 & 0.014 & -0.003 & 5.74 & 5.63 & 8.30 & 10.25 & 4.51 & -0.11 & 2.67 & 1.95 \\
\hline Uganda & 20.9 & 0.553 & 0.732 & 0.492 & 0.379 & -0.174 & 0.179 & -0.239 & -0.113 & 5.42 & 9.37 & 8.04 & 7.92 & 2.50 & 3.95 & -1.33 & -0.12 \\
\hline Ghana & 18.5 & 0.049 & 0.110 & 0.202 & 0.202 & 0.153 & 0.062 & 0.092 & 0.000 & 0.42 & 1.18 & 3.00 & 3.72 & 3.31 & 0.76 & 1.82 & 0.72 \\
\hline Mozambique & 16.9 & 0.030 & 0.160 & 0.271 & 0.268 & 0.238 & 0.130 & 0.111 & -0.003 & 0.28 & 1.94 & 3.84 & 4.54 & 4.25 & 1.65 & 1.90 & 0.70 \\
\hline Madagascar & 14.6 & 0.084 & 0.190 & 0.396 & 0.506 & 0.422 & 0.106 & 0.206 & 0.109 & 0.57 & 1.69 & 4.61 & 7.38 & 6.80 & 1.11 & 2.92 & 2.77 \\
\hline Cote d'luoire & 14.5 & 0.065 & 0.030 & 0.070 & 0.049 & -0.015 & -0.035 & 0.041 & -0.021 & 0.36 & 0.24 & 0.82 & 0.72 & 0.36 & -0.11 & 0.57 & -0.10 \\
\hline Zimbabwe & 11.7 & 0.175 & 0.149 & 0.113 & 0.105 & -0.070 & -0.026 & -0.035 & -0.008 & 0.92 & 1.04 & 1.10 & 1.23 & 0.31 & 0.12 & 0.06 & 0.13 \\
\hline Burkina Faso & 10.7 & 0.609 & 0.534 & 0.485 & 0.433 & -0.176 & $\begin{array}{l}-0.076 \\
-0.076\end{array}$ & $\begin{array}{l}-0.049 \\
-0.04\end{array}$ & $\begin{array}{l}-0.052 \\
-0.052\end{array}$ & 3.43 & 3.71 & 4.31 & 4.65 & 1.22 & 0.28 & 0.59 & 0.34 \\
\hline Mali & 10.6 & 0.555 & 0.461 & 0.530 & 0.514 & -0.040 & -0.094 & 0.069 & -0.016 & 2.96 & 3.04 & 4.49 & 5.4 & 2.49 & 0.08 & 1.45 & 0.96 \\
\hline Niger & 10.1 & 0.235 & 0.279 & 0.398 & 0.442 & 0.207 & 0.044 & 0.118 & 0.044 & 0.98 & 1.56 & 3.07 & 4.48 & 3.50 & 0.58 & 1.51 & 1.41 \\
\hline Zambia & 9.7 & 0.192 & 0.305 & 0.404 & 0.516 & 0.324 & 0.113 & 0.099 & 0.112 & 0.80 & 1.75 & 3.14 & 4.99 & 4.18 & 0.94 & 1.39 & 1.85 \\
\hline Senegal & 9.0 & 0.209 & 0.223 & 0.230 & 0.234 & 0.025 & 0.014 & 0.007 & 0.004 & 0.87 & 1.23 & 1.69 & 2.12 & 1.25 & 0.37 & 0.45 & 0.43 \\
\hline Rwan & 8.1 & 0.312 & 0.175 & 0.195 & 0.238 & -0.074 & -0.137 & 0.020 & 0.0 & & 0.90 & 1. & 1. & 0.76 & -0.26 & 0.45 & 0.57 \\
\hline Guinea & 7.1 & 0.027 & 0.022 & 0.027 & 0.016 & -0.010 & -0.005 & 0.005 & -0.011 & 0.10 & 0.10 & 0.16 & 0.12 & 0.01 & -0.01 & 0.06 & -0.04 \\
\hline Burundi & 6.5 & 0.356 & 0.359 & 0.321 & 0.511 & 0.155 & 0.004 & -0.038 & 0.189 & 1.25 & 1.48 & 1.75 & 3.34 & 2.09 & 0.23 & 0.27 & 1.59 \\
\hline Sierra Leone & 4.9 & 0.423 & 0.444 & 0.487 & 0.591 & 0.168 & 0.021 & 0.043 & 0.104 & 1.12 & 1.44 & 1.95 & 2.87 & 1.75 & 0.31 & 0.51 & 0.93 \\
\hline Central African Rep. & 3.5 & 0.298 & 0.356 & 0.432 & 0.537 & 0.239 & 0.058 & 0.077 & 0.104 & 0.55 & 0.82 & 1.27 & 1.87 & 1.32 & 0.27 & 0.45 & 0.60 \\
\hline Lesotho & 2.1 & 0.461 & 0.240 & 0.238 & 0.234 & -0.228 & -0.221 & -0.002 & -0.005 & 0.49 & 0.32 & 0.41 & 0.48 & -0.01 & -0.17 & 0.09 & 0.07 \\
\hline Botswana & 1.6 & 0.354 & 0.080 & 0.012 & 0.004 & -0.350 & -0.275 & -0.068 & -0.008 & 0.23 & 0.07 & 0.01 & 0.01 & -0.22 & -0.15 & -0.06 & -0.01 \\
\hline Gambia, The & 1.2 & 0.251 & 0.175 & 0.299 & 0.353 & 0.102 & -0.076 & 0.124 & 0.054 & 0.12 & 0.11 & 0.27 & 0.43 & 0.31 & 0.00 & 0.16 & 0.15 \\
\hline Gabon & 1.2 & 0.007 & 0.002 & 0.002 & 0.004 & -0.003 & -0.005 & 0.000 & 0.002 & 0.00 & 0.00 & 0.00 & 0.00 & 0.00 & 0.00 & 0.00 & 0.00 \\
\hline Guinea & 1.2 & 0.506 & 0.626 & 0.540 & 0.611 & 0.105 & 0.120 & -0.086 & 0.071 & 0.27 & 0.50 & 0.53 & 0.71 & 0.44 & 0.23 & 0.03 & 0.18 \\
\hline Mauritius & 12 & 0.003 & 0.001 & 0.001 & 0,001 & -0.002 & -0.002 & 0.000 & 0.000 & 0.0 & 000 & 0.00 & 0.00 & 0.00 & 0.00 & 0.00 & 0.00 \\
\hline Total & 4706 & & & & & & & & & 59.17 & 81.95 & 13367 & 18647 & 127.31 & 2278 & 5172 & 5280 \\
\hline & & & & & & & & & & & & & & & & & \\
\hline Congo, Dem. Rep. & 48.2 & 0 & 0 & 0 & 1 & & & & & 0.0 & 0.0 & 0.0 & 48.2 & & & & \\
\hline Cameroon & 14.3 & 0 & 0 & 0 & 0 & & & & & 0 & 0 & & & & & & \\
\hline Ango & 12. & 0 & 0 & 0 & 0 & & & & & 0.0 & 0.0 & 0.0 & U & & & & \\
\hline Malawi & 10.5 & 0 & 0 & 0 & 0 & & & & & 0.0 & 0.0 & 0.0 & 0.0 & & & & \\
\hline & 7.3 & 0 & 0 & 0 & 0 & & & & & 0. & 0. & 0. & & & & & \\
\hline Benin & 5.9 & 0 & 0 & 0 & 0 & & & & & 0. & 0.0 & 0.0 & 0.0 & & & & \\
\hline Togo & 4 & 0 & 0 & 0 & 0 & & & & & . & 00 & 00 & 0 & & & & \\
\hline Congo, Rep. & 2.8 & 0 & 0 & 0 & 0 & & & & & 0.0 & 0.0 & 0.0 & 0.0 & & & & \\
\hline Namil & 1.7 & 0 & 0 & 0 & 0 & & & & & 0.0 & 0.0 & 0.0 & 0.0 & & & & \\
\hline Como & 0.5 & 0 & 0 & 0 & 0 & & & & & 0.0 & 0.0 & 0.0 & 0.0 & & & & \\
\hline Equatorial Guinea & 0.4 & 0 & 0 & 0 & 0 & & & & & 0.0 & 0.0 & 0.0 & 0.0 & & & & \\
\hline Cape Verde & 0.4 & 0 & 0 & 0 & 0 & & & & & 0.0 & 0.0 & 0.0 & 0.0 & & & & \\
\hline Sao Tome & 0.1 & 0 & 0 & 0 & 0 & & & & & 0. & 0.0 & 0.0 & 0.0 & & & & \\
\hline Seychel & 01 & $\Omega$ & 0 & 0 & 0 & & & & & 10 & 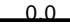 & - & e & & & & \\
\hline
\end{tabular}


TABLE 7B. POVERTY IN AFRICA: \$2/DAY

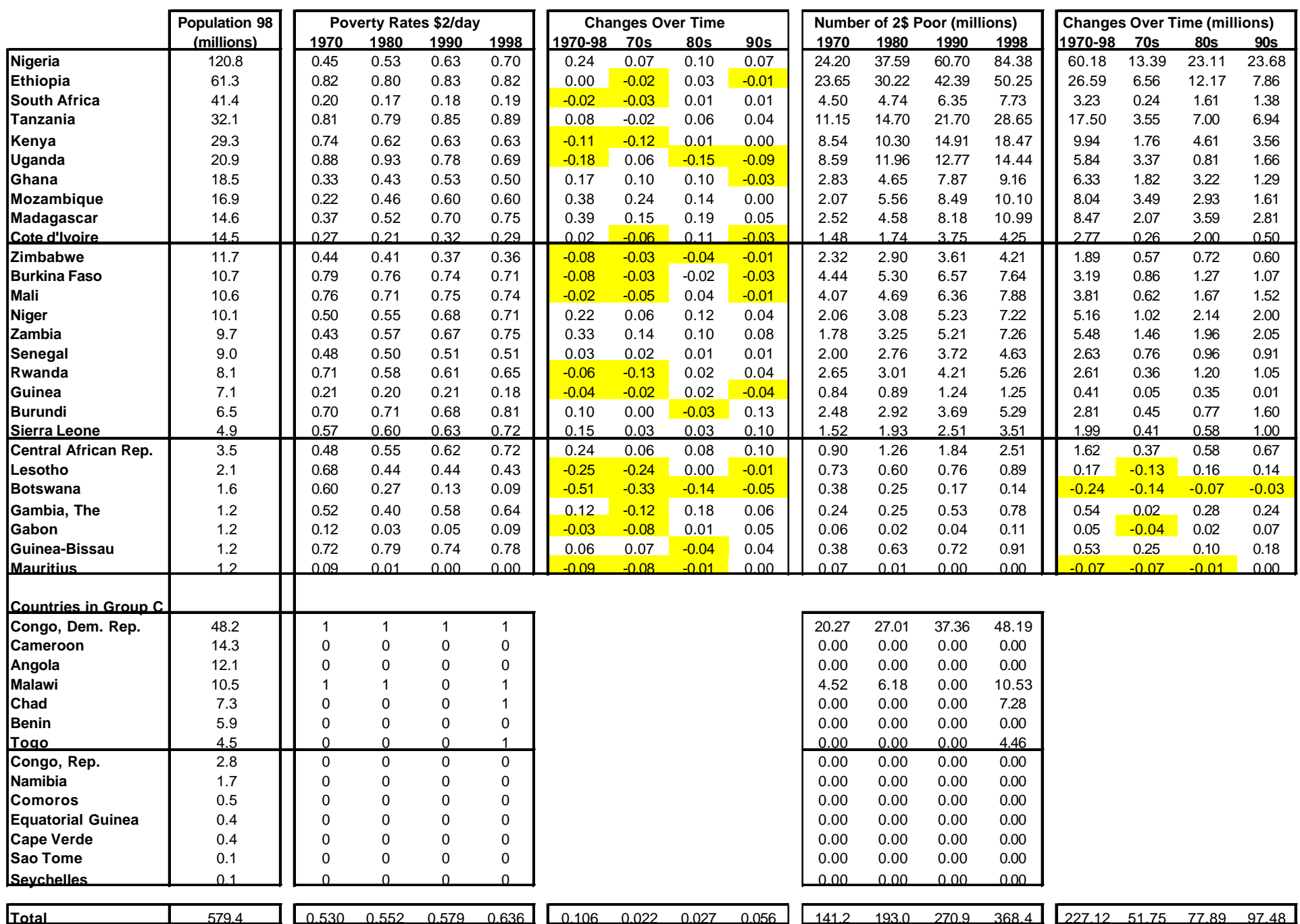


Table 8. Income Inequality Indexes

\begin{tabular}{|c|c|c|c|c|c|c|c|}
\hline year & Gini & Theil & MLD & $A(0.5)$ & $A(1)$ & Sq. CV & Var. Log \\
\hline 1970 & 0.657 & 0.835 & 0.863 & 0.356 & 0.578 & 1.503 & 1.530 \\
\hline 1971 & 0.658 & 0.838 & 0.867 & 0.358 & 0.580 & 1.505 & 1.536 \\
\hline 1972 & 0.663 & 0.853 & 0.889 & 0.364 & 0.589 & 1.526 & 1.577 \\
\hline 1973 & 0.667 & 0.863 & 0.904 & 0.368 & 0.595 & 1.536 & 1.607 \\
\hline 1974 & 0.665 & 0.856 & 0.899 & 0.366 & 0.593 & 1.512 & 1.605 \\
\hline 1975 & 0.661 & 0.843 & 0.881 & 0.361 & 0.586 & 1.484 & 1.575 \\
\hline 1976 & 0.666 & 0.856 & 0.904 & 0.367 & 0.595 & 1.503 & 1.624 \\
\hline 1977 & 0.664 & 0.853 & 0.897 & 0.365 & 0.592 & 1.499 & 1.610 \\
\hline 1978 & 0.667 & 0.861 & 0.905 & 0.368 & 0.596 & 1.520 & 1.626 \\
\hline 1979 & 0.666 & 0.858 & 0.900 & 0.366 & 0.593 & 1.515 & 1.612 \\
\hline 1980 & 0.662 & 0.848 & 0.885 & 0.362 & 0.587 & 1.492 & 1.587 \\
\hline 1981 & 0.660 & 0.844 & 0.875 & 0.360 & 0.583 & 1.496 & 1.564 \\
\hline 1982 & 0.655 & 0.829 & 0.853 & 0.353 & 0.574 & 1.469 & 1.524 \\
\hline 1983 & 0.653 & 0.825 & 0.843 & 0.350 & 0.570 & 1.472 & 1.504 \\
\hline 1984 & 0.652 & 0.826 & 0.839 & 0.350 & 0.568 & 1.491 & 1.491 \\
\hline 1985 & 0.650 & 0.823 & 0.832 & 0.348 & 0.565 & 1.491 & 1.480 \\
\hline 1986 & 0.649 & 0.821 & 0.828 & 0.346 & 0.563 & 1.491 & 1.472 \\
\hline 1987 & 0.650 & 0.824 & 0.829 & 0.347 & 0.564 & 1.499 & 1.472 \\
\hline 1988 & 0.651 & 0.828 & 0.832 & 0.348 & 0.565 & 1.513 & 1.477 \\
\hline 1989 & 0.656 & 0.842 & 0.848 & 0.354 & 0.572 & 1.545 & 1.504 \\
\hline 1990 & 0.654 & 0.837 & 0.845 & 0.352 & 0.570 & 1.533 & 1.505 \\
\hline 1991 & 0.650 & 0.823 & 0.834 & 0.347 & 0.566 & 1.497 & 1.500 \\
\hline 1992 & 0.645 & 0.810 & 0.821 & 0.342 & 0.560 & 1.471 & 1.494 \\
\hline 1993 & 0.639 & 0.790 & 0.803 & 0.335 & 0.552 & 1.428 & 1.480 \\
\hline 1994 & 0.638 & 0.787 & 0.805 & 0.335 & 0.553 & 1.424 & 1.502 \\
\hline 1995 & 0.635 & 0.779 & 0.798 & 0.332 & 0.550 & 1.402 & 1.499 \\
\hline 1996 & 0.633 & 0.772 & 0.793 & 0.329 & 0.547 & 1.388 & 1.503 \\
\hline 1997 & 0.633 & 0.772 & 0.794 & 0.329 & 0.548 & 1.383 & 1.513 \\
\hline 1998 & 0.633 & 0.776 & 0.796 & 0.330 & 0.549 & 1.380 & 1.520 \\
\hline \multicolumn{8}{|c|}{ Change since 1970} \\
\hline & $-3.7 \%$ & $-7.4 \%$ & $-8.1 \%$ & $-7.7 \%$ & $-5.2 \%$ & $-8.6 \%$ & $-0.6 \%$ \\
\hline \multicolumn{8}{|c|}{ Change since 1978} \\
\hline & $-5.1 \%$ & $\%$ & $\%$ & $0.8 \%$ & $-8.2 \%$ & $6 \%$ & $-6.7 \%$ \\
\hline
\end{tabular}


Figures

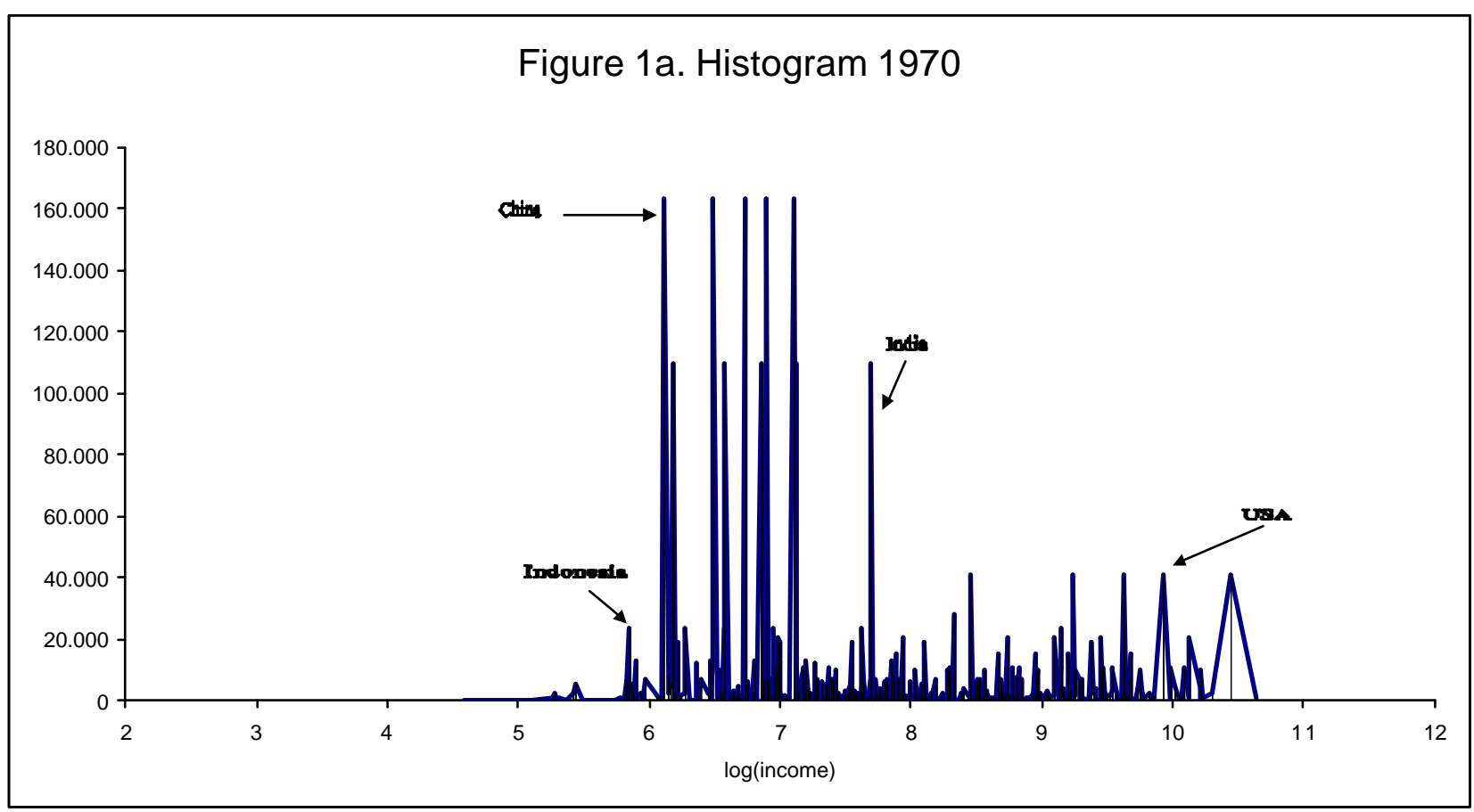

Figure 1b. Histogram 1998

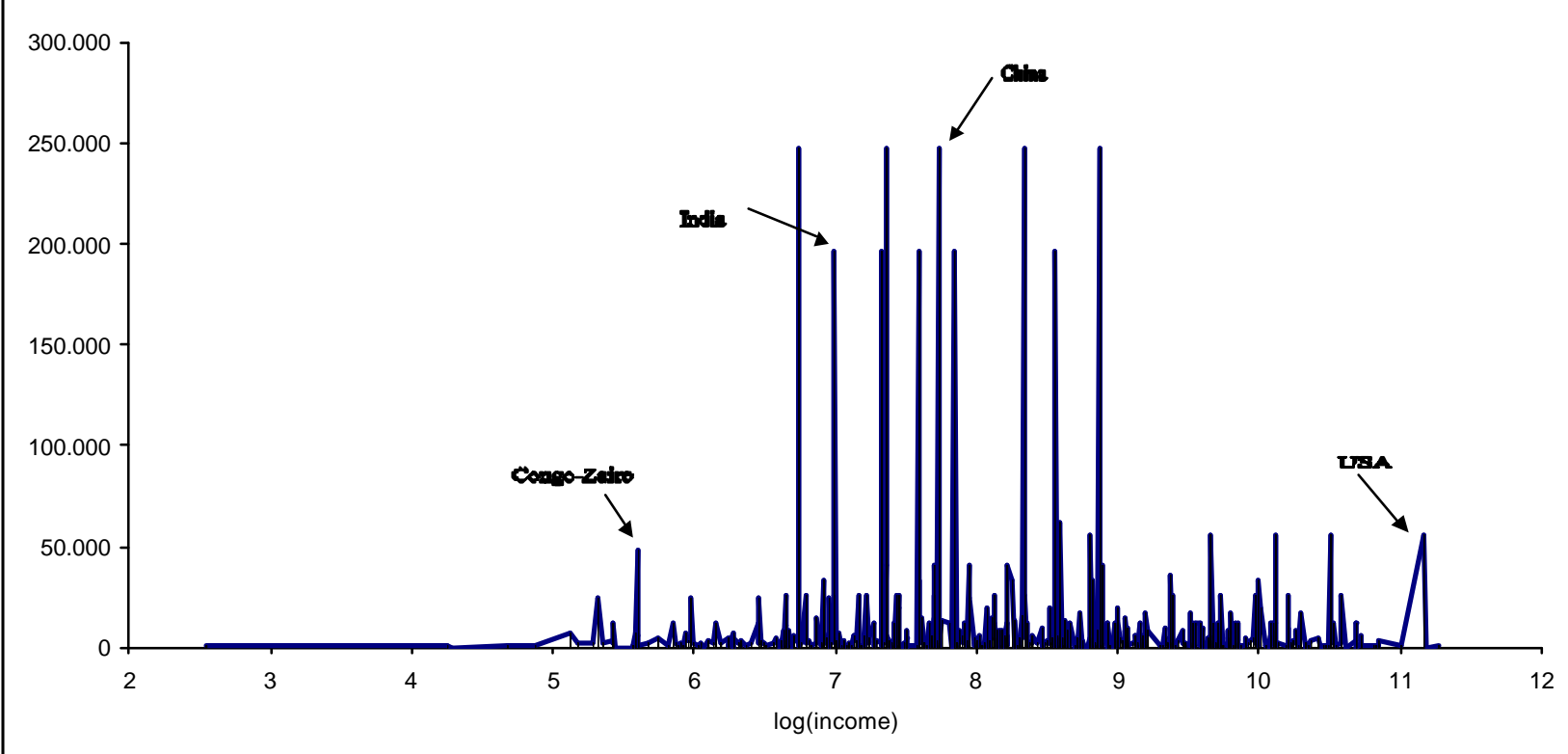




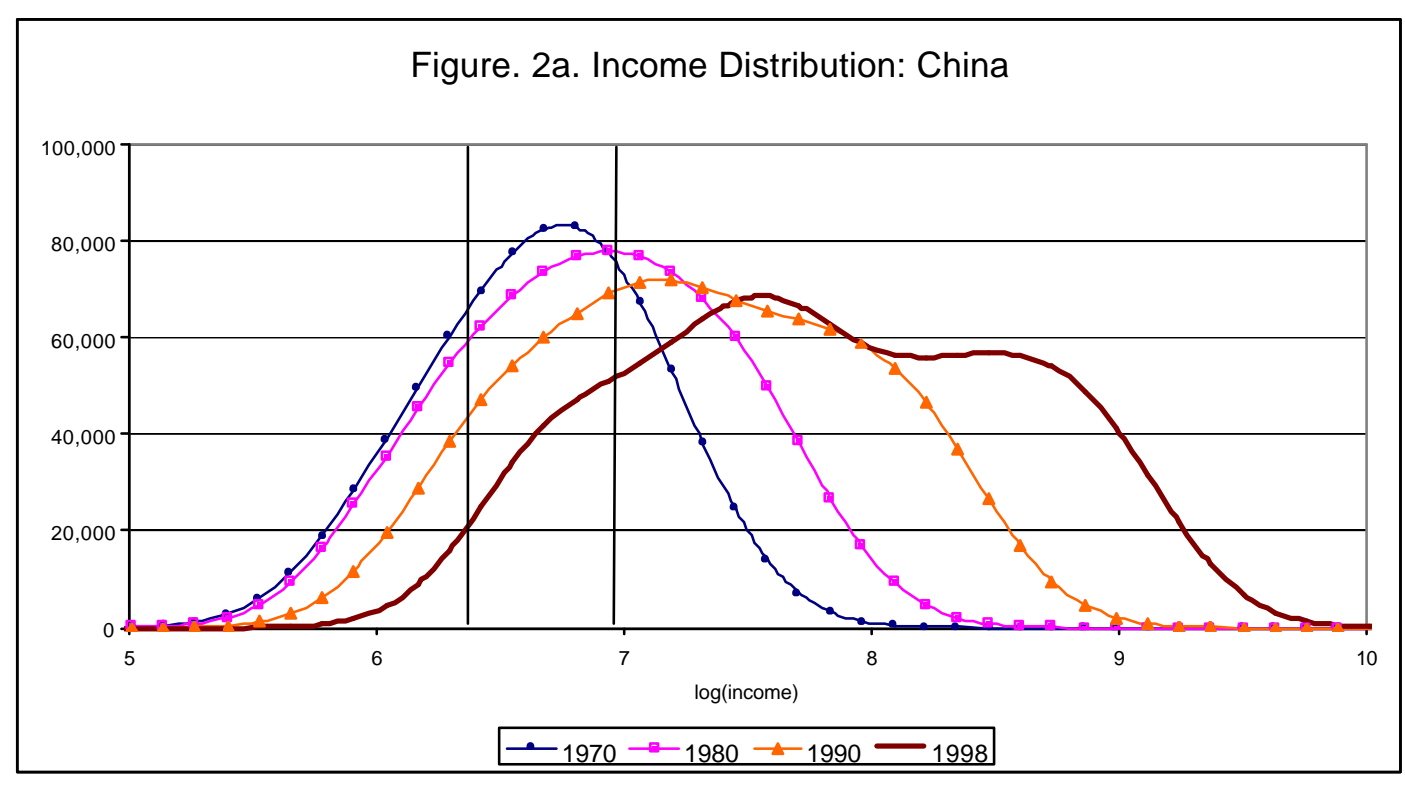

Figure. 2b. Income Distribution: India

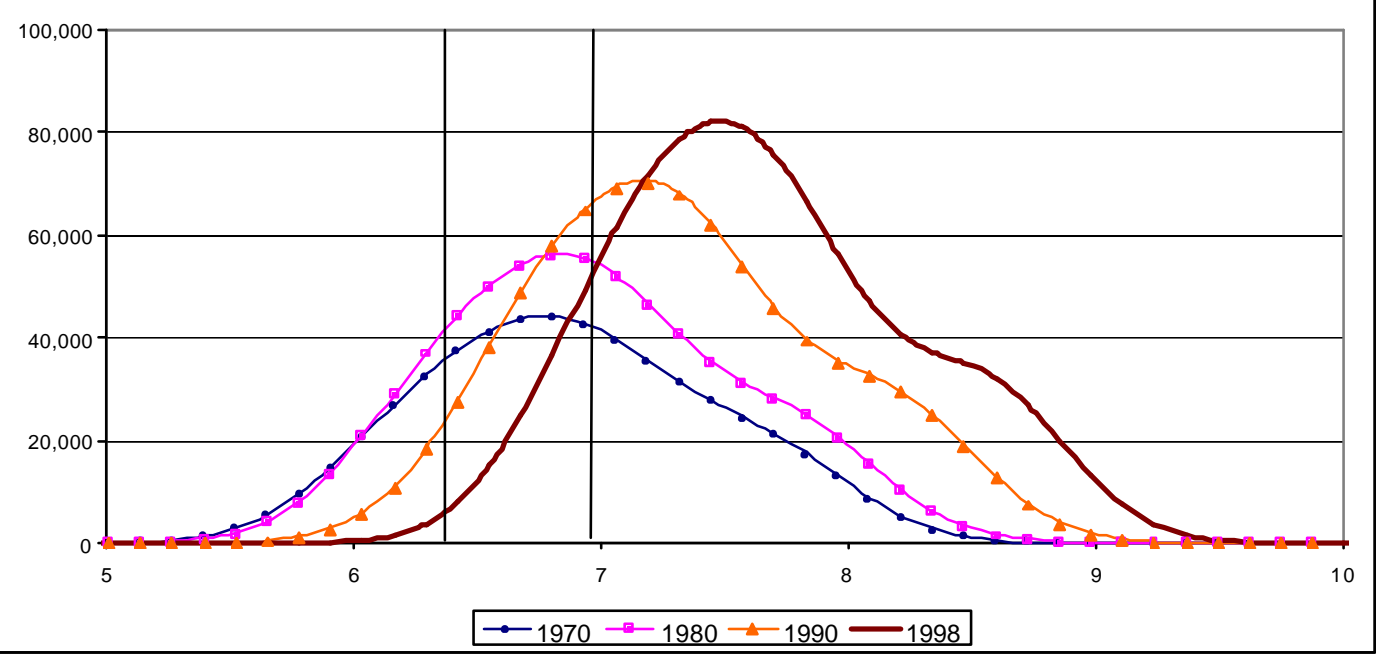

Figure. 2c. Income Distribution: USA

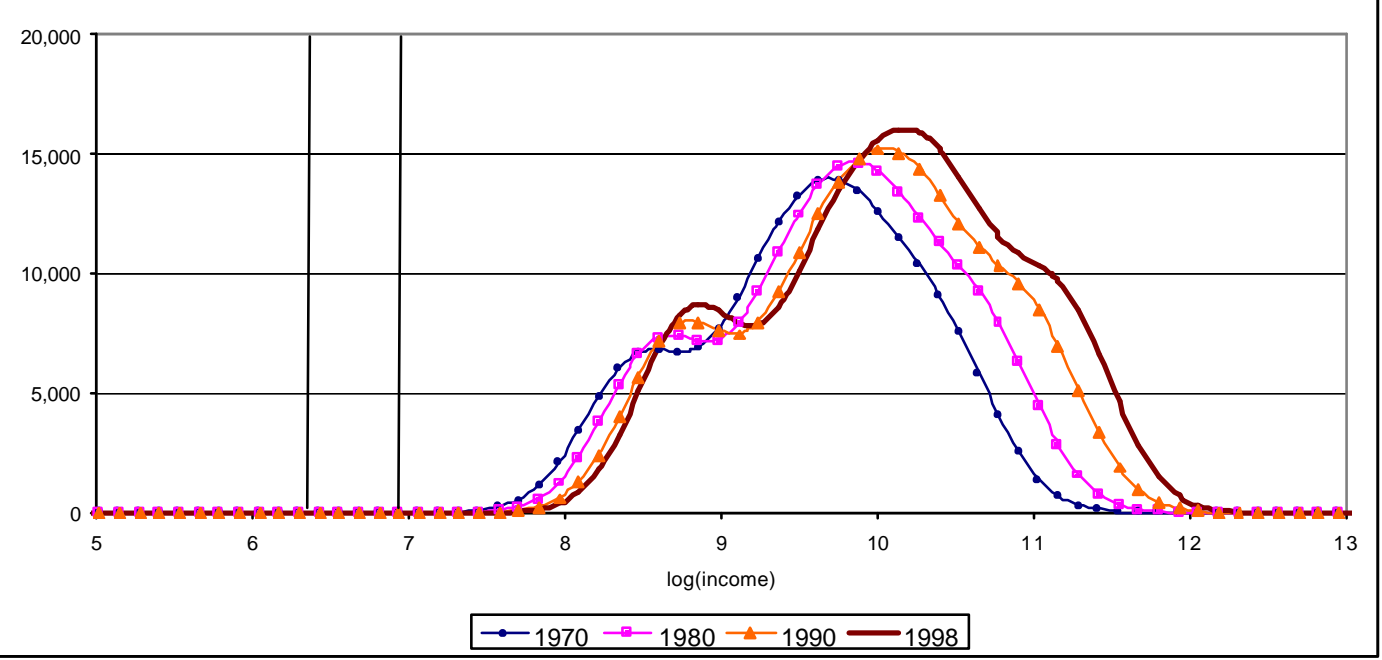




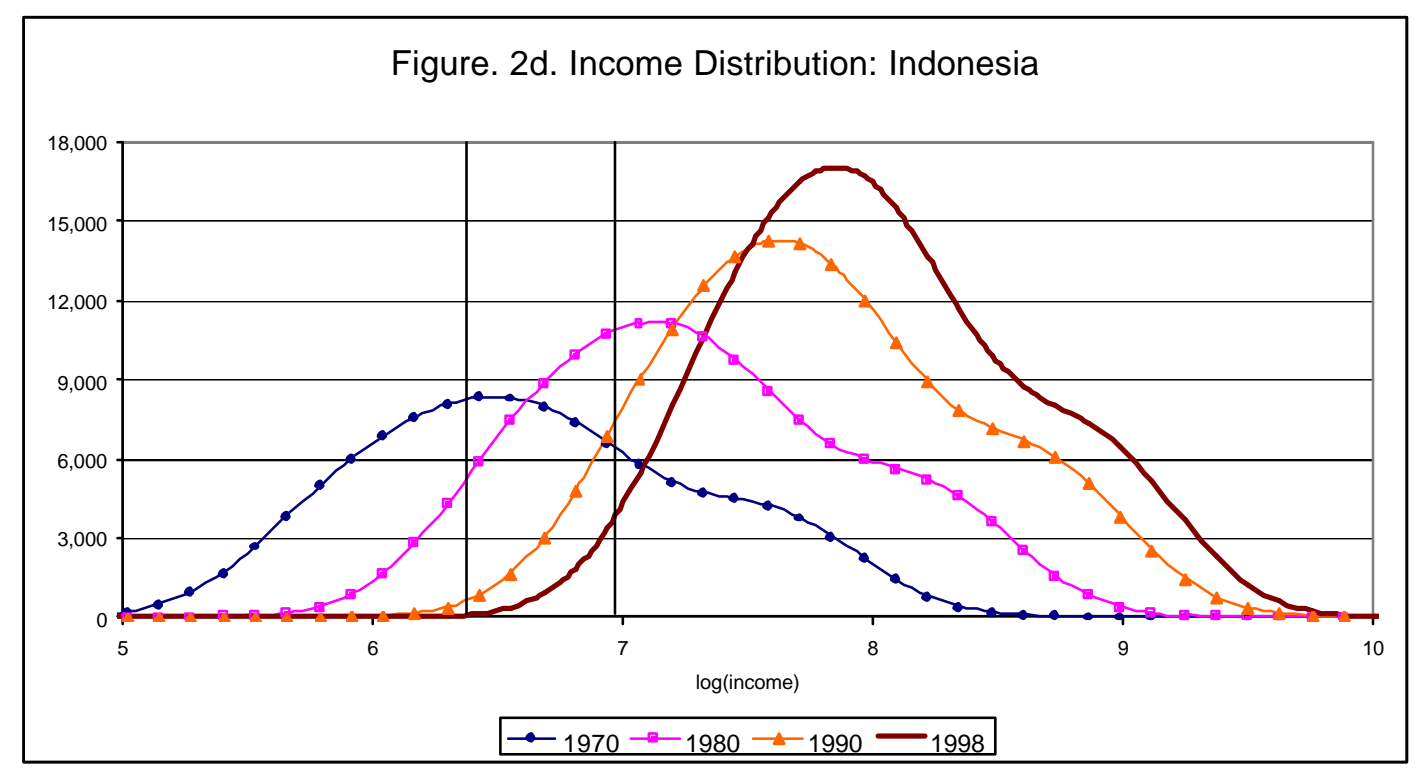

Figure. 2e. Income Distribution: Brazil

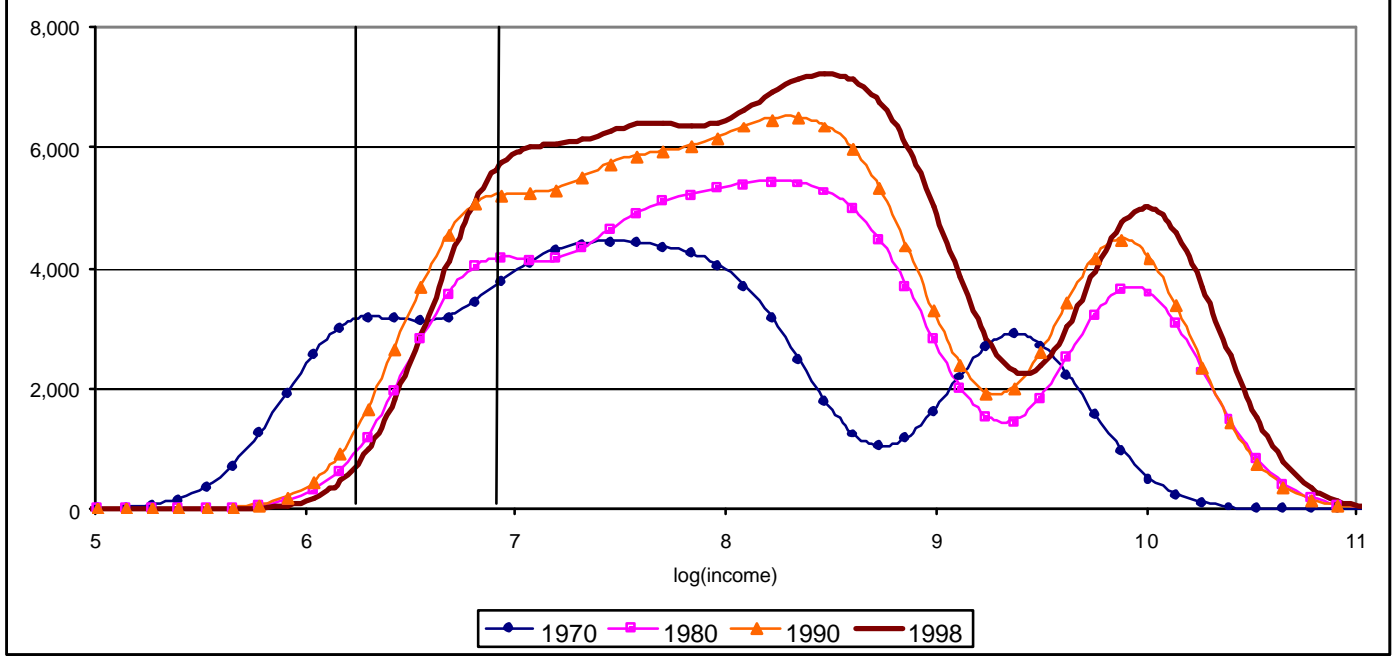

Figure. 2f. Income Distribution: Pakistan

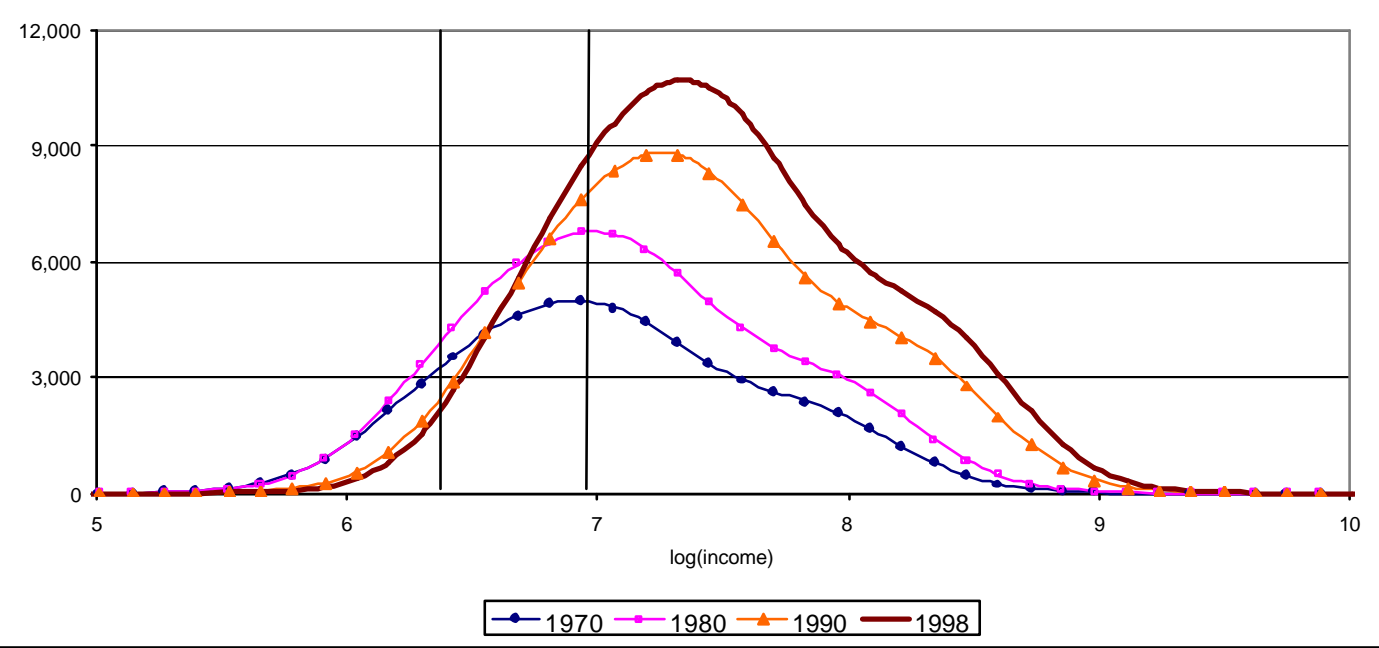




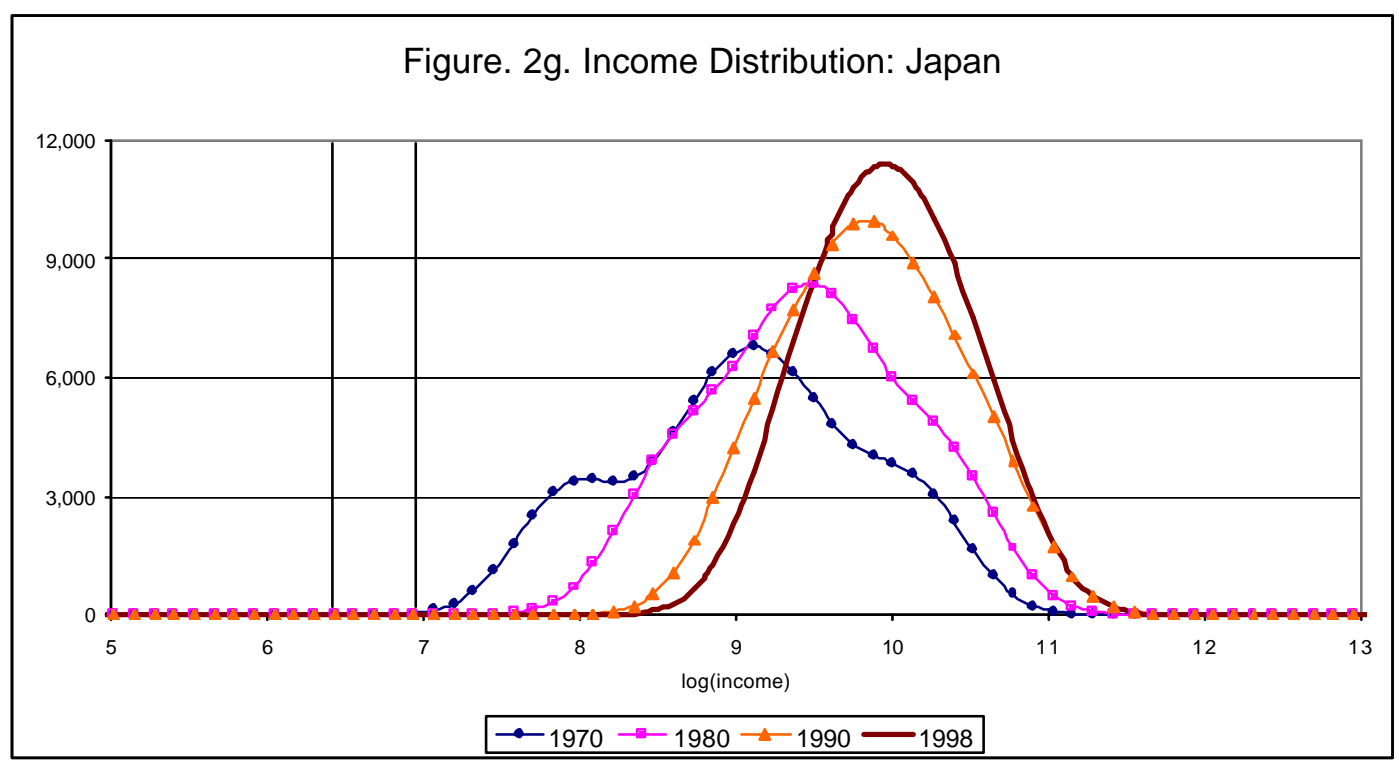

Figure. 2h. Income Distribution: Bangladesh

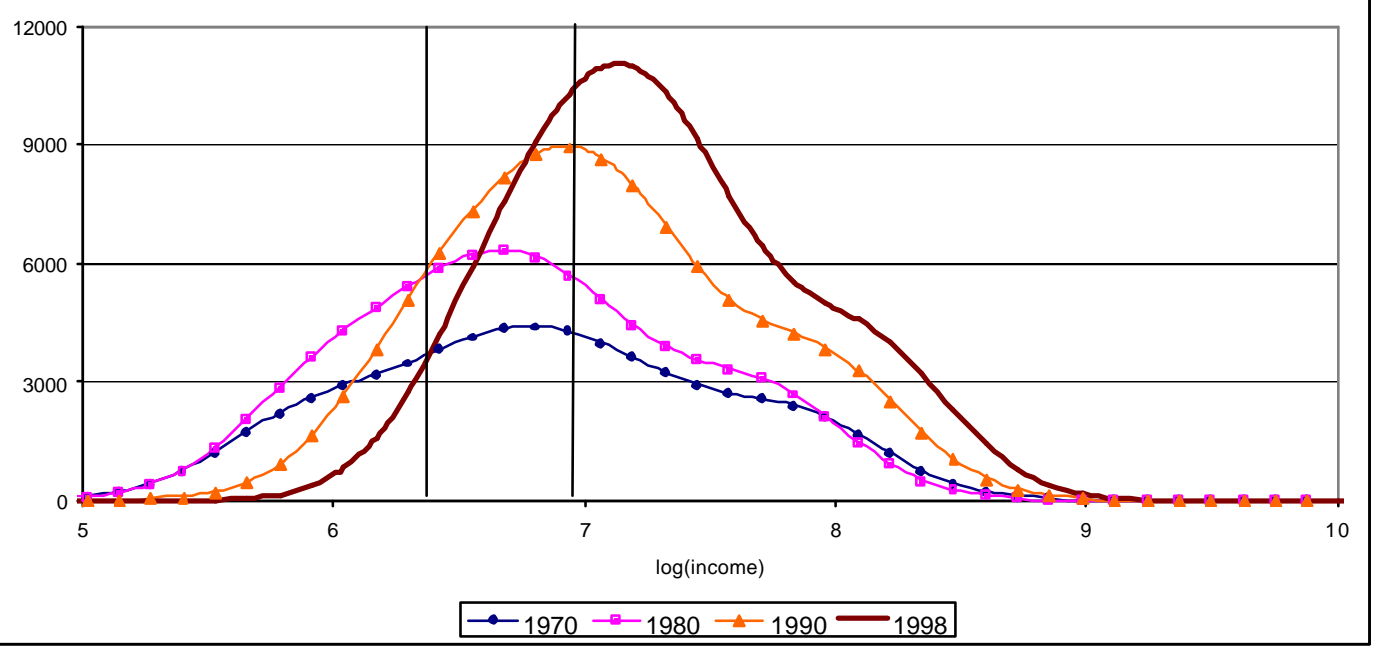

Figure. 2i. Income Distribution: Nigeria

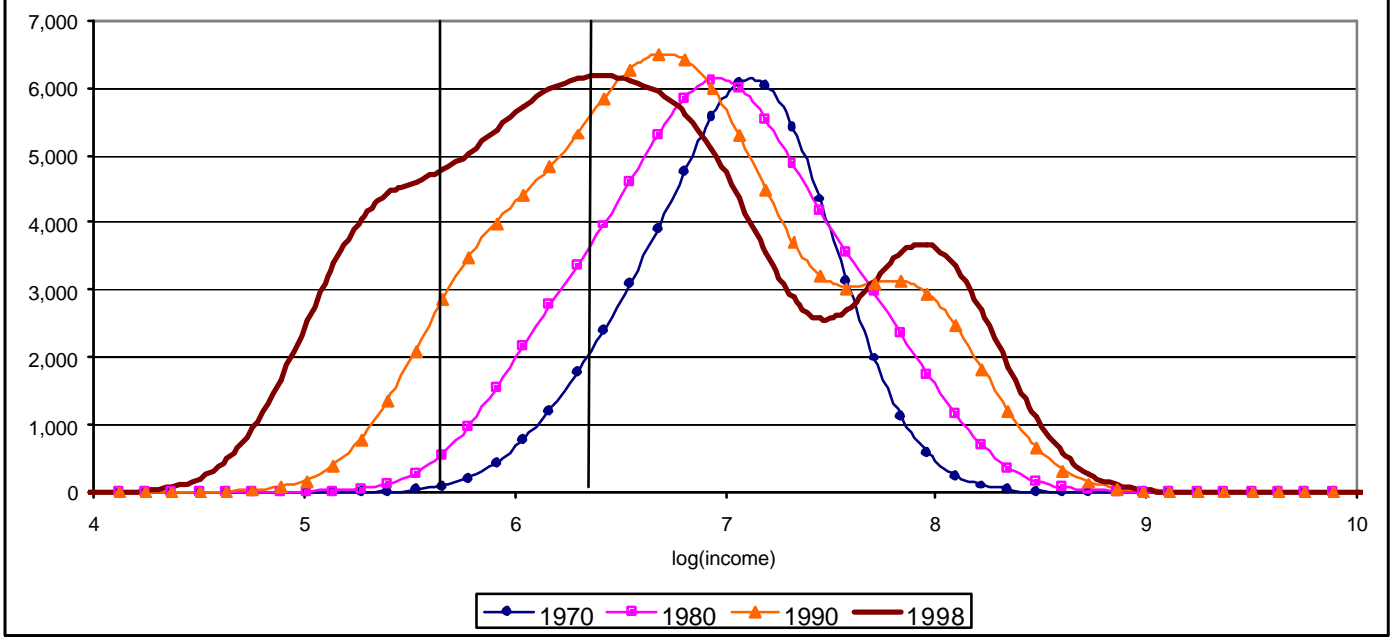




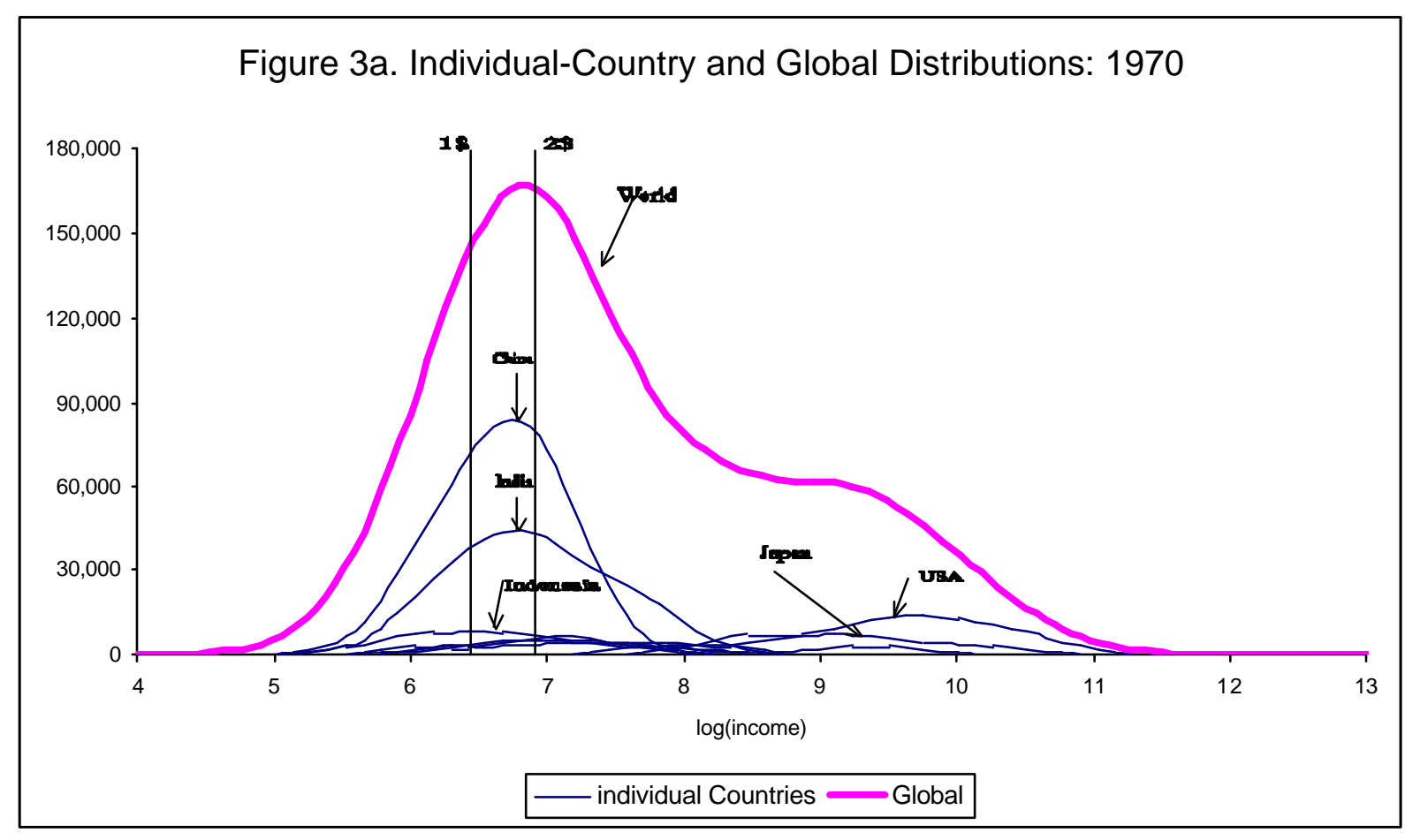

Figure 3b. Individual-Country and Global Distributions: 1980

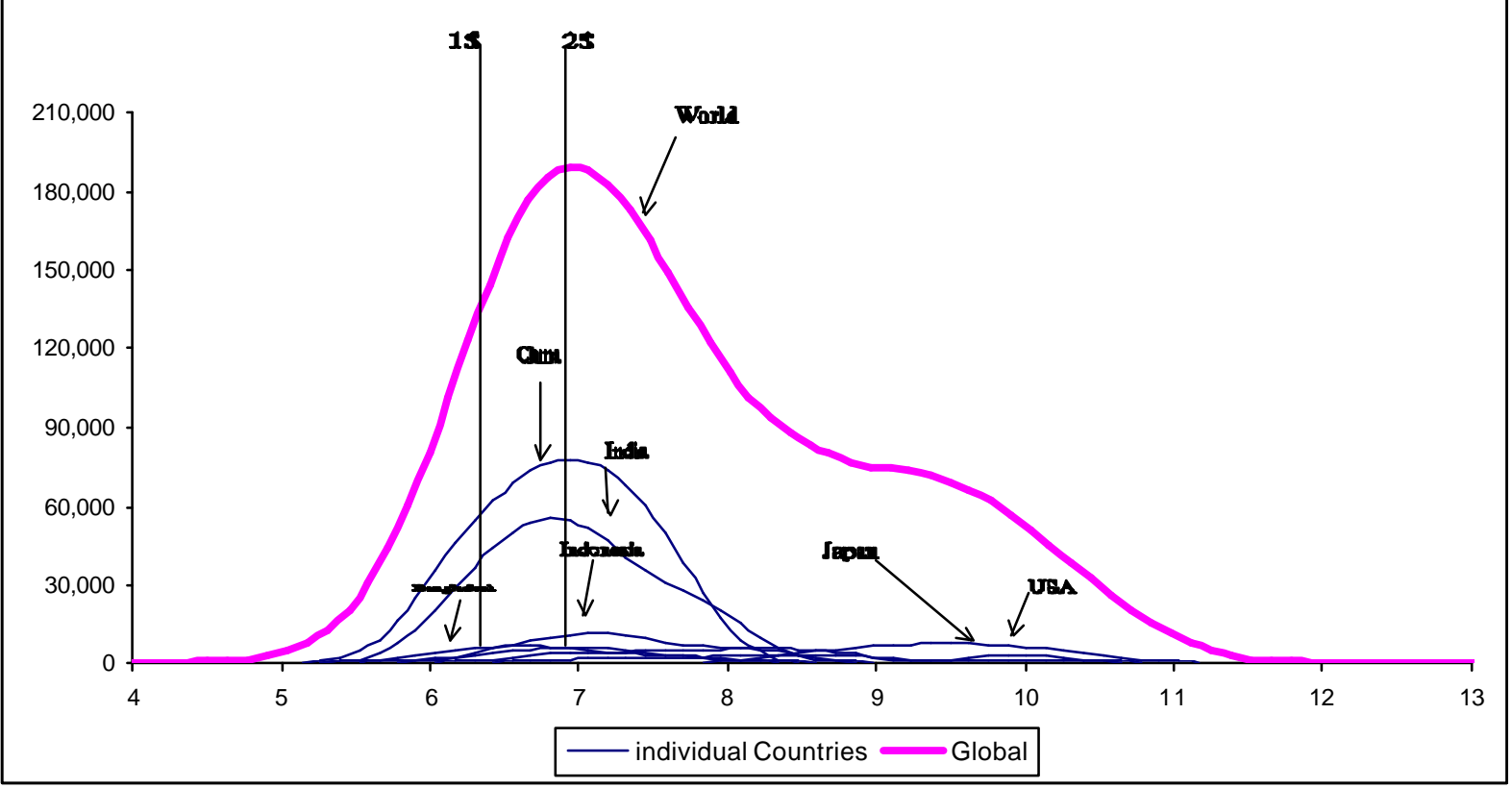




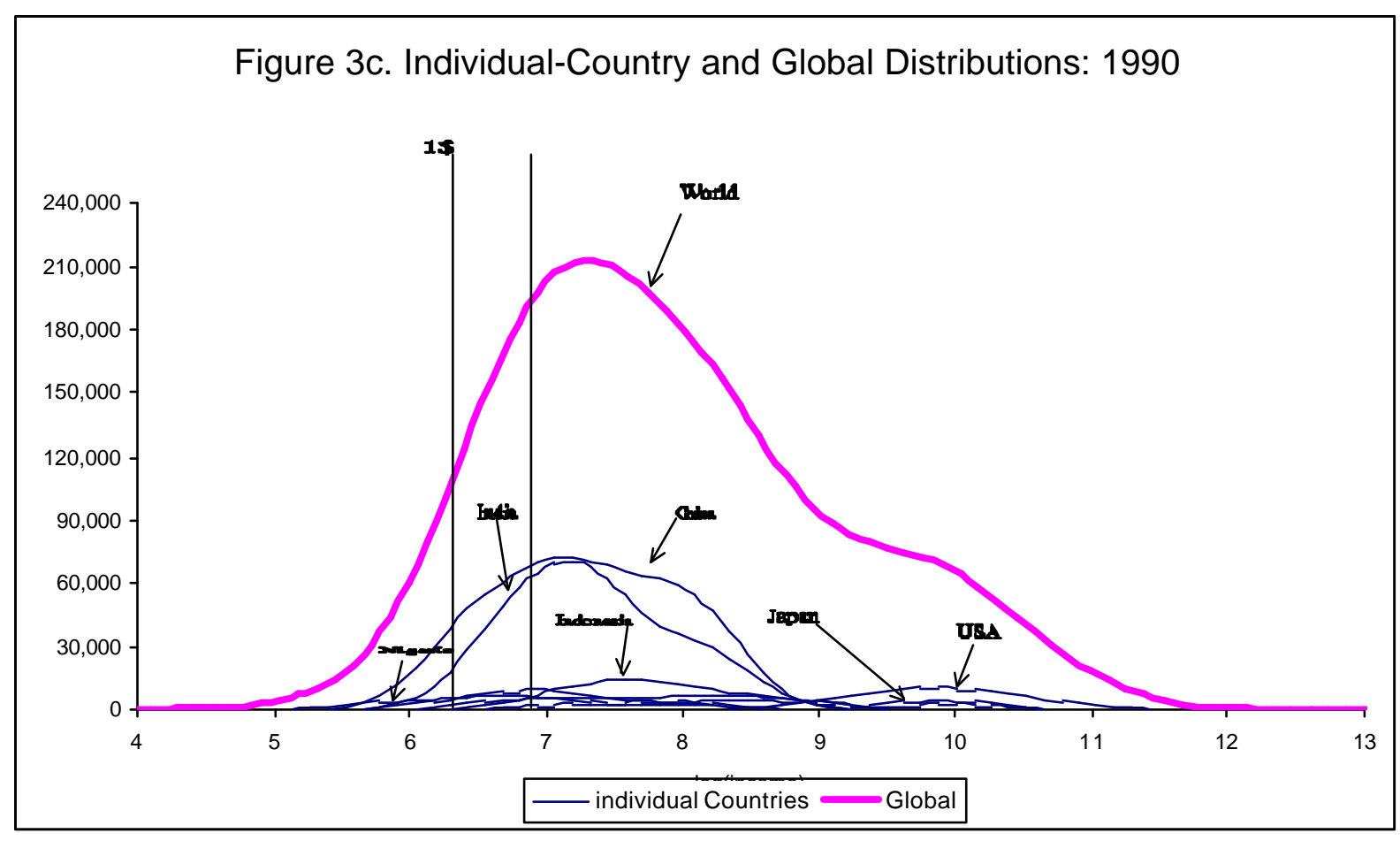

Figure 3d. Individual-Country and Global Distributions: 1998

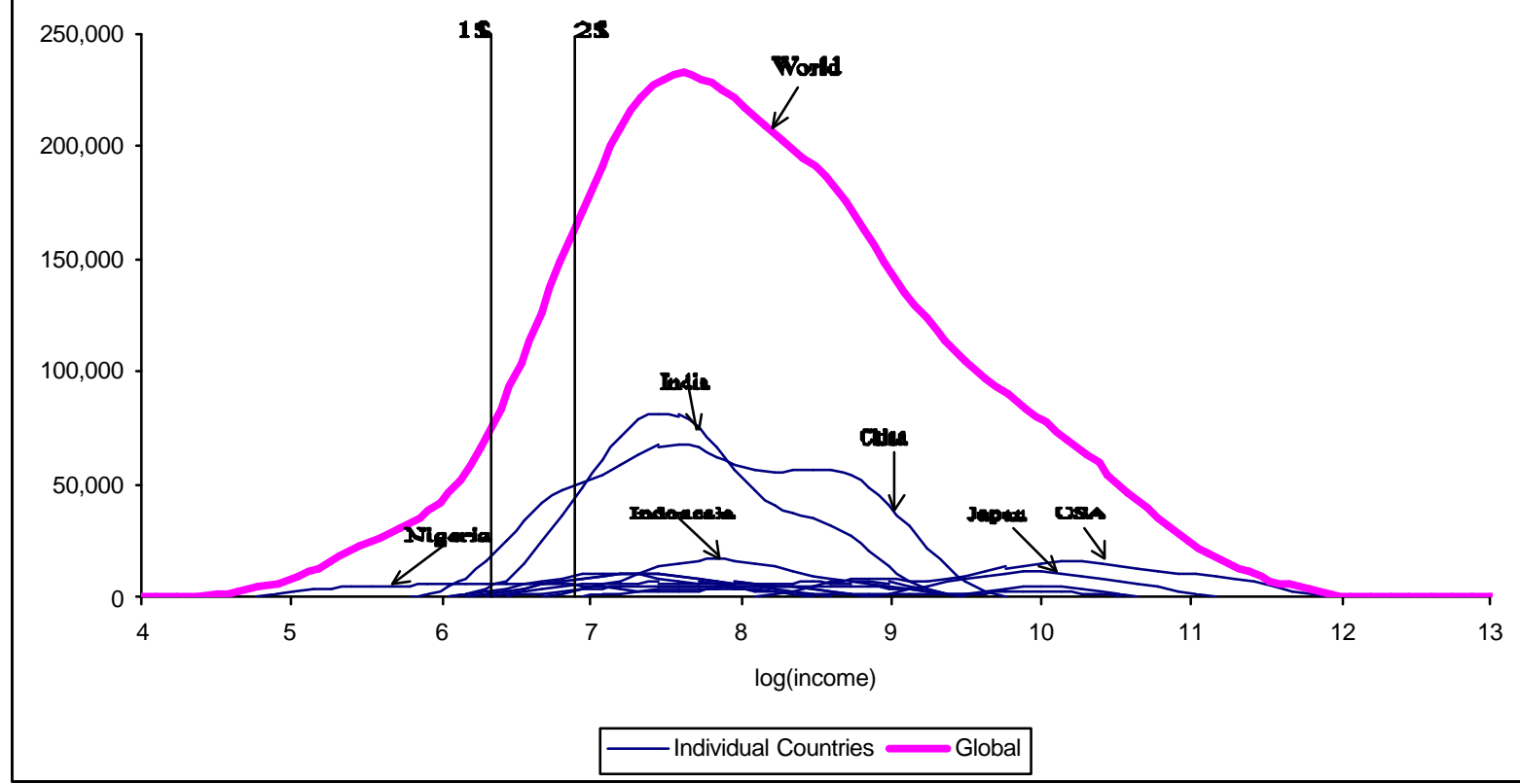



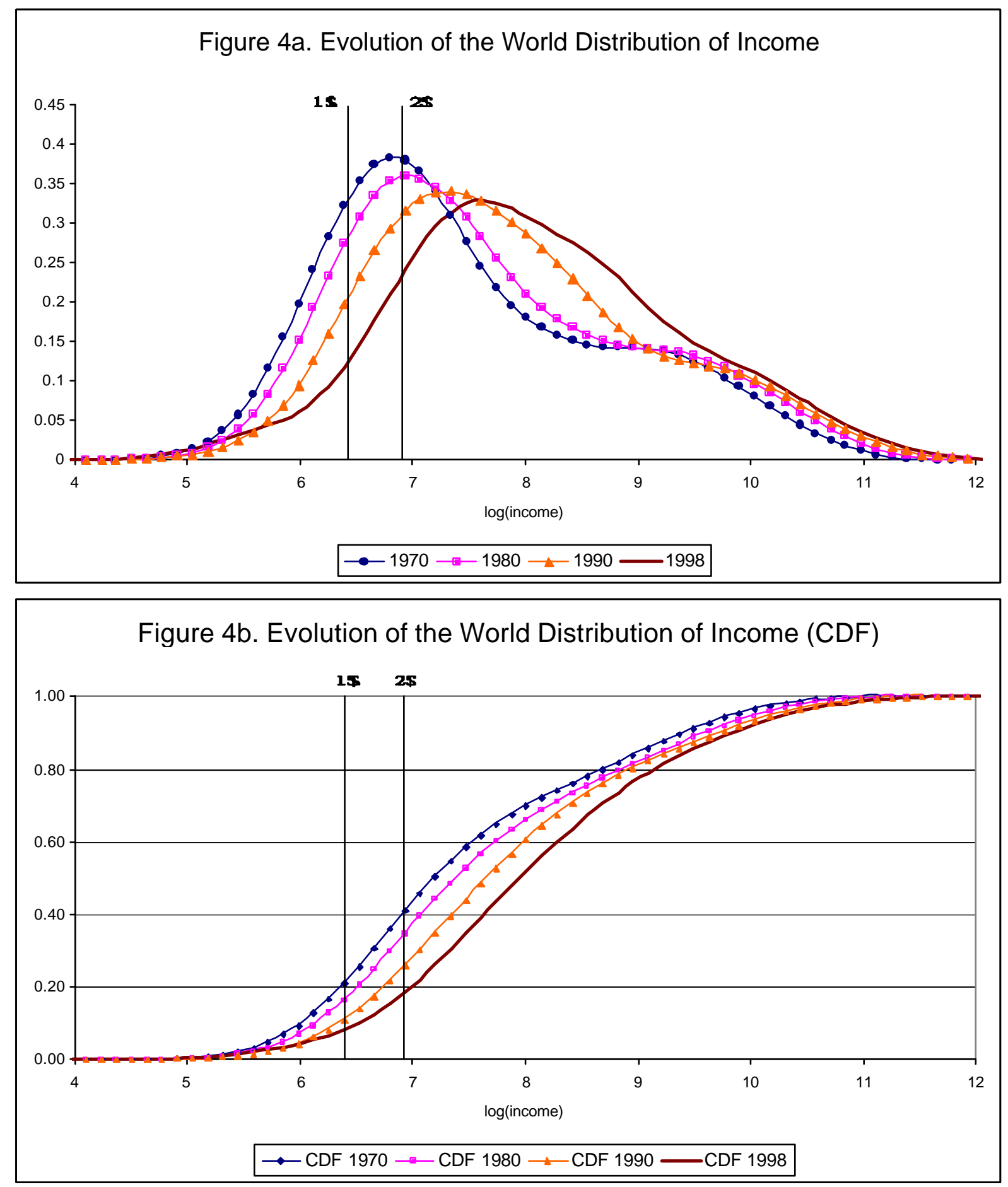


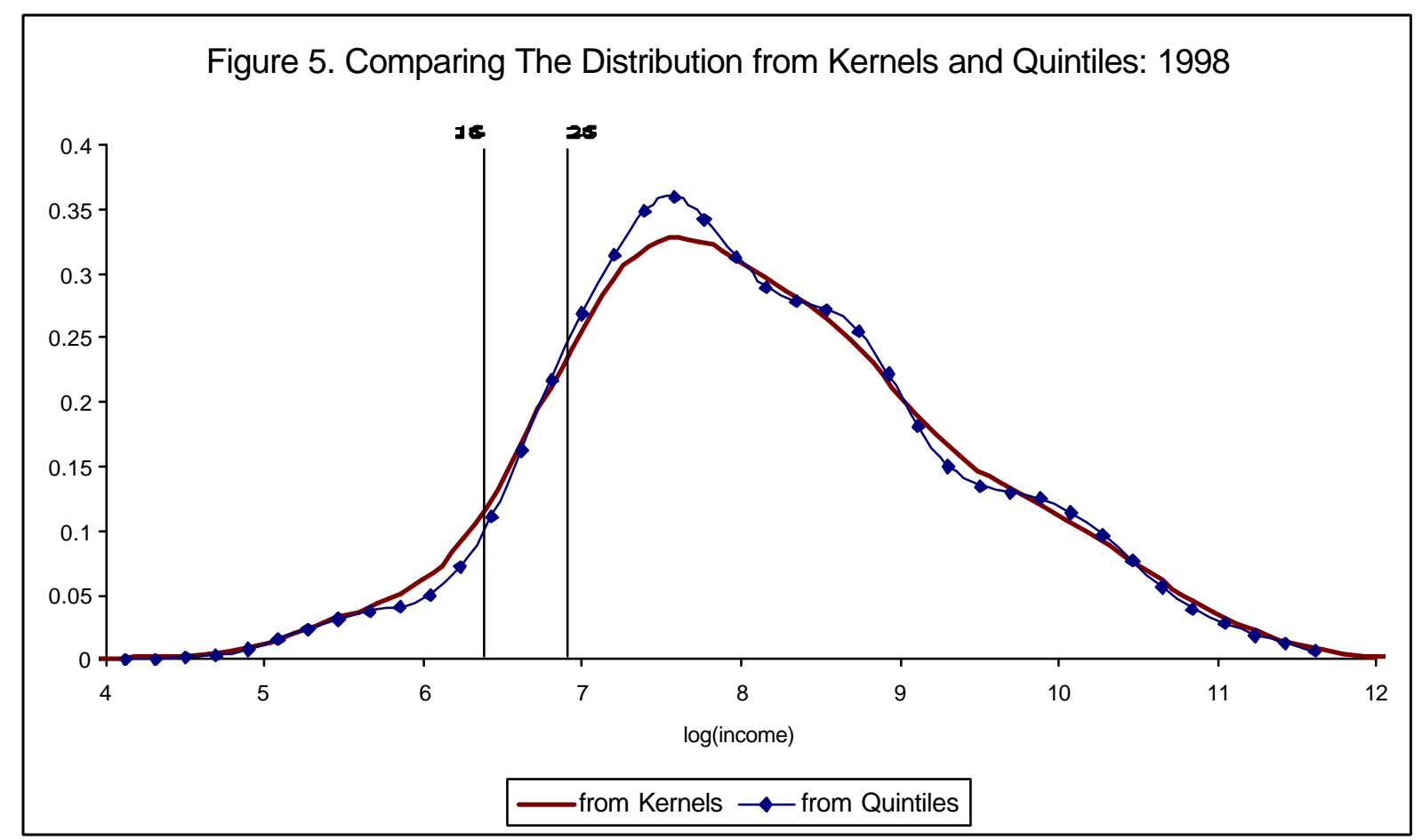



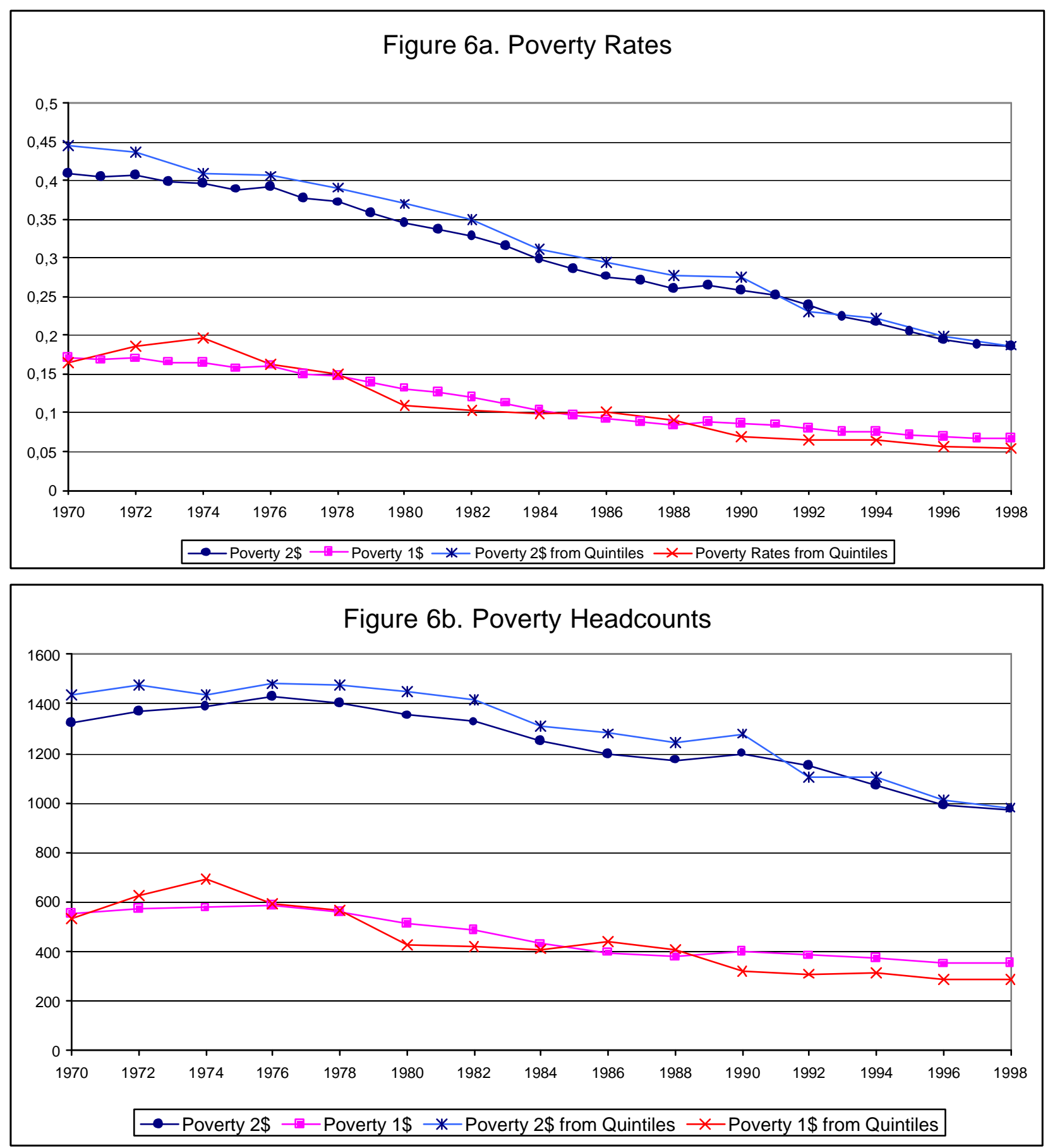

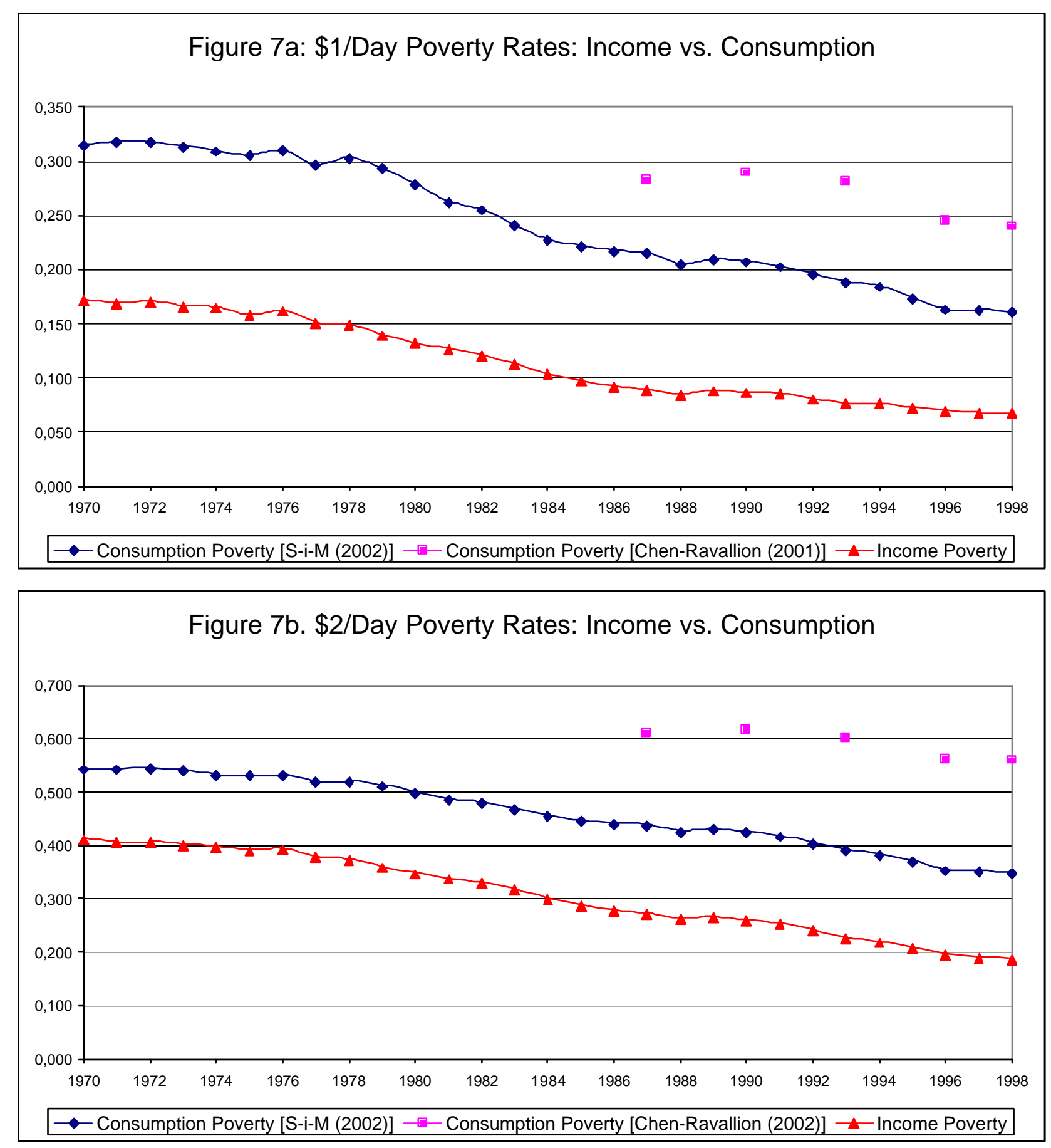

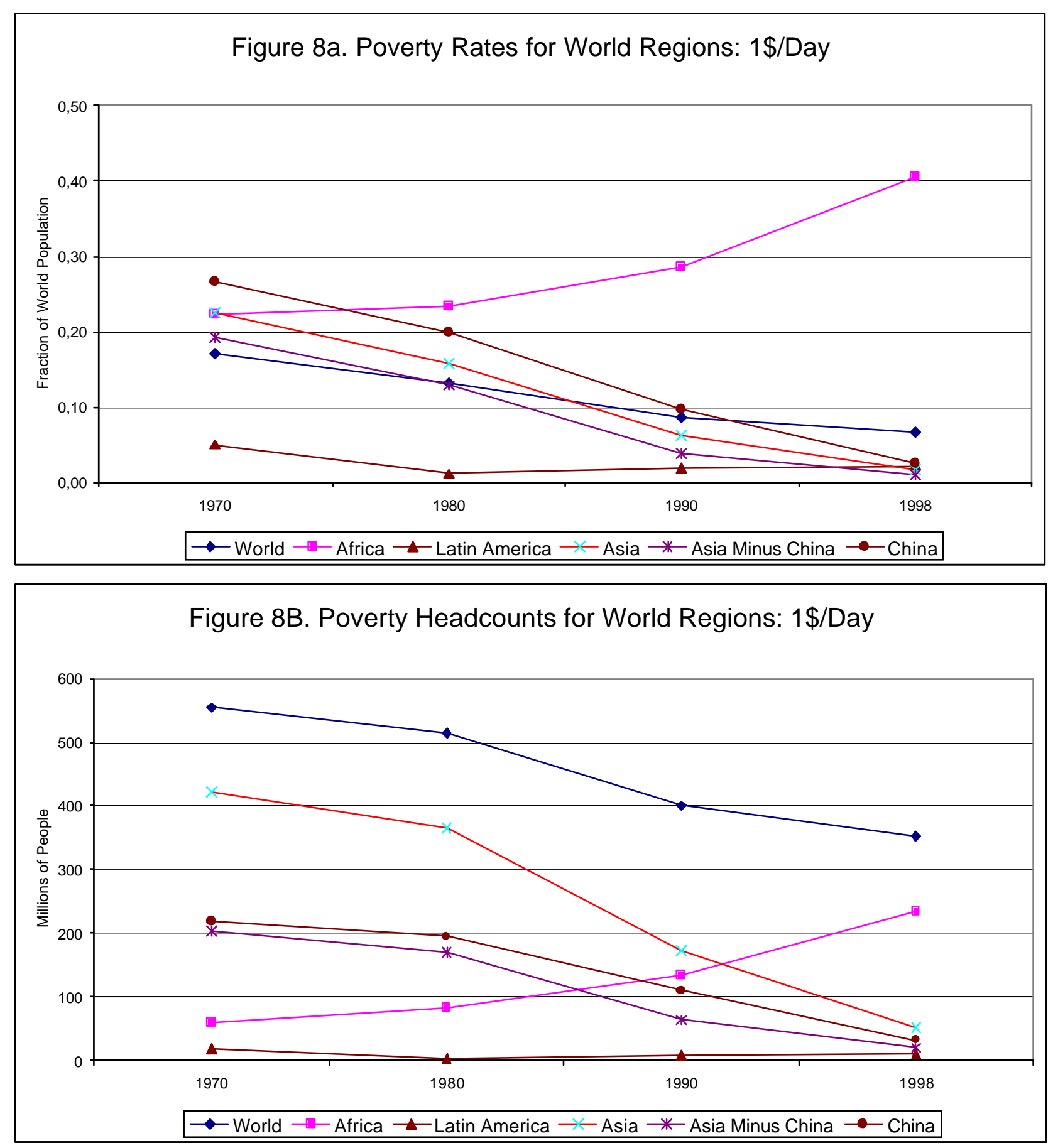

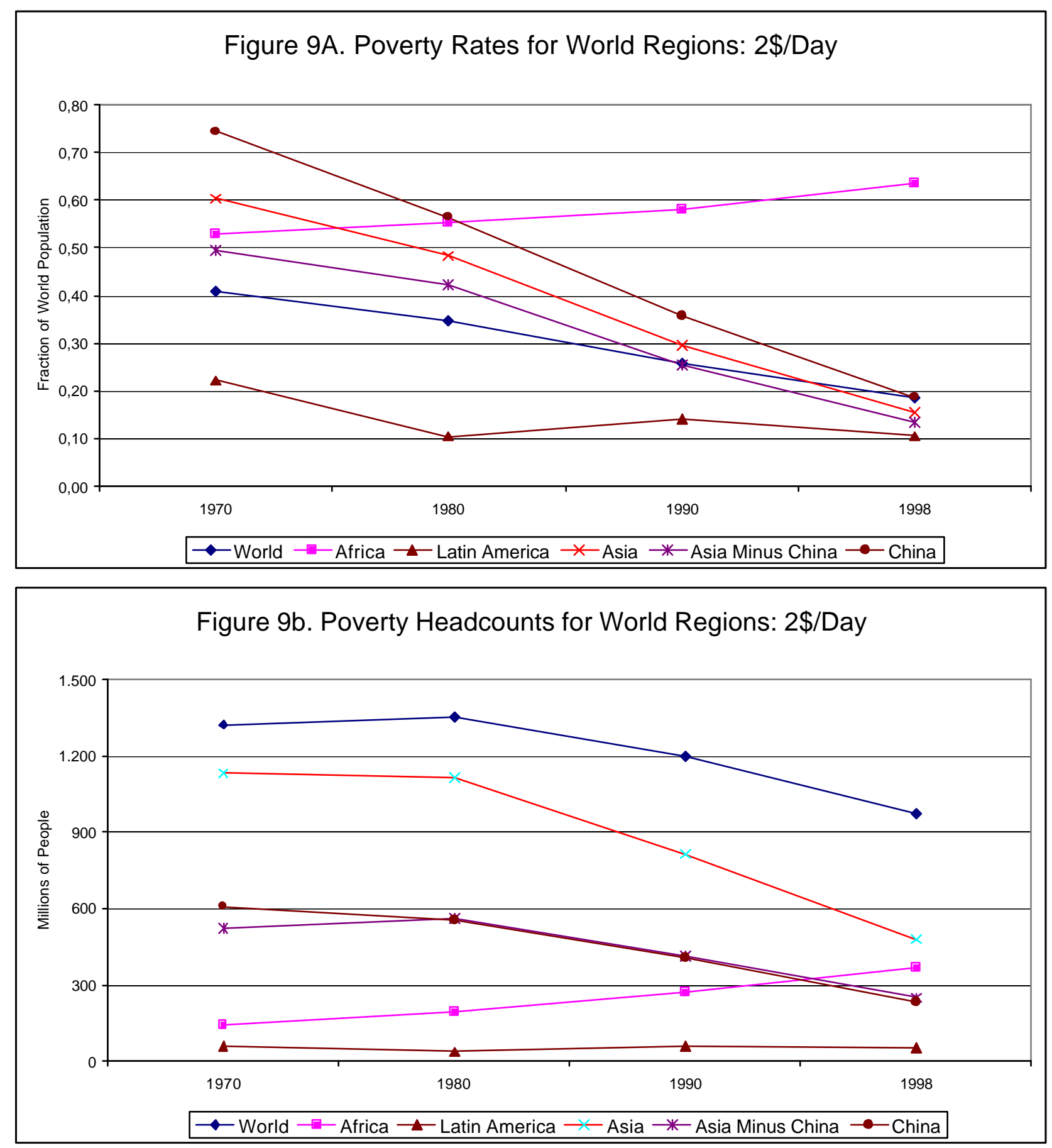


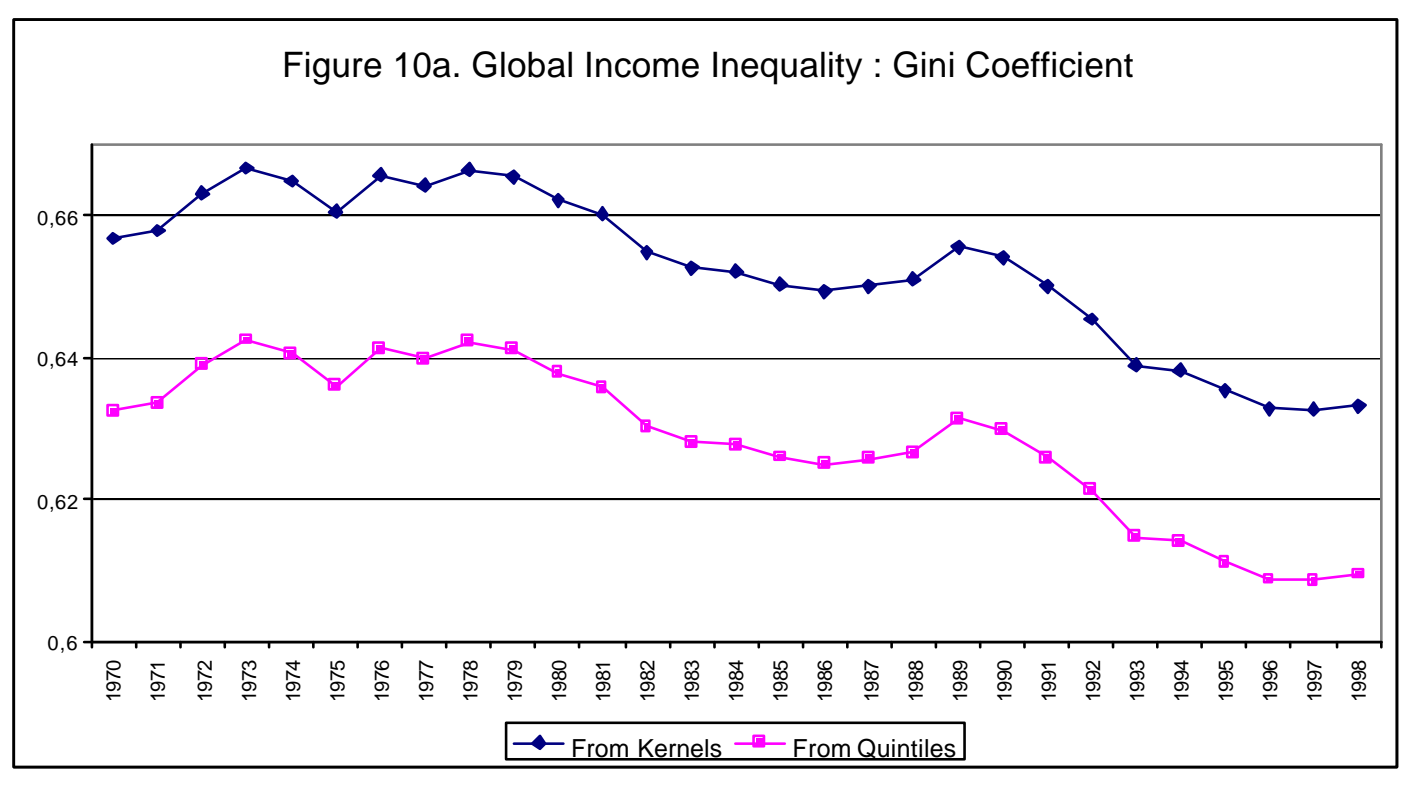

Figure 10b. Global Income Inequality: Theil Index

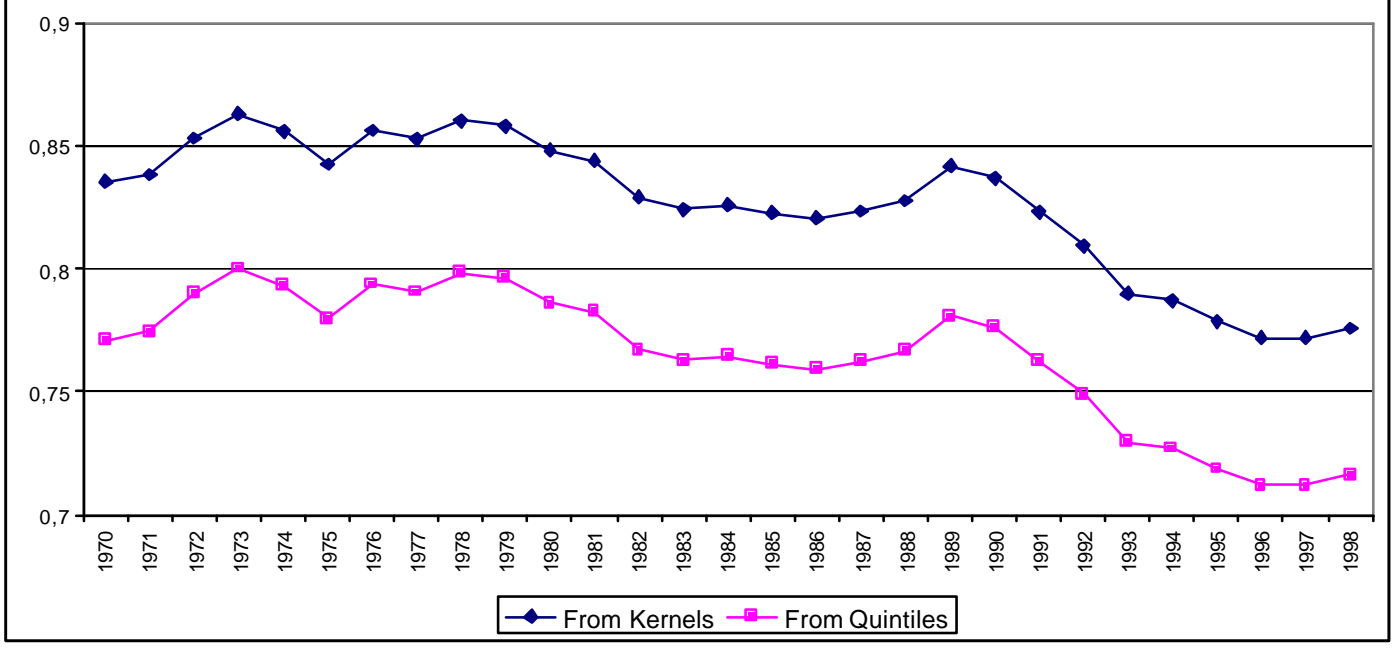

Figure 10c. Global Income Inequality: MLD

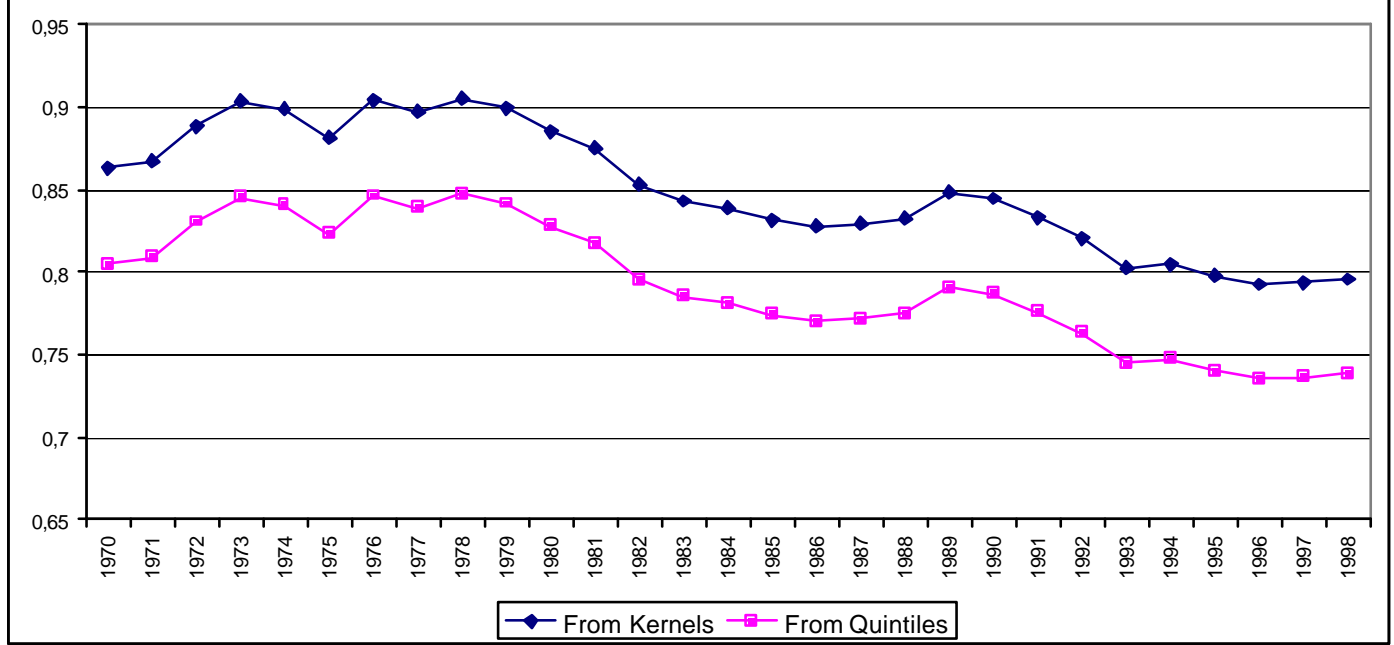




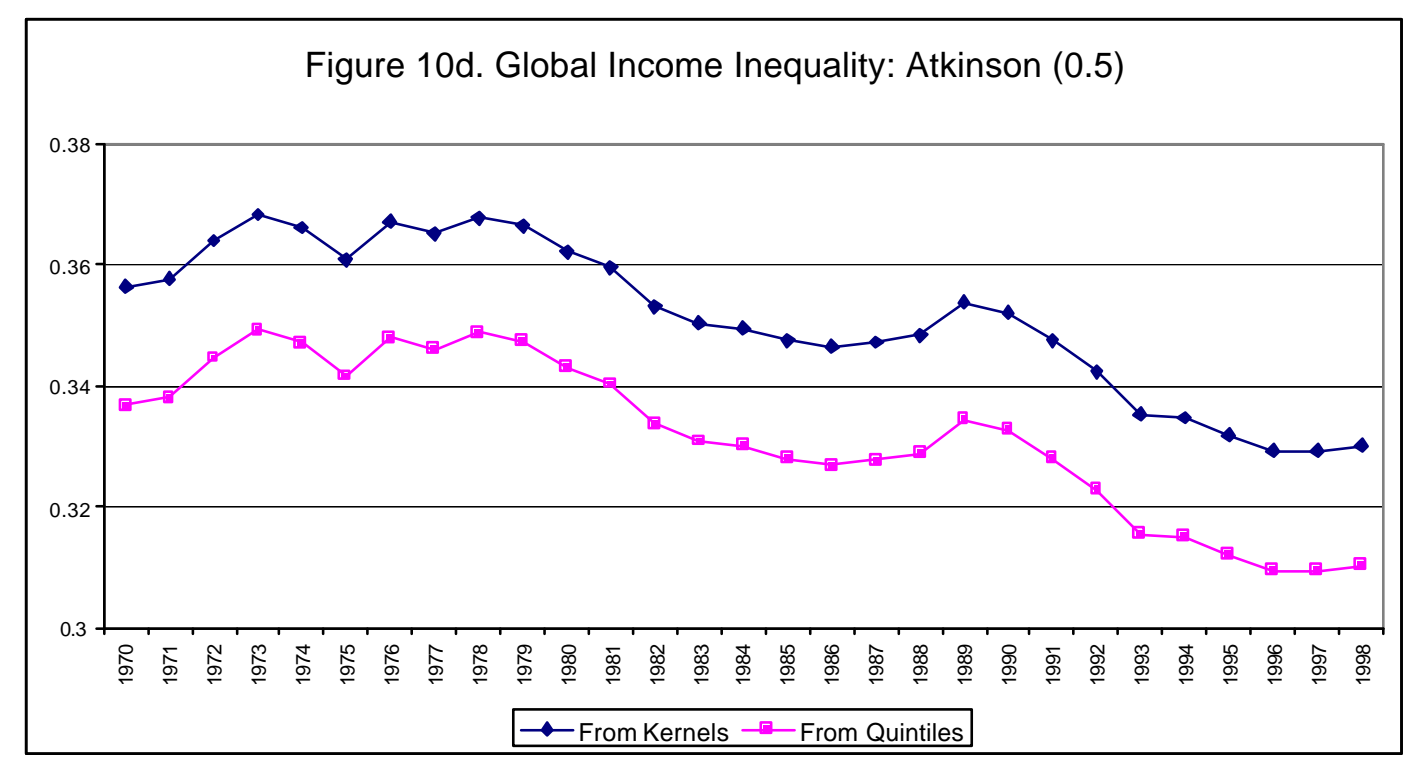

Figure 10e. Global Income Inequality: Atkinson (1)

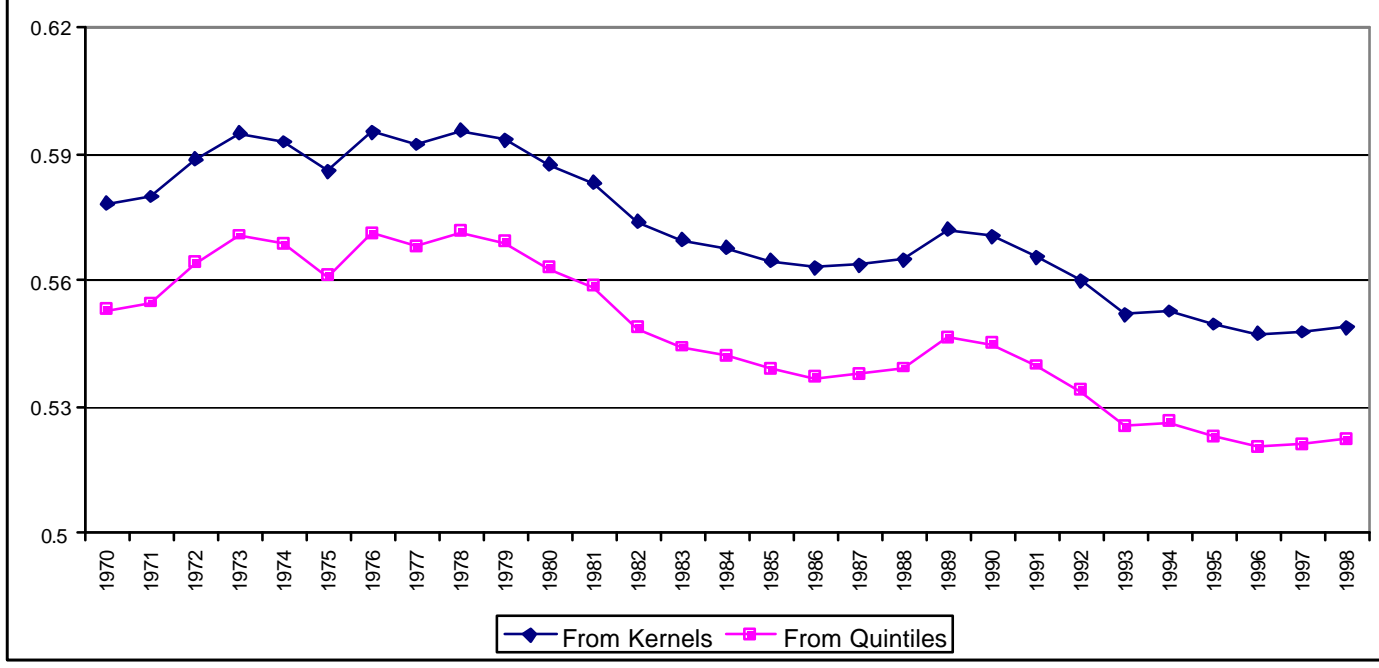

Figure 10f. Global Income Inequality: Squared of CV

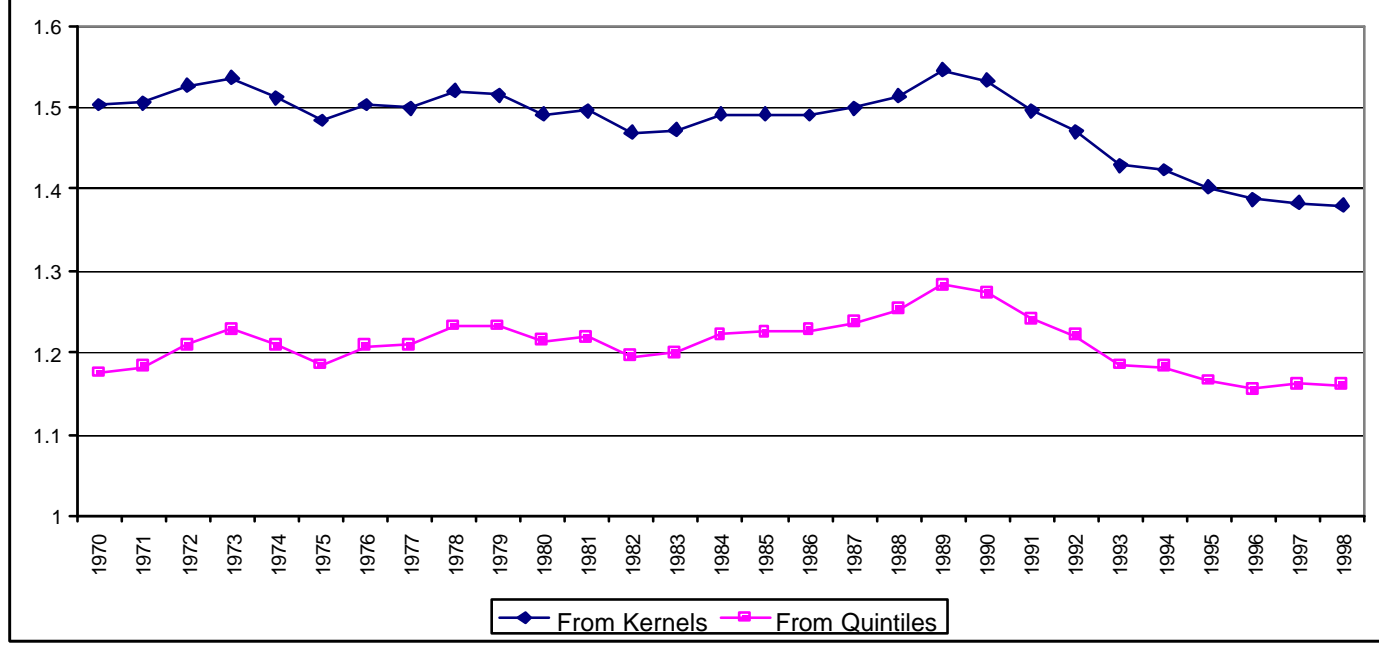



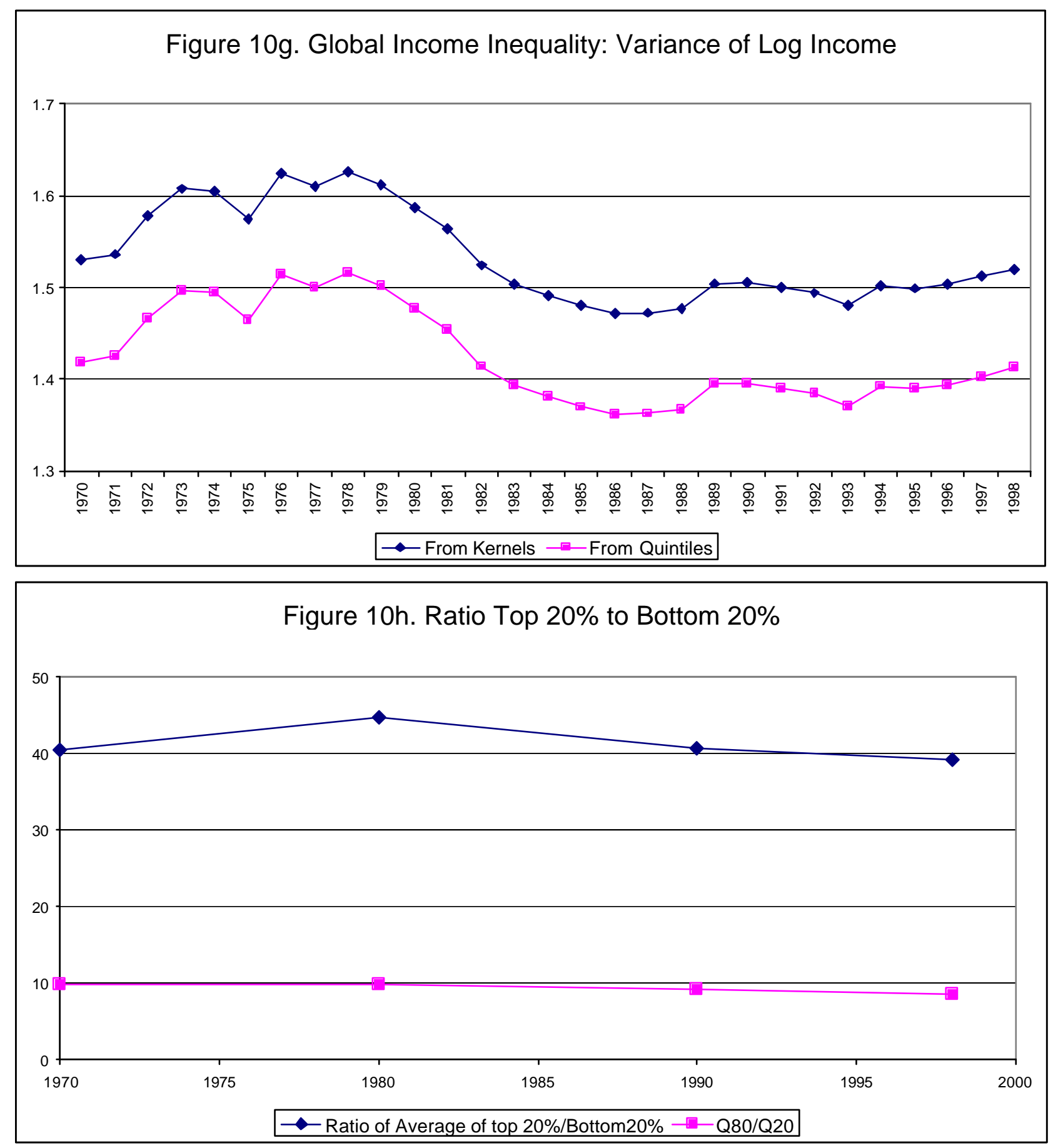


\section{Appendix Figures: Income Shares for Selected Large Countries}
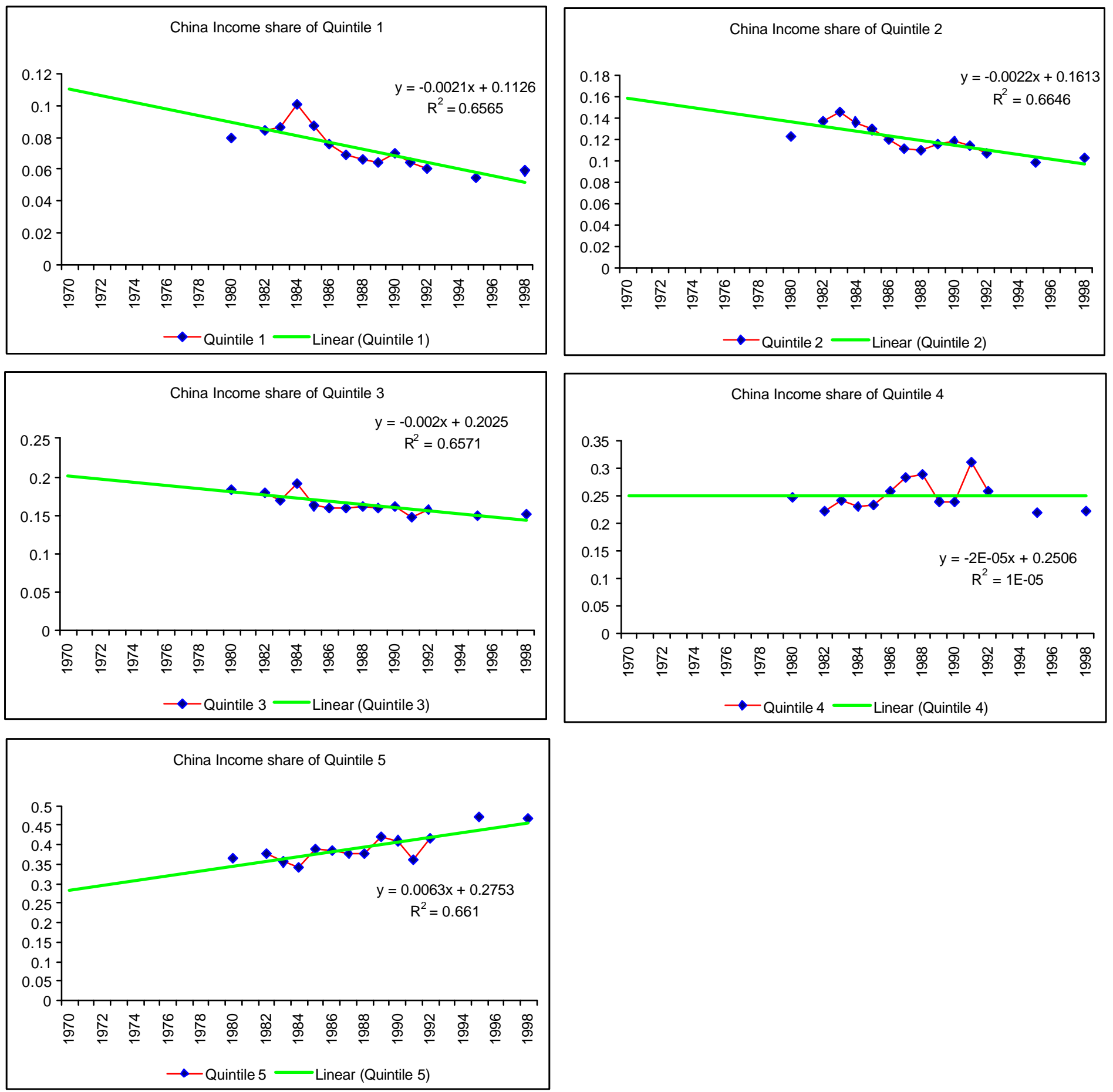

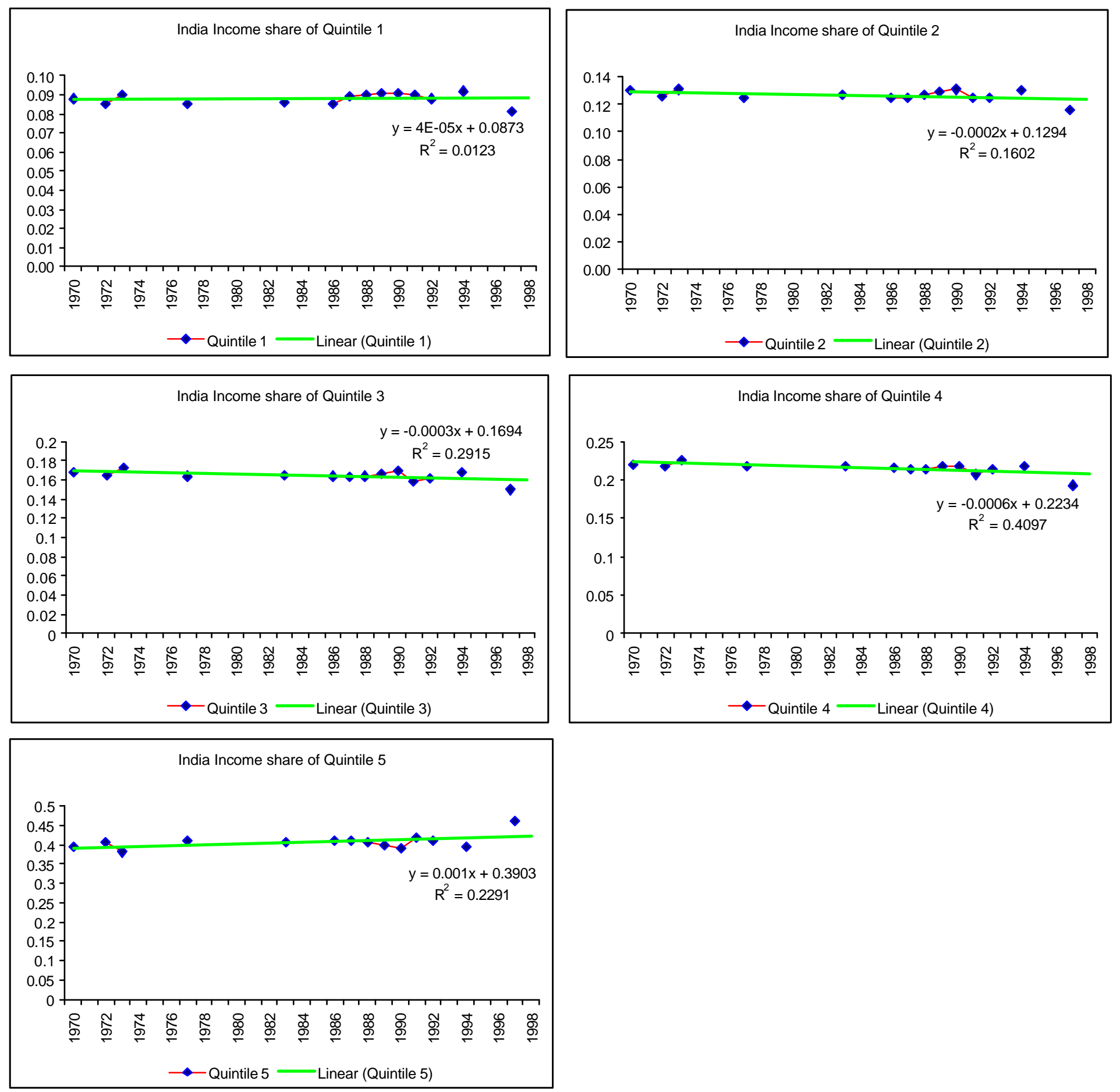

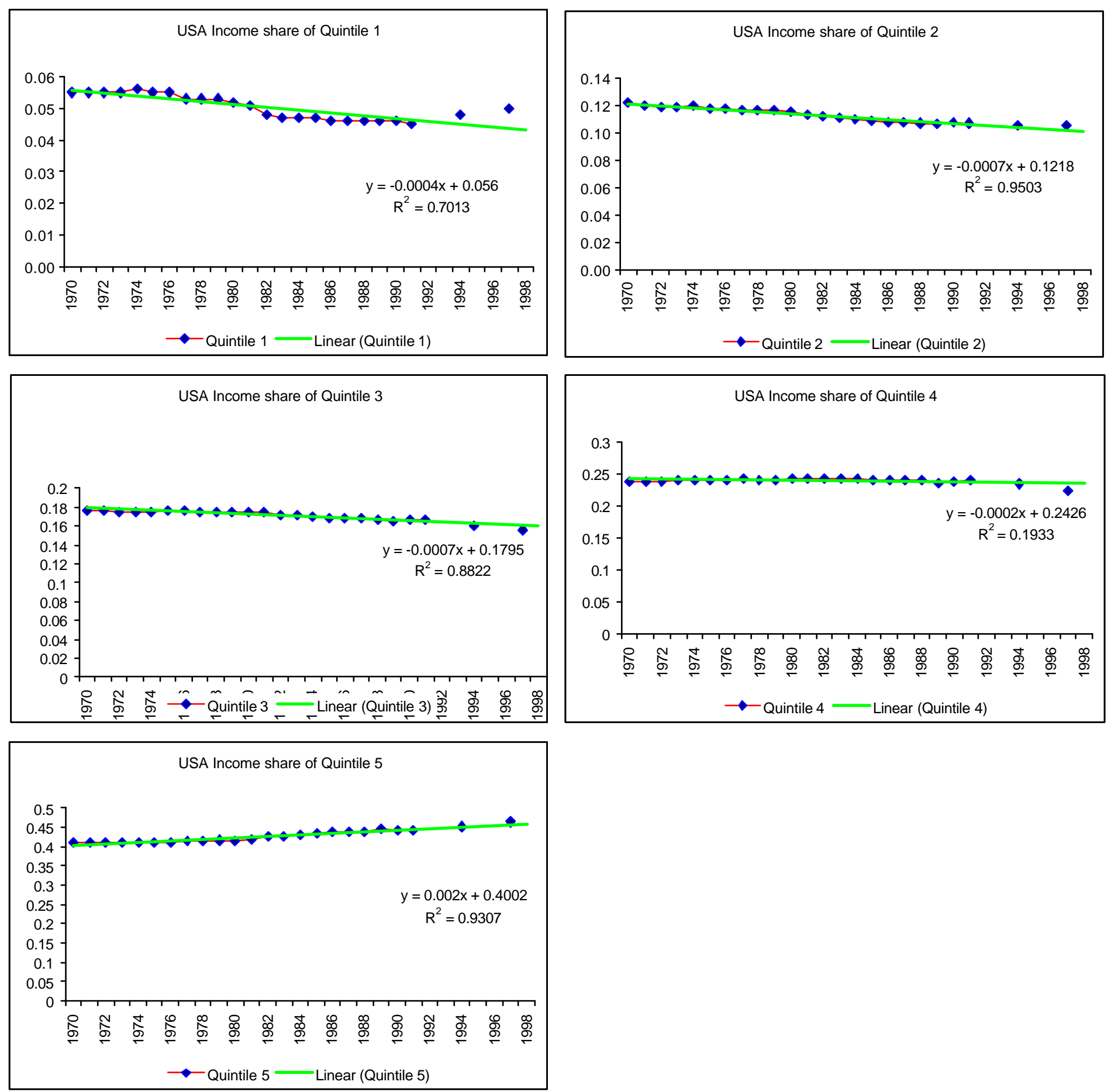

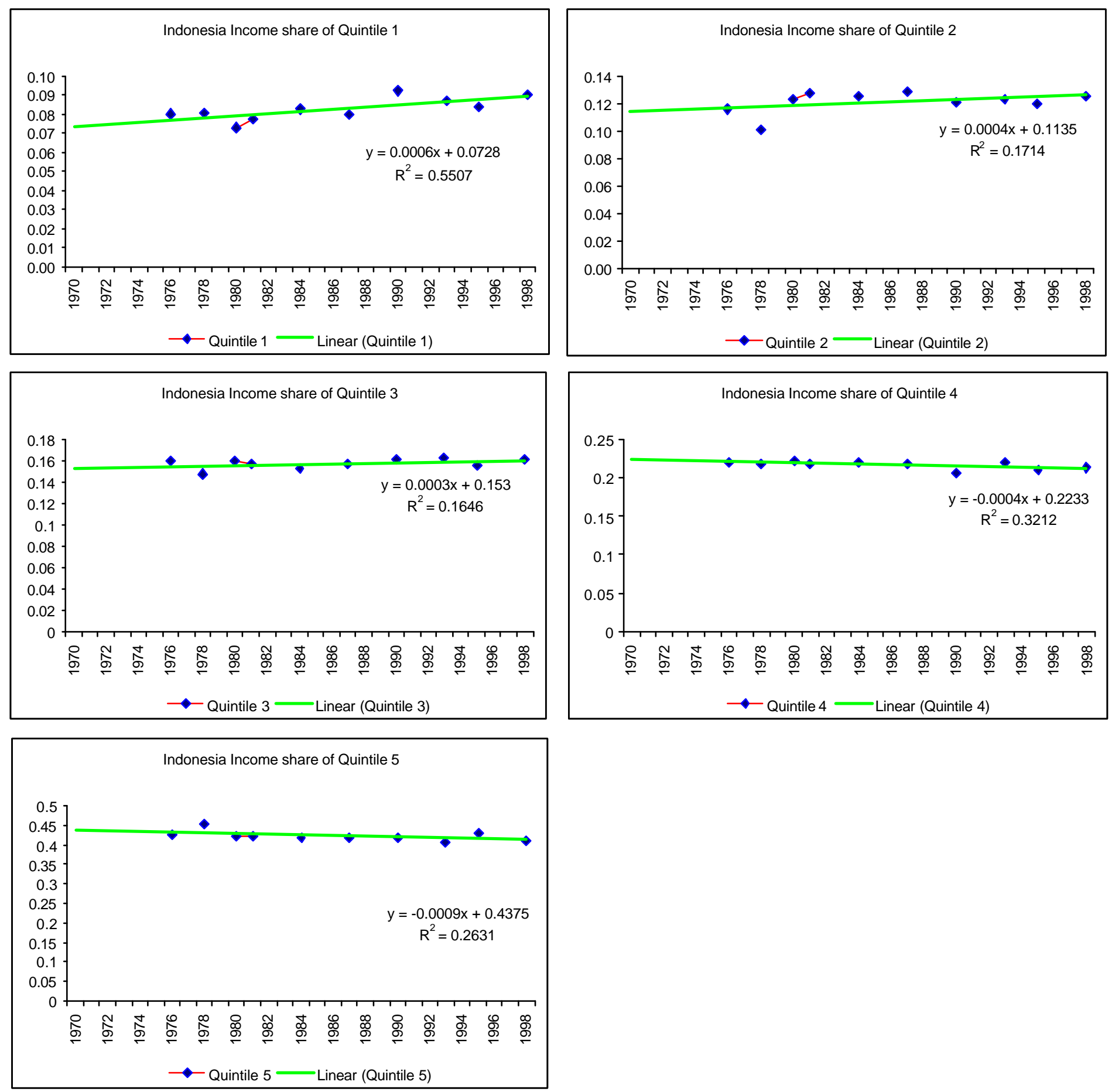

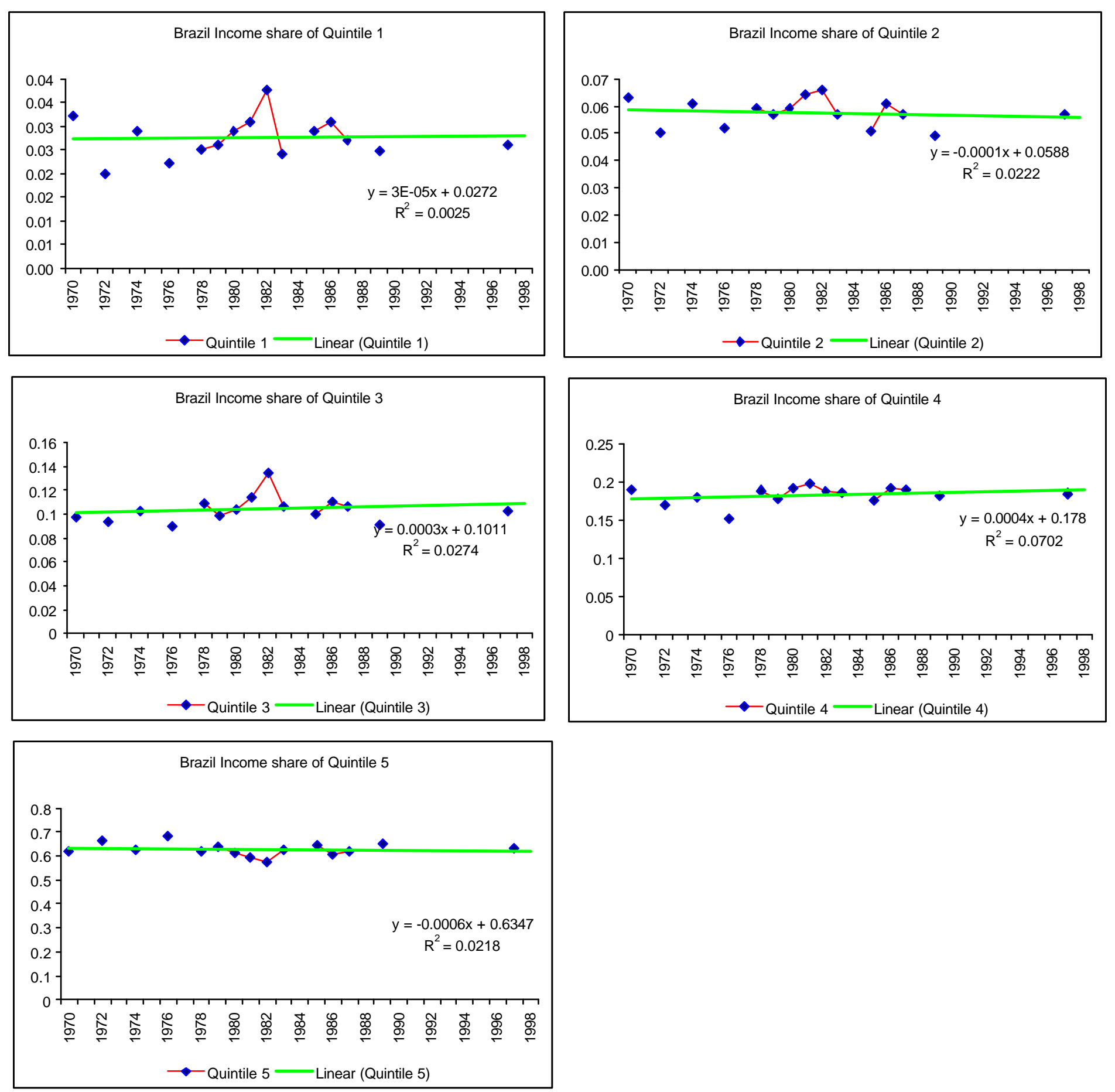

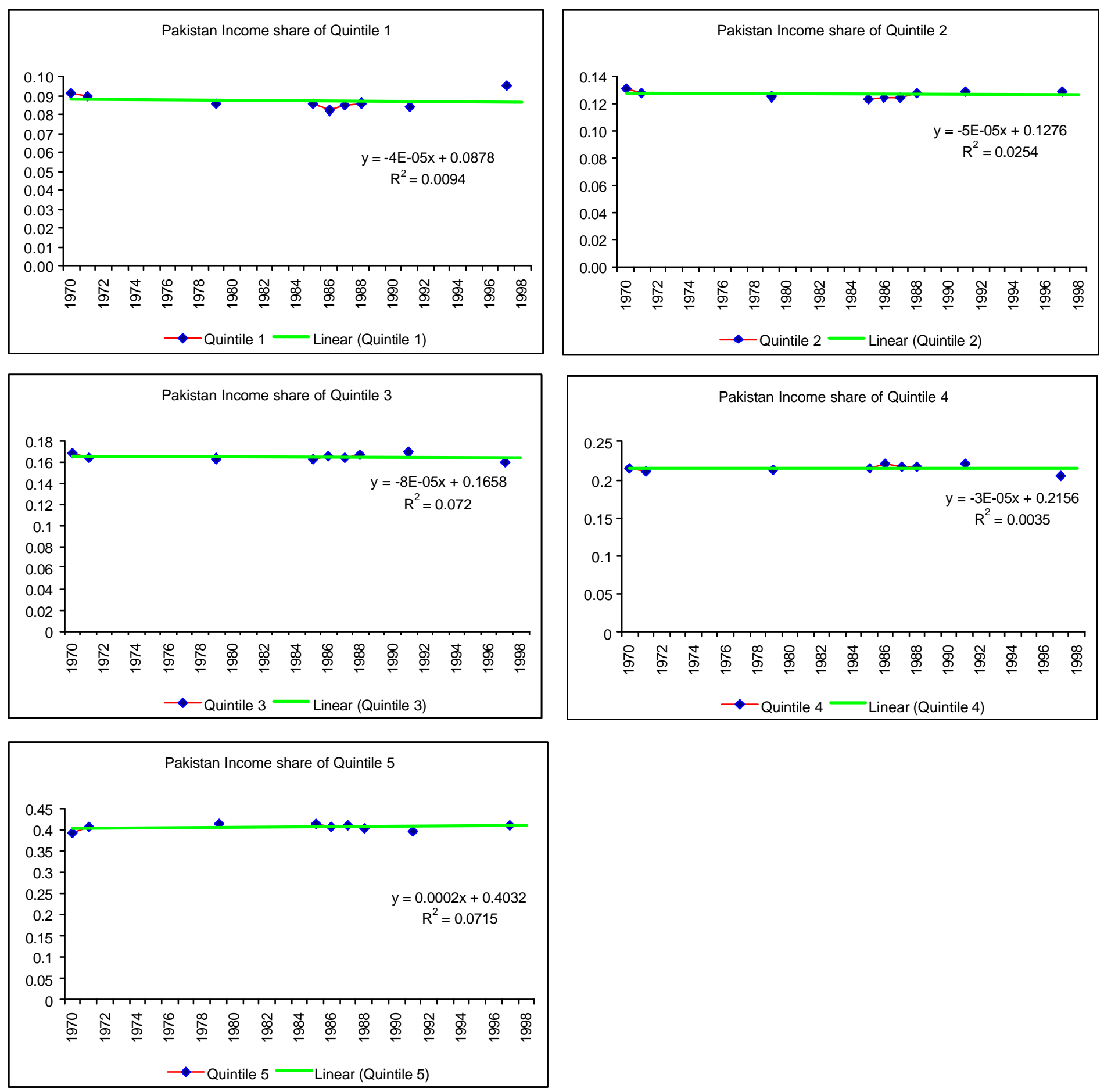
APPENDIX TABLE. COUNTRIES BY GROUP AND 1998 POPULATION (in Millions)

\begin{tabular}{|c|c|c|c|c|c|}
\hline Group A & Population & Group B & Population & Group C & Population \\
\hline Algeria & 29,922 & Austria & 8,078 & Angola & 12,070 \\
\hline Australia & 18,751 & Barbados & 265 & Argentina & 36,125 \\
\hline Bangladesh & 125,629 & Botswana & 1,562 & Benin & 5,948 \\
\hline Belgium & 10,204 & Burkina Faso & 10,730 & Cameroon & 14,303 \\
\hline Bolivia & 7,950 & Burundi & 6,548 & Cape Verde & 416 \\
\hline Brazil & 165,874 & Central African Republic & 3,480 & Comoros & 531 \\
\hline Canada & 30,301 & Ecuador & 12,175 & Congo, Dem. Rep. & 48,190 \\
\hline Chile & 14,822 & Ethiopia & 61,266 & Congo, Rep. & 2,783 \\
\hline China & $1,238,599$ & Gabon & 1,180 & Equatorial Guinea & 430 \\
\hline Colombia & 40,804 & Gambia, The & 1,216 & Fiji & 788 \\
\hline Costa Rica & 3,526 & Guinea & 7,082 & Iceland & 274 \\
\hline Cote d'Ivoire & 14,492 & Guinea-Bissau & 1,161 & Iran, Islamic Rep. & 61,947 \\
\hline Czechoslovakia & 15,686 & Guyana & 849 & Malawi & 10,534 \\
\hline Denmark & 5,301 & Israel & 5,963 & Namibia & 1,662 \\
\hline Dominican Republic & 8,254 & Kenya & 29,295 & Seychelles & 79 \\
\hline Egypt, Arab Rep. & 61,401 & Lesotho & 2,058 & Syrian Arab Republic & 15,277 \\
\hline El Salvador & 6,058 & Mali & 10,596 & Togo & 4,458 \\
\hline Finland & 5,153 & Mauritania & 2,529 & St. Vincent & 113 \\
\hline France & 58,847 & Mozambique & 16,947 & Sao Tome e Principe & 143 \\
\hline Germany & 82,047 & Niger & 10,143 & Chad & 7,283 \\
\hline Ghana & 18,460 & Papua New Guinea & 4,603 & Haiti & 7,647 \\
\hline Greece & 10,515 & Paraguay & 5,219 & St. Kitts \& Nevis & 41 \\
\hline Guatemala & 10,799 & Rwanda & 8,105 & Sta. Lucia & 152 \\
\hline Honduras & 6,156 & Senegal & 9,039 & Cyprus & 758 \\
\hline Hong Kong, China & 6,687 & South Africa & 41,402 & Grenada & 96 \\
\hline Hungary & 10,114 & Switzerland & 7,106 & Dominica & 73 \\
\hline India & 979,673 & Tanzania & 32,128 & Belize & 239 \\
\hline Indonesia & 203,678 & Uruguay & 3,289 & Antigua & 68 \\
\hline Ireland & 3,705 & Zimbabwe & 11,689 & & \\
\hline
\end{tabular}

Italy $\quad 57,589$

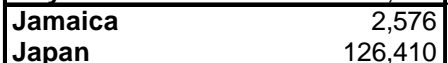

Japan $\quad 126,410$

Jordan 4,563

Korea, Rep. $\quad 46,430$

$\begin{array}{lr}\text { Luxembourg } & 427 \\ \text { Madagascar } & 14,592\end{array}$

$\begin{array}{ll}\text { Madagascar } & 14,592 \\ \text { Malaysia } & 22,180\end{array}$

Mauritius $\quad 1,160$

Mexico 95,846

Morocco 27,775

Nepal 22,851

Netherlands $\quad 15,698$

New Zealand $\quad 3,812$

Nicaraqua $\quad 4,794$

Nigeria $\quad 120,817$

$\begin{array}{lr}\text { Norway } & 4,432 \\ \text { Pakistan } & 131,582\end{array}$

Panama $\quad 2,764$

Peru 24,801

Philippines $\quad 75,174$

Poland $\quad 38,666$

Portugal 9,961

Romania 22,503

Sierra Leone $\quad 4,862$

Singapore 3,164

Spain 39,371

Sri Lanka 18,778

Sweden $\quad 8,852$

Taiwan $\quad 21,777$

Thailand 61,201

Trinidad and Tobago

61,201
1,285

Tunisia 9,335

Turkey 63,451

Uganda 20,897

United Kingdom $\quad 59,055$

United States 275,675

Venezuela 23,242

Zambia $\quad 9,666$

\begin{tabular}{|lr|r|r|r|}
\hline Total & $4,691,422$ & 315,703 & & 232,428 \\
Percent of Total & $89.54 \%$ & $6.03 \%$ & $4.44 \%$ \\
\hline
\end{tabular}

